\title{
4 Neue diasporafilmische Räume
}

\begin{abstract}
Denn der Film visualisiert und aktualisiert stets sein grundlegendes Potenzial, den Raum selbst zu transformieren.
\end{abstract} (Frahm, „Logiken“ 271)

Pierre Bourdieu konstatiert, dass der Akt kultureller Verortung keine große Veränderlichkeit mit sich brächte: „Because prises de position arise quasimechanically - that is, almost independently of the agents' consciousness and wills - from the relationship between positions, they take relatively invariant forms“ (339; Hervorhebung im Original). Dies, so soll in diesem Kapitel gezeigt werden, ist für Filme der iranischen Diaspora nicht zutreffend. Sie unterliegen Transformationsprozessen, die ständig neue filmische Räume der Aushandlung hervorbringen. Da es kaum grundlegende Erkenntnisse zu diesem Themenkomplex gibt, möchte ich mich ihm filmanalytisch nähern. Dazu sollen - ohne das Ziel, dem Anspruch auf Vollständigkeit gerecht zu werden - sechs bedeutende wie auch akademisch vernachlässigte, in jedem Fall aber enorm medien- und raumsensible und daher aufschlussreiche iranische Diasporafilme in den Fokus gerückt werden, in denen klar diasporafilmische Räume etabliert werden. Unter diasporafilmischen Räumen verstehe ich filmische Räume, in denen Diasporakultur verstärkt, quasi wie durch ein Vergrößerungsglas, verhandelt wird. Diese Verhandlung unterscheidet sich in den neueren Filmen der iranischen Diaspora seit der Jahrtausendwende im Gegensatz zu früheren Filmen dahingehend, dass Diaspora nicht mehr als bloßer Zustand des „,betwixt-and-between“ (Turner 95) 
dargestellt wird, sondern filmische Formen hervorbringt, die sich klaren kulturellen Zuschreibungen entziehen.

Um die anhand der Untersuchungsgegenstände herausgearbeiteten Thesen $\mathrm{zu}$ untermauern, wird neben der filmwissenschaftlichen Forschungsliteratur ein Korpus aus zahlreichen Raumtheorien zu Rate gezogen. Während im ersten Kapitel „Zwischenräume“ anhand der beiden Filme Zanan bidun-i mardan von Shirin Neshat und A Girl Walks Home Alone at Night von Ana Lily Amirpour die Spuren eines Dazwischen, obschon in bereits stark abgewandelter Form, noch zu finden sind, widmet sich das zweite Kapitel „Kosmopolitische Räume“ anhand von Shirin Etessams und Erica Jordans Walls of Sand und Marjane Satrapis Persepolis filmischen Räumen, die durch ihre Widersprüchlichkeit etablierte Vorstellungen von Diaspora aufbrechen. Das letzte Kapitel „Rebellische Räume“" setzt schwerpunktmäßig mit Analysen der Filme The Green Wave von Ali Samadi Ahadi und Schwarzkopf von Arman T. Riahi auf filmische Räume, die verstärkt Überlappungen und Verflechtungen fokussieren.

\subsection{Zwischenräume}

Theoretische Vorstellungen, die Zwischenräume konzeptuell zu fassen suchen, verweisen zumeist auf Räume, die sich außerhalb bestehender Strukturen befinden. So unterscheidet der Philosoph Michel Foucault in seinem oft zitierten, „anderen Räumen“ gewidmeten Vortrag zwei Arten solcher Räume: die Utopien als „emplacements sans lieu réel“ und die Heterotopien als sogenannte „contreemplacements“ (Dits et écrits 46-49). Der Begriff der hétérotopie adressiert lokalisierte Räume, in denen und durch die Utopien als gelebte Wirklichkeiten und mediale Formen generiert werden können. Der Sozialanthropologe Marc 
Augé seinerseits wendet mit seinem Konzept der non-lieux den traditionellen ethnologischen Blick in die Ferne programmatisch auf Europa zurück: „So wie ein Ort durch Identität, Relation und Geschichte gekennzeichnet ist, so definiert ein Raum, der keine Identität besitzt und sich weder als relational noch als historisch bezeichnen lässt, einen Nicht-Ort“ (83). Diese Wendung ist vor allem für die sozialwissenschaftlich orientierte Raumforschung produktiv gemacht geworden, beruht aber auf einer hinterfragbaren Vorstellung von Negativität: NichtOrte sind für Augé zunächst einmal etwas, das defizitär im Verhältnis zu sogenannten anthropologischen Orten ist. Während relational oder historisch bestimmbare Orte identitätsstiftend wirken, sind Nicht-Orte jene, die eine solche kulturelle Identitätsstiftung nicht mehr leisten können.

Demgegenüber stehen Konzepte, die den Zwischenraum als Raum kultureller und sozialer Transformation verstehen. Die Medienwissenschaftlerinnen Silke Martin und Anke Steinborn schlagen in diesem Zusammenhang den alternativen Begriff „Ab-Ort“ vor, einen Raum, der durch Bewegung nicht nur ein Phänomen der Gegenörtlichkeit, also des Ausstieges beschreibt, sondern auch und vor allem einen Raum der Fluidität, also der Öffnung:

\section{Während dem Ort etwas Statisches und Sesshaftes zu eigen ist, changiert der Ab-Ort - ausgehend von der Vorsilbe ,ab- ', die eine Bewegung von etwas weg impliziert - zwischen dem Durablen und dem Flüchtigen. Damit bewegt sich der $\mathrm{Ab}-\mathrm{Ort}$ in einem unkonkreten Sowohl-als-auch und konsti- tuiert sich nur vage über ein Weder-noch. (,Ab-Orte“ 7-8)}

Das Konzept des Ab-Ortes ermöglicht dadurch, im Gegensatz zu Michel Foucaults Heterotopien und Marc Augés Nicht-Orten, den Zwischenraum nicht als einen Raum außerhalb, sondern innerhalb bestehender Strukturen zu fassen. Diese Zwischenräume sind Räume, die durch Bewegung, Dynamik und Aus- 
tausch geprägt sind. Sie sind damit nicht-statische und nicht-fixierte Räume, denen Wandel eingeschrieben ist:

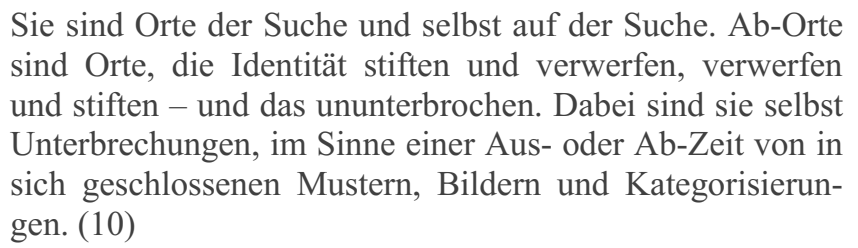

Dies wiederum bedeutet für diasporafilmische Zwischenräume, dass diese sowohl auf ihre Wurzeln Bezug nehmen als auch neue Wege einschlagen können. Zwischenräume treten, so meine Beobachtung in den Filmen der iranischen Diaspora, zunehmend nicht mehr als identitätsstiftende Räume - des Überganges von einer Lebensphase in die andere -, sondern als Räume, denen die Suche selbst eingeschrieben ist, in Erscheinung.

Für die nachstehenden Filmanalysen verstehe ich sonach Zwischenräume als Räume der Bewegung, der Öffnung und der Transformation. Herausgearbeitet werden sollen, nach einer Skizzierung traditioneller diasporafilmischer Zwischenräume wie der Flughafen und das Hotel, der Garten in Shirin Neshats Zanan bidun-i mardan und die Stadt in Ana Lily Amirpours A Girl Walks Home Alone At Night, die als Vergleichsfolien für ein erweitertes Verständnis von diasporafilmischen Zwischenräumen dienen sollen.

\subsubsection{Flughafen und Hotel}

Die Beschäftigung mit der „liminality of deterritorialization“ (Naficy, An Accented Cinema 155) steht in den frühen Filmen der iranischen Diaspora, die außerhalb Irans produziert wurden und das Leben außerhalb Irans zum Inhalt haben, 
im Vordergrund: „The dominance of transitional and liminal spaces signals that migrant and diasporic films are concerned with identities in flux“ (Berghahn und Sternberg, „Locating“ 41). Hamid Naficy definiert Liminalität in seinen Kategorien cinema of transition und liminal cinema als ,living between psychological states and social formations“ (An Accented Cinema 291). Mehrheitlich setzen diese Filme aus den 1980er und 1990er Jahren, zumeist eingebettet in Narrative rund um die Themen Migration und Reise, Zwischenräume in Szene, die als Räume des Überganges und der Passage fungieren: „There are the important transitional and transnational places and spaces, such as borders, tunnels, seaports, airports, and hotels and vehicles of mobility, such as trains, buses, and suitcases“ (5). Das überwiegende Vorkommen von Motiven, wie beispielsweise Hotels und Flughäfen, findet sich vor allem in den frühen Filmen der iranischen Diaspora aus den 1980er und 1990er Jahren wieder. Diese Zwischenräume haben verschiedene Funktionen: Sie sind erstens Räume der Umgrenzung, zweitens Räume der Parallelität und drittens Räume des Überganges. Räume der Umgrenzung sind sie, weil ihnen die Aushandlung von Grenzen und Grenzziehungen nationalen wie subjekthaften - sowohl narrativ als auch ästhetisch-filmisch eingeschrieben sind. Darin sind sie insofern von Parallelität gekennzeichnet, als dass binäre Raumkonstellationen - Iran/Westen, Heimatland/Ankunftsland et cetera - konstruiert werden. Übergänge sind zwar möglich, die Parallelität und beengte Eindirektionalität der Räume jedoch bleibt festgeschrieben wie beispielsweise in den Filmen: Sarhad von Parviz Sayyad (USA, 1982), The Suitors von Ghassem Ebrahimian (USA, 1988), Mihman-ha-yi Hotel Astoria von Reza Allamehzadeh (USA, 1989), I Love Vienna von Hushang Allahyari (Österreich, 1991) und I Don't Hate Las Vegas Anymore (USA, 1994) von Caveh Zahedi.

In The Suitors von Ghassem Ebrahimian beispielsweise steht die Emanzipation der Protagonistin Maryam im Vordergrund. Der Kampf um eine selbstbe- 
stimmte Identität kulminiert am Ende des Filmes in einer Szene am New Yorker Flughafen John F. Kennedy: Maryam beschließt, um den Schein zu wahren, mit einem ihrer aufdringlichen Verehrer gemeinsam nach Amsterdam zu fliegen. Als sie bemerkt, dass sie ihren Pass nicht bei sich hat, steigt sie in einen Koffer und lässt diesen aufgeben. $\mathrm{Ab}$ diesem Zeitpunkt ist zunächst sekundenlang ein schwarzes Bild zu sehen und lediglich Maryams Atmen zu hören. Die Kamera nimmt ihre Perspektive ein, das Gefühl der Beklemmung wird visualisiert. Maryam wählt den engsten vorstellbaren Raum, wo all ihre Emotionen kulminieren, um die Emanzipation aus ihren Zwängen zu vollziehen. Die Kamera folgt dem Koffer auf dem Förderband und changiert zwischen Innenperspektive und Außenperspektive. Als der Koffer vom Förderband heruntergenommen wird und zum Stillstand kommt, schlüpft Maryam aus dem Koffer und läuft zum Ausgang Richtung New York City ${ }^{33}$. Der Zwischenraum ist hier auf verschiedenen Ebenen sichtbar: einerseits in Form des Flughafens, der per se ein Ort des Überganges und der Überschreitung ist und dem das Moment der Mobilität innewohnt, und andererseits in Form des Koffers, der nicht nur Reise, sondern auch Ankunft symbolisiert. Die Szene bildet die Auflösung des Filmes für die weibliche Hauptfigur Maryam, die den Übergang von Iran in die Vereinigten Staaten sowie von einem verheirateten zu einem ledigen Status und damit schlussendlich von einem fremdbestimmten zu einem selbstbestimmten Leben markiert. Der Flughafen bildet hierbei den Zwischenraum in der Funktion als Übergangsraum, wie auch schon in der ersten Sequenz des Filmes, als Maryam mit ihrem Mann Haji am Flughafen ankommt. In dieser Szene läuft Maryam ihrem Mann desorientiert und unsicher Richtung Ausgang nach. In einer Aufsicht, die die amerikanische Flagge ins Zentrum setzt, gleitet ihr Tschador von ihren Schultern ${ }^{34}$. Die Symbolik der zugleich schützenden und einengenden Umhüllung des Tschadors hallt im Motiv des Koffers wider. Der Koffer ist hierbei das Symbol sowohl für Aufbruch 
als auch für Ankommen, für Einengung und Freiheit, für äußere und innere Reise. Die Sequenz repräsentiert Maryams Emanzipation bildlich durch das Changieren der Kamera zwischen Außen- und Innenperspektive, Flughafen und Koffer, Schwarzbild und Farbbild, die die Analogie zwischen dem Weg entlang des Förderbandes und dem inneren Wandel verdeutlicht. Der Flughafen trennt hierbei nicht nur geographische Territorien oder Nationalstaaten voneinander, sondern als Zwischenraum auch das alte vom neuen Ich. Die Passage durch einen Flughafen, eine Alltagssituation, verwandelt sich für Maryam, in Anknüpfung an die Sozialanthropologen Arnold van Gennep und Victor Turner, somit in einen rituellen Prozess der Passage (Strohmaier, „Irangeles: Zwischenorte“).

Reza Allamehzadehs Film Mihman-ha-yi Hotel Astoria zeigt ebenfalls mehrere ineinander verschachtelte Zwischenräume: erstens die Türkei - als Land zwischen Iran und einer Weiterreise in ein westliches Land Europas oder Nordamerikas; zweitens das Hotel Astoria - als vorübergehenden Ort zur Überbrückung der Wartezeit auf falsche Pässe und positive Asylbescheide; drittens die darin befindlichen Teilbereiche Rezeption, Bar, Lobby, Gang, Zimmer und Gemeinschaftsdusche. In der Lobby versammeln sich die Flüchtlinge zum gemeinsamen Tee- oder Alkoholtrinken, führen Gespräche und hören iranische Musik. In den Gesprächen tauschen sie biographische Fakten aus, klagen ihr Leid, motivieren einander und geben Informationen und Tipps weiter. Hierbei entsteht das, was Victor Turner „,communitas“ nennt, eine soziale „Anti-Struktur“ im Moment des Überganges, in der Hierarchien vorübergehend aufgehoben sind:

The first is of society as a structured, differentiated, and often hierarchical system of politico-legal-economic positions with many types of evaluation, separating men in terms of ,more ${ }^{6}$ or ,less'. The second, which emerges recognizably in the liminal period, is of society as an unstructured or ru- 
dimentarily structured and relatively undifferentiated comitatus, community, or even communion of equal individuals. (96; Hervorhebung im Original)

In langen Kamerafahrten visualisiert der Film dabei Warten und Zeitvertreib, Bewegung und Stillstand. Die Figuren haben wenig Interaktion mit der Welt außerhalb des Hotels, das Leben in Istanbul ist nur indirekt über den Lärm des Verkehrs oder einige vereinzelte Treffen mit Mittelsmännern spür- und sichtbar, die „,communitas“ wird nur selten verlassen. Zugrunde liegt dem eine Narration der Isolation und der Klaustrophobie. Veranschaulicht wird diese räumliche und symbolische Luftknappheit in der Sequenz, in der das Hotel von der türkischen Polizei durchsucht wird, durch die Mise en Scène: Das Zimmer der Protagonist_innen Puri und Karim ist winzig und bietet gerade einmal Platz für ein Doppelbett. Es ist sehr schlicht eingerichtet und beinhaltet keine persönlichen Gegenstände. Das Ehepaar liegt im Bett, Puri wälzt sich wach von einer Seite zur anderen, als sie auf dem Gang Stimmen hört. Auch Karim wacht auf, und die nächste Einstellung macht sichtbar: Vier schwarz uniformierte türkische Polizisten kontrollieren die Hotelgäste und werden vom Rezeptionisten von einem Zimmer ins andere geführt. Den schwarzen gepanzerten Uniformen der Polizisten stehen die Flüchtlinge in weißen Baumwoll-Pyjamas gegenüber, wodurch ihre Verletzbarkeit und Schutzlosigkeit visuell verstärkt wird. Als sich die Polizei Puris und Karims Zimmer nähert, suchen diese in letzter Instanz Schutz im Bett. Wie kleine Kinder ziehen sie die Decke bis weit über das Kinn, um in ihrer Schutzlosigkeit doch noch etwas Sicherheit zu erlangen. Aber Puri und Karim können nicht entkommen und das Hotel, und im engeren Sinne das Hotelzimmer, werden damit zur Falle. Die Kamera nimmt sie in einer halbnahen Einstellung auf, die Enge des Zimmers und die Beklommenheit der Situation verschmelzen in diesem Moment im sich umarmenden Paar $^{35}$. Das Hotel als Zwischenraum 
beinhaltet also zwei Dynamiken, die innerhalb der Raumkonstellation beobachtbar sind: Räume, die den Moment der Gemeinschaftsbildung, sowie solche, die den Moment klaustrophobischer Einengung darstellen. Diese einander widersprechenden, aber auch wechselseitig bedingenden Räume stellen eine für den Zwischenraum in den frühen Filmen der iranischen Diaspora typische Raumkonstellation dar. ${ }^{36}$

In Weiterentwicklung dieser traditionellen Zwischenräume wie Flughafen und Hotel(-Zimmer) lassen sich in den jüngsten außerhalb Irans entstandenen Filmen, so meine These, andere und neue Zwischenräume, wie der Garten und die Stadt, ausmachen. Diese deuten darauf hin, dass Kategorien wie Hamid Naficys cinema of transition und liminal cinema mittlerweile nicht mehr ausreichen, um das zeitgenössische Filmschaffen der iranischen Diaspora zu beschreiben, denn sowohl der Garten als auch die Stadt weisen nicht zuletzt auf die Veränderung der kulturellen Verortung der iranischen Diaspora hin und tragen damit zu einem veränderten Verständnis von Diasporafilm selbst bei.

\subsubsection{Garten}

Als erstes Beispiel wird zunächst auf Shirin Neshats ersten Langfilm Zanan bidun-i mardan [Women Without Men] (USA/Frankreich/Österreich, 2009) und den darin vorkommenden Garten eingegangen. Der Film basiert auf dem gleichnamigen Roman von Sharnush Parsipur und wurde 2009 auf den Internationalen Filmfestspielen von Venedig uraufgeführt. Die vier Protagonistinnen Munis (Shabnam Toloui), Faezeh (Pegah Ferydoni), Zarin (Orsolya Tóth) und Fakhri (Arita Shahrzad) finden im diegetisch zentralen Garten Zuflucht, Schutz, Heilung und Erstarkung. Im von politischen Turbulenzen des Jahres 1953 gebeutelten Teheran, dessen Straßen voller Menschen und Gefahren sind, und der 
Einengung patriarchaler Strukturen, in Form von herrischen Ehemännern, Brüdern und fordernden Freiern, bietet der Garten einen willkommenen Rückzugsort.

Den Garten, vielmehr den persischen Garten, führt bereits Michel Foucault als das historische Paradebeispiel seiner Heterotopie an:

Der traditionelle Garten der Perser war ein Rechteck, das in vier Teile unterteilt war - für die vier Elemente, aus denen die Welt bestand. In der Mitte, am Kreuzungspunkt der vier Teile, befand sich ein Springbrunnen oder ein Tempel. Um diesen Mittelpunkt herum war die Pflanzenwelt angeordnet, die gesamte Vegetation der Welt, beispielhaft und vollkommen. Bedenkt man nun, dass die Orientteppiche ursprünglich Abbildungen von Gärten waren - also buchstäblich ,Wintergärten “ -, wird auch die Bedeutung der legendären fliegenden Teppiche verständlich, der Teppiche, die durch die Welt flogen. Der Garten ist ein Teppich, auf dem die ganze Welt zu symbolischer Vollkommenheit gelangt, und zugleich ist er ein Garten, der sich durch den Raum bewegen kann. (Heterotopien 14)

Die Regisseurin Shirin Neshat selbst bezieht sich in einem Interview zu ihrem Film ebenfalls auf dieses kulturelle Erbe des persischen Gartens:

The concept of a garden has been central to the mystical literature in Persian and Islamic traditions, such as in the classical poetry of Hafez, Khayyam and Rumi where the garden is referred to as the space for ,spiritual transcendence'. (,Extras")

Sie erinnert vor diesem historischen Hintergrund auch an den symbolischen Gehalt, der dem Garten beigemessen wird: „In Iranian culture, the garden has also been regarded in political terms, suggesting ideas of ,exile‘, ,independence and ,freedom““ („Extras“). Im Sinne dieses Ansatzes verfolgt die nachstehende 
Analyse die These, dass der Garten als filmischer Raum besonders gut für die Verhandlung, Verortung und Positionierung der iranischen Diaspora geeignet ist. Hierzu möchte ich drei Szenen heranziehen: das erste Betreten des Gartens durch Zarin, die den Garten als feministischen Raum etabliert; die Traumsequenz von Faezeh, die den Garten als dritten Raum ausstellt, und die im Tümpel liegende Zarin, die den Garten als filmisch-somatischen Raum versinnbildlicht. Diese drei Attribute des Gartens veranschaulichen die Veränderung von den alten zu den neuen diasporafilmischen Räumen.

\section{Garten als feministischer Raum}

Der Garten in Zanan bidun-i mardan ist kein minutiös angeordnetes Rechteck, wie Foucault ihn beschreibt, sondern tritt im Gegenteil in der Gestalt eines verwilderten Waldes in Erscheinung, der zum Streunen und Sich-Verlieren einlädt. Auf der einen Seite des Gartens ist das alte Landhaus, auf der anderen Seite öffnet er sich in eine steppenartige Wüstenlandschaft. Im Garten selbst gibt es wiederum erneut Zwischenräume wie den Tümpel (zwischen Wasser und Erde) oder die Blumenwiese (zwischen Wald und Wüste).

Zarin betritt ihn als Erste: Nachdem sie aus dem Bordell geflohen und zu Fuß über die Landstraße gewandert ist, erreicht sie ein niedriges erdiges Loch, welches sie - ähnlich wie Lewis Carrolls Alice - durchquert (Abb. 1.1). Wo sich das Loch in der Wand befindet, bleibt unklar, eine geographische Lage oder örtliche Zuschreibung - im Gegensatz zur Stadt und ihrer klaren historischen wie geographischen Verortung im Teheran des Jahres 1953 - wird nicht gegeben. Zu hören ist Vogelgezwitscher, eine paradiesische Ruhe, in der auch das menschliche Wort verstummt. Diese Stille evoziert Entschleunigung, die Kamera macht im Gegensatz zu den schnellen Bewegungen und Schnitten bei den Demonstrati- 
ons- und Straßenszenen - gleitende und langsame Fahrten und verharrt eine Weile am Bild der bewegungslosen Zarin im Garten, ein blasses Tableau Vivant. Es ist eine selbstgewählte Stille, in die auch die anderen Frauen eintreten und den Garten gerade dadurch zum Raum der Aushandlung von Alterität machen. Der Garten symbolisiert damit nicht nur Rückzug von der Welt, sondern auch die Möglichkeit auf ein anderes Leben. Dabei ist es wichtig herauszustreichen, dass Stille keine passive, sondern eine durchaus aktive Haltung darstellt und den Garten damit zu einem feministischen Raum macht. Die Frauen entscheiden selber über diese Stille und kreieren dadurch einen Raum nicht nur des Rückzuges, sondern auch der Ermächtigung, wodurch der Garten zum Schauplatz eines feministischen Aushandlungsprozesses wird. Die Szene koppelt hierbei Sozialkritik an Medienkritik, um soziopolitische Transformationsprozesse in einer medialen Verstärkung nachvollziehbar und erkennbar zu machen. Dabei geht es in erster Linie um eine patriarchatskritische Ausrichtung der Medienkritik, die die seit den 1970er Jahren virulente Frage nach der Repräsentation von Weiblichkeit aufwirft.

Das Eintreten von Zarin über/durch das Erdloch ist dabei nicht zufällig gewählt. Eine Gartentür hätte den Garten als funktionalen Raum ausgestellt, und so betritt in Zanan bidun-i mardan nur der Gärtner diesen Raum durch solch eine Gartentür. Zarin hingegen schlüpft durch einen Schwellenraum in den Garten. Sie streift dabei das ihr als Tschador-Ersatz dienende Bettlaken ab und lässt es buchstäblich links liegen (Abb. 1.2). Die doppelte Funktion des Lakens als Symbol ihrer unfreien Tätigkeit im Bordell und der sozialen Funktion, „ordentlich“ gekleidet zu sein und vor fremden Blicken geschützt zu bleiben, ist im Garten obsolet. Das liegengebliebene Laken deutet auf den Transformationsprozess hin, dem sie innerhalb des Gartens unterliegen wird. Die Kamera folgt ihr nicht, sondern lässt dieses Bild einige Sekunden stehen und gibt dem erdigen Loch in der 
Wand als Portal zu dieser anderen Welt, einem Möglichkeitsraum ohne Männer, in dem die Frauen ihre eigenen Erkenntnisse über soziokulturelle Prozesse aushandeln und erzielen können, zusätzlich Gewicht.

Auf der anderen Seite eröffnet sich ihr, und damit auch den Zusehenden, ein üppiger Garten, der wild verwachsen ist und nur einzelne Sonnenstrahlen durchlässt. Die Totale zeigt Zarin in dem Garten stehend, klein gegenüber den jahrhundertealten Bäumen und alleine, ohne andere Menschen. Der Garten bildet einen deutlichen Kontrast zum überfüllten Hamam und geschäftigen Bordell sowie zu ihrem beengten kleinen Zimmer, in dem ein Freier nach dem anderen durchzog. Einzig der alte Steinbrunnen erinnert an eine mögliche angelegte Urform des Gartens nach traditionellem Muster. Die Kamera folgt Zarin in den Garten, sie und nicht den Brunnen in den Mittelpunkt setzend (Abb. 1.3). Der Garten ist laut der Kommunikationswissenschaftlerin Valerie Palmer-Mehta „,[a] feminist epistemic space - a productive, working site where old beliefs are questioned“ (93). In diesem Garten bildet sie - die Frau - das Zentrum, den Kreuzungspunkt der Welt. Zarin steht damit in diesem Moment nicht nur im Zentrum des Gartens, sondern auch im Zentrum der Aushandlung dessen, was ihr Frausein in der Welt betrifft. Sie hat ihr Bettlaken abgestreift und ist durch die ihr gegebene zentrale Position von einer passiven zu einer aktiven Haltung vorgerückt. Der Schnitt auf die darauffolgende Szene untermauert diese Erstarkung, indem die treppenaufsteigende Protagonistin Fakhri gezeigt wird, deren Spiegelbild sich dreimal bricht und sie somit als multipel fragmentierte Frau in Szene setzt (Abb. 1.4). Sie wird den Garten zu einem späteren Zeitpunkt betreten. 

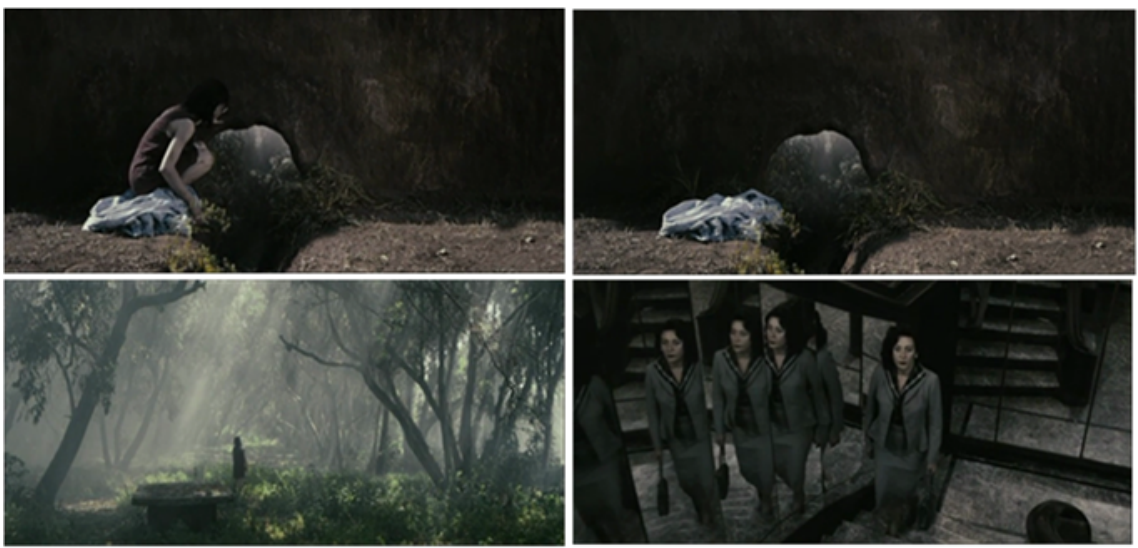

Abb. 1.1-1.4 Zanan bidun-i mardan, „Zarin betritt den Garten“, USA 2009 (29:09-30:18)

Der Garten als feministischer Raum wird durch diese Gegenüberstellung einmal mehr betont, denn durch seine Position zwischen Stadt und Wüste, zwischen dem Öffentlichen und dem Privaten fungiert der Garten als Zwischenraum, dem eine besondere Funktion zukommt: jene der Aushandlung von Positionen und Positionierungen in der Welt.

Garten als dritter Raum

Laut der Literatur- und Filmwissenschaftlerin Rosa Holman ist der Garten ,an in-between, liminal, temporary shelter“ (11). Dabei handelt es sich meines Erachtens jedoch nicht um den Garten als Heterotopie im Sinne Foucaults - als Raum der Zuflucht und Gegenörtlichkeit -, sondern um einen dritten Raum im Sinne Homi K. Bhabhas - einen Raum der Aushandlung kultureller Prozesse. Der Garten wird damit zu einem Zwischenraum jenseits von Hybridität.

Besonders deutlich tritt dies in folgender Sequenz hervor: Als die Protagonistin Faezeh nach einer Alptraumnacht - in der sie alleine durch den dunklen 
Garten irrt und ihre eigene Vergewaltigung von außen nochmals sieht und durchlebt - morgens aufwacht und in ihrem weißen Nachthemd hinausgeht, folgt die Kamera ihrem entschlossenen Schritt: Die frontale Großaufnahme ihres Gesichtes mit offenen Haaren ohne Tschador erlaubt die Umrisse des Gartens nur zu erahnen. Die Nähe zum Traum - diesmal bei Tag - wird dadurch nicht nur narrativ, sondern vor allem bildlich evoziert. Sie bleibt stehen, und die nächste Einstellung zeigt in einem Eyeline-Match, was vor ihr liegt: Die Zusehenden erblicken mit ihr den Übergang vom Garten in die Wüste in einer totalen Einstellung inklusive Himmel, Wolken und Horizont. Faezeh ist am Rand der Bäume stehen geblieben, der Schnitt geht auf Zarin, die hingegen abermals im Zentrum des Bildes inmitten der Ausläufer des Gartens sitzt - in einem Zwischenraum im Zwischenraum. Die Kamera löst in einem langsamen Zoom-in schließlich die anfängliche Rahmung der Bäume auf (Abb. 1.5) und offenbart das volle Panorama der Grenzlandschaft (Abb. 1.6), um in einem letzten Schritt in einer halbnahen Einstellung Zarin in einem Blumenkleid im Blumenbeet zu zeigen (Abb. 1.7), erneut ein impressionistisches Tableau Vivant.
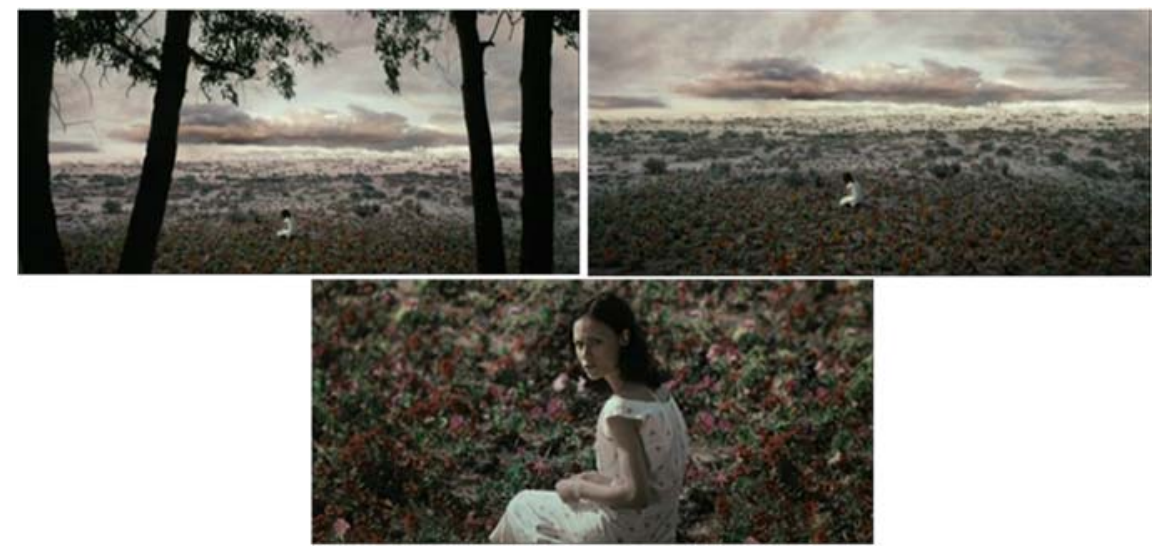

Abb. 1.5, 1.6 und 1.7 Zanan bidun-i mardan, ,Zarin im Blumenbeet“, USA 2009 
Es ist dieser Zwischenraum im Zwischenraum, der den Garten als Raum, dem eine eigene Raumlogik innewohnt, veranschaulicht. Die Rahmung der Bäume definiert hierbei, in Anlehnung an die Auslegung der Kadrierung der Medientheoretikerin Doris Agotai, den Übergang von einem Zwischenraum in den nächsten: „Die Kadrierung kann [...] als grenzgenerierendes Gestaltungsmittel verstanden werden, welches Räume zueinander in Beziehung setzt. Sie lenkt den Blick von einem Raum in den nächsten und definiert den Übergang“ (58). Durch die langsame Veränderung der Kadrage in dieser Sequenz wird zunächst die bildinterne Rahmung betont, ehe sie mit den Bäumen ins Off verschwindet. Die Filmwissenschaftlerin Kathrin Rothemund meint in ihrem Sammelbandbeitrag „Übergänge: Das Einfließen der Grenze in das filmische Bild“: „In der Zone zwischen Sichtbarem und Unsichtbarem ereignet sich der eigentliche Diskurs um die Begrenzung des Bildes“ (66), und sie hebt fernerhin die Grenze als ästhetisches Gestaltungsmittel hervor: „Als ästhetisches Gestaltungsmittel fungiert daher eine Grenzzone durch einen fließenden Übergang vom Sichtbaren zum Unsichtbaren, der nicht länger als klar definierte Rahmung mit exakten Kanten zu verstehen ist, sondern sich ein Stück weit der festen Zuschreibung entzieht“ (61). Der Medienwissenschaftler Lorenz Engell unterstreicht seinerseits in seiner Monographie Bilder der Endlichkeit die Grenze im Hinblick auf die Verschiebung der Wahrnehmungsebene:

Vielmehr ist das Verhältnis zwischen der Sichtgrenze und dem, was sie umschließt, für die Struktur der ganzen Wahrnehmungswelt bestimmend. Die Grenze ist zugleich Produkt und Negativ der Gegebenheiten. Sie modelliert das Sichtbare, indem sie es in seiner virtuellen Überschreitung zeigt. (13) 
Die verschiedenen filmischen Raumebenen in dieser Sequenz bilden zusammen einen Komplex, der den Charakter eines virtuellen Überganges hat. Dieser virtuelle Übergang verläuft dabei auf folgenden Ebenen: die des chromatisch über Rottöne markierten Gartenbereiches, die des durch die Bäume markierten Blickfeldes und die des sich in der Ferne zwischen Boden und Himmel verlierenden Horizontes. Als Zusammenhang von Räumen ist die Grenze in dieser Szene ein bewusst eingesetztes filmisches Mittel, welches überdies die soziokulturellen Aushandlungsprozesse der Frauen visualisiert. Die Grenze zwischen Garten und Wüste ist in dieser Szene auch die Grenze zwischen Realität und Fiktion, der ein Moment des Utopischen innewohnt und mit dem filmischen Zwischenraum von Sichtbarem und Unsichtbarem korreliert. In diesem Übergang wird das Mediale des Gartens als filmischer Raum sichtbar.

Die Fähigkeit, Schwellen zu überschreiten und Grenzen zu überwinden, sprich: den filmischen Raum stets neu zu konstituieren, lässt sich an Homi K. Bhabhas Konzept des dritten Raumes anschließen. Michel Foucaults Heterotopie und Marc Augés Nicht-Orte stellen jeweils Konzepte bereit, die den Zwischenraum stärker als einen Raum fernab aller Räume, als einen Raum des Außerhalb, darlegen. Das utopische Moment des Gartens jedoch, so zeigt meine Analyse, bedeutet keinen Ausstieg, sondern ein Hier und Jetzt der Kulturen. Denn die filmischen Transformationsprozesse, die zwischen politischem Aktivismus und ästhetischer Umsetzung ablaufen, finden an jenem paradoxalen Zwischenraum der Störung und Einmischung statt, den Homi K. Bhabha als dritten Raum beschrieb. 
Garten als filmisch-somatischer Raum

Einen Zwischenraum im Zwischenraum bildet neben dem Blumenfeld auch der Tümpel, in dem Zarin von Fakhri und dem Gärtner gefunden wird. Die Kamera zeigt Detailaufnahmen eines im Wasser liegenden Körpers: zunächst die Füße (Abb. 1.6), dann die Beine und Knie (Abb. 1.7), anschließend den Rumpf (Abb. 1.8) - an dessen Auf- und Ab-Bewegungen des Bauches erst erkennbar wird, dass der Körper noch lebt - und zu guter Letzt das Gesicht von Zarin mit geschlossenen Augen (Abb. 1.9). In einem letzten Schritt - nach einem Gegenschuss auf Fakhri, die Zarin nichtsahnend im Tümpel entdeckt - zeigt die Kamera Zarin aus der Vogelperspektive, im Wasser liegend, von Wasserpflanzen umringt (Abb. 1.10).

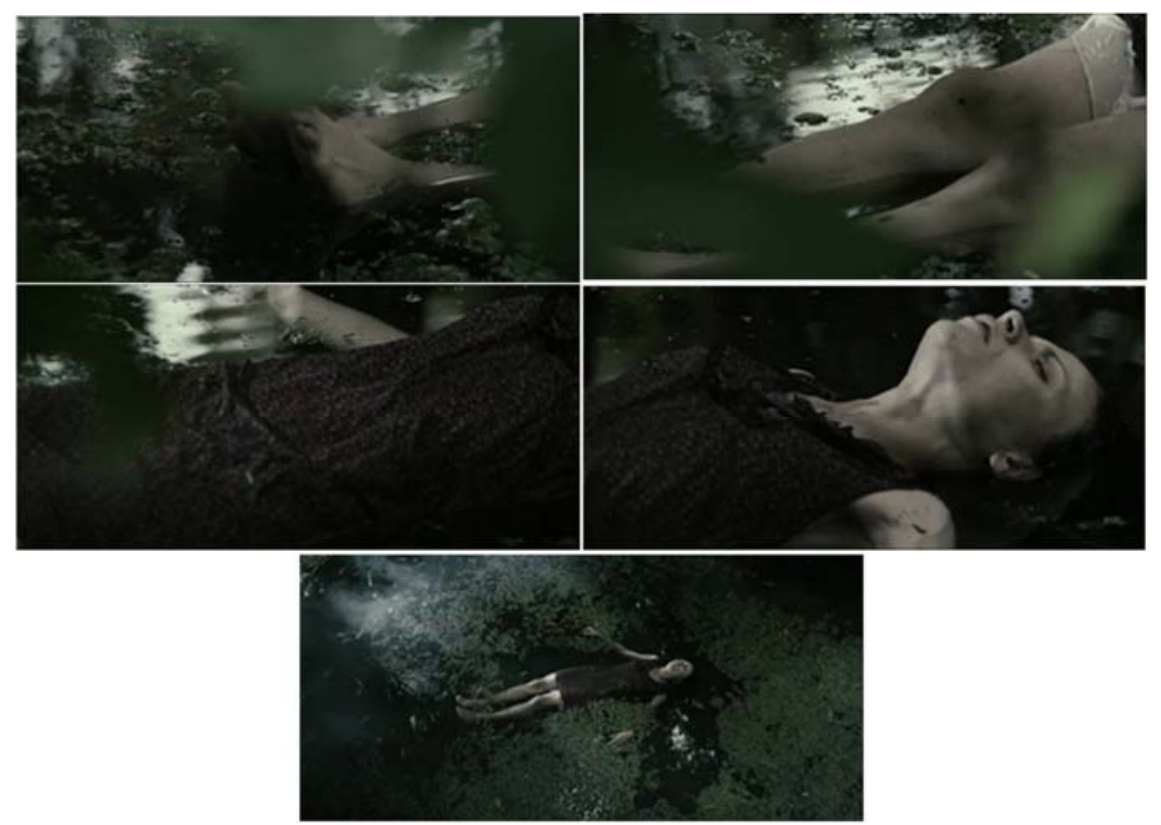

Abb. 1.6, 1.7, 1.8, 1.9 und 1.10 Zanan bidun-i mardan, „Zarin im Tümpel liegend“, USA 2009 
Die Pflanzen treten in den Detailaufnahmen als verschwommene grüne Unschärfen in den Vordergrund, wodurch das technische (Un-)Vermögen der Kamera gegenüber dem menschlichen Auge und somit die Materialität von Film selbst in Erscheinung tritt. Das Phänomen der Unschärfe ist laut Kathrin Rothemund symptomatisch für den Zwischenraum:

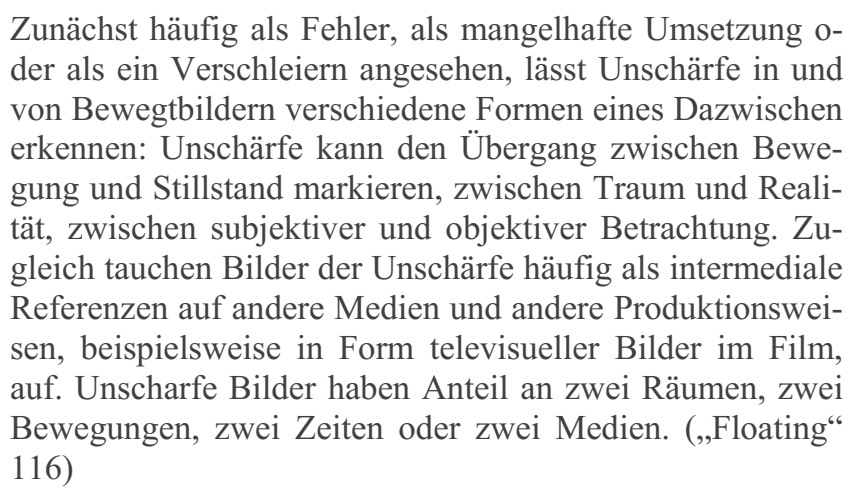

Die Bewegungsunschärfe der grünen Blätter etabliert in dieser Szene die folgenden kontrapunktischen Räume: Stillstand (des Körpers) und Bewegung (des Wassers), reale Elemente und Traumelemente, Tableau und Film. Die Kamera verweist damit auf die Herstellung von Körperlichkeit, insbesondere da Zoom-in und Zoom-out sowie (Un-)Scharfstellungen nur bestimmte Wahrnehmungen und Blickwinkel zulassen. Das Wechselspiel zwischen totalen und nahen Einstellungen setzt die Protagonistin nicht nur in Bezug zum Garten und umkehrt, sondern etabliert den Garten damit als einen per se filmischen Raum. Die Filmwissenschaftlerin Lavinia Brydon betont in ihrem Zeitschriftenartikel „Navigations and Negotiations: Examining the (Post)Colonial Landscape of The Assam Garden“, dass der filmische Raum des Gartens ein aktives Einlassen auf die Welt ermöglicht: „The garden as an intensely mobile space with connections to the grand and persuasive movements of colonialism goes against its current appeal 
as a sanctuary: a means of escaping, rather than engaging, with the wider world" (178). Sie konzipiert den Garten als solchen weiter als favorisierten Raum filmischer Mobilität per se: „The garden has a privileged relation to the forms, feelings and mobilities of cinema“" (185). Diese Mobilität weist den Garten in Zanan bidun-i mardan als jenen „Ab-Ort“ aus, den Silke Martin und Anke Steinborn als fluiden Zwischenraum konzipieren. Die Transformation der Protagonistinnen findet nicht nur im Garten statt, weil er als Zwischenraum einen dritten Raum, ein „epistemic and rebellious site that enables new ways of thinking about, and responding to, dominant social structures“ (Palmer-Mehta 94) konstituiert, vielmehr geschieht dies überwiegend durch filmische Transformationsprozesse wie Schärfe-Unschärfe-Relationen, die ihn als Raum mit einer eigenen Mediensensibilität ausweisen:

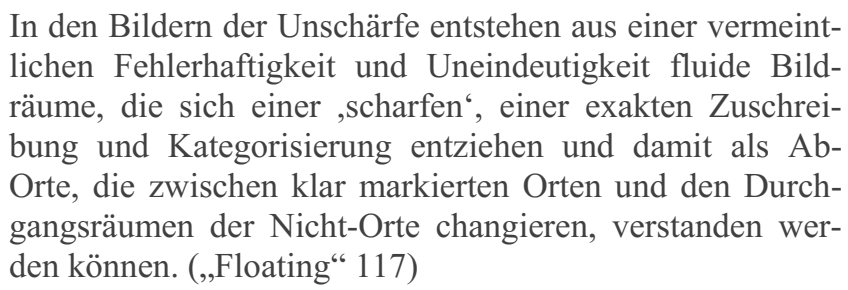

Die Bewegung der Kamera in dieser Sequenz offenbart, dass der Garten kein hermetisch von der Welt abgeschotteter Unterschlupf, sondern ein Aushandlungsraum ist. Dadurch kann die sinnstiftende Eigenschaft des Gartens sowohl für feministische Aushandlungsprozesse als auch für das Filmische produktiv gemacht werden, indem, wie ich mit Lavinia Brydon nachdrücklich argumentieren möchte, „the garden as inherently cinematic“ (178) konzipiert wird. ${ }^{37}$ Der Garten in Zanan bidun-i mardan ist damit auch ein Zwischenraum, der die Erfahrung von Diaspora selbst verhandelt.

Zum einen geht es mir also um den Garten als einen bestimmten filmischen Raum in einem bestimmten Film mit einem Bezug zu einem bestimmten nicht- 
filmischen Raum, zum anderen geht es mir um den Diasporafilm als übergeordnete Kategorie. Diasporafilm selbst wird dabei als prozessualer Raum begriffen, der sich verändert und immer wieder neu definiert und konstituiert; ein Raum, der eine erhöhte Mediensensibilität aufweist und somit die Frage nach dem Verhältnis zwischen Raum und Medien stellt. Der Diasporafilm ist in diesem Zusammenhang nicht nur Teil des Raumdiskurses, sondern die Wirksamkeit des Zwischenraumes „Garten“ macht ihn zu einem Brennglas raumbildender Elemente.

\subsubsection{Shahr-i Bad}

Als zweites Beispiel für Zwischenräume, abseits von Übergangsräumen wie Flughäfen und Hotels, möchte ich auf Ana Lily Amirpours Regiedebüt aus dem Jahr 2014, A Girl Walks Home Alone at Night, und die darin entworfene Stadt Shahr-i Bad näher eingehen. Der Film wurde in den Vereinigten Staaten mithilfe einer Crowdfunding-Aktion produziert und auf dem Sundance Film Festival 2014 uraufgeführt.

Auch in A Girl Walks Home Alone at Night ist der Zwischenraum, so möchte ich in der Analyse aufzeigen, kein dritter Raum, der als bloßes Endergebnis zweier oder mehrerer kultureller oder filmischer Elemente entsteht, vielmehr bildet er den Ausgangspunkt, die Prämisse des Filmes. Innerhalb des Zwischenraumes Shahr-i Bad eröffnen sich im Laufe des Filmes weitere, nicht miteinander kommunizierende Zwischenräume: Die elterliche Villa des reichen nasenoperierten Mädchens (Rome Shadanloo) mit schickem Garten - gleich einer Oase inmitten der Wüste; ein Parkplatz, auf dem sich der hiesige Drogendealer (Dominic Rains) mit der teilnahmslosen Prostituierten (Mozhan Marnò) trifft; ein Hinterhof zwischen mehreren Häusern, in dem ein Transsexueller 
(Reza Sixo Safai) mit einem Luftballon tanzt; Landschaften von Ölraffinerien mit gigantischen Pumpen, die das Erdöl - wie die Vampirin (Sheila Vand) das Blut aus den Menschen - aus der Erde saugen; und die Souterrain-Wohnung der Protagonistin, ein überladenes Sammelsurium popkultureller Artefakte mit Schallplatten von Lionel Richie, Punkpostern und Covern von Patti Smith.

Anhand des Vorspannes möchte ich den Zwischenraum Shahr-i Bad als interkulturellen Raum konzipieren, bevor ich anhand von drei weiteren Sequenzen auf den für diesen Film maßgeblichen Genre-Raum eingehe: das Erscheinen der Protagonistin als Vampirin sowie die Inszenierung der fahrbaren Untersätze „Skateboard“ und „Ford Mustang“. Zu guter Letzt soll die Analyse Shahr-i Bad als filmisch-hybriden Zwischenraum ausweisen, der sich eindeutigen kulturellen Zuschreibungen entzieht und so die Positionierung der iranischen Diaspora abseits kulturessentialistischer Verortungen ausstellt.

\section{Shahr-i Bad als interkultureller Raum}

Der Film ist in Schwarz-Weiß gedreht und beginnt mit einer halbnahen Aufnahme des jungen Mannes Arash (Arash Marandi), der in James-Dean-Manier lässig mit Sonnenbrille an einem Gartenzaun lehnt und raucht (Abb. 2.1). Der hohe Holzzaun nimmt dreiviertel der Bildfläche ein, dadurch wird der Protagonist visuell in das letzte Viertel am linken Bildrand gedrängt. Die Sicht auf die Umgebung bleibt damit zunächst eingeschränkt. Der Schriftzug des Vorspannes läuft im Stil alter Westernfilme, die Kamera hält die Einstellung lange, um Arashs Warten zu visualisieren - ein Anfang, der an jenen von Sergio Leones Italowestern Once Upon a Time in the West aus dem Jahr 1968 erinnert. Plötzlich scheint sich etwas hinter dem Zaun zu tun, Arash springt durch den Schlitz 
und kommt mit einer Katze im Arm wieder heraus. Dann macht er sich zu Fuß auf den Weg, die Kamera folgt seinem entschlossenen Schritt.

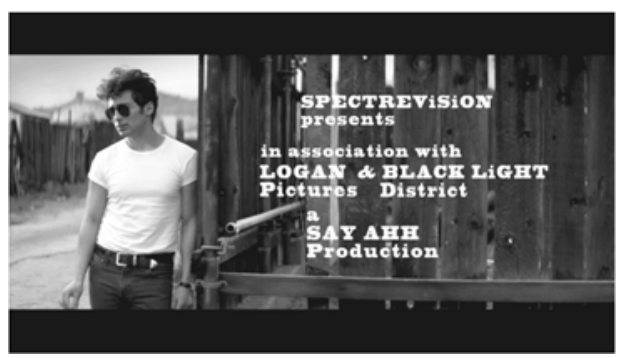

Abb. 2.1 A Girl Walks Home Alone at Night, „Arash lehnt am Zaun“, USA 2014

Stück für Stück wird im Vorspann Einstellung für Einstellung der umliegende Raum preisgegeben: staubige Straßen, leere Parkplätze, große Industriegebäude und zu guter Letzt: die Stadt. Arash geht zielstrebig auf der Straße entlang, die Kamera folgt seinem Gang aus erhöhter Perspektive. Er geht an einem Straßenschild vorbei, auf dem in Farsi „Shahr-i Bad“ zu lesen ist (Abb. 2.2). Es ist der Name der Stadt - „Schlechte Stadt“ - und langsam geht die Perspektive in eine weite Einstellung über, die Umgebung eines amerikanischen „Suburbs“ enthüllend, ein Ort, der durch seine Lage zwischen Stadt und Land bereits per se ein Zwischenraum ist. Die Vogelperspektive zeigt nur ein paar Häuser und Shahr-i Bad nicht in Gänze, ein Zentrum in Form von Kirche, Moschee, Rathaus, Markt oder Platz gibt es nicht (Abb. 2.3). Eine geographische Zuordnung ist unmöglich, allerdings auch nicht nötig, denn die Geschichte, so die Regisseurin, betrifft alle Menschen unabhängig vom Standort gleichermaßen:

I think things that happen, happen inside me, and they happen in all the places in the world [...], which is loneliness, being misunderstood, wanting to find a connection, feeling isolated. I feel there is a heaviness that a lot of societies 
wear. And I don't really think it's a geographically specific thing. (,Q\&A“)
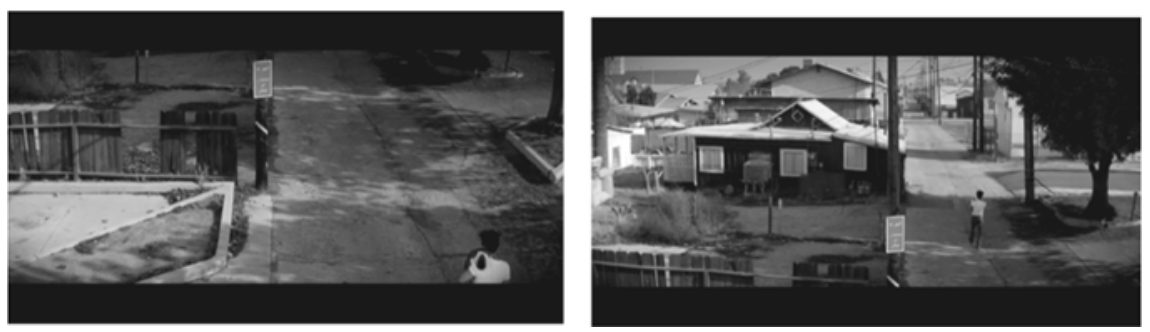

Abb. 2.2 und 2.3 A Girl Walks Home Alone at Night, „,Gang in die Stadt“, USA 2014

Die Straßenschilder und die wenigen gesprochenen Sätze in Farsi legen die Vermutung nahe, die Geschichte spiele in Iran, der Film wurde jedoch in der kalifornischen Stadt Taft gedreht. Auf die Frage von Filmproduzent Roger Corman, ob die Regisseurin lieber in Iran, „on the actual locations“, gedreht hätte, antwortet diese Folgendes:

I do think it's a fairytale and for me it's just an Iran of my mind. Film is an opportunity to make your own universe, make your own world. I think that's what is exciting and wonderful about it. [...] The great thing about art is that the limitations are actually the thing that encourages the creativity and push you to new places. I wanted to do this thing, ok so I cannot do it there, but then it became this limitless to really make my own place, make my own rules: we made the money, we reinvented the posters, the street signs, it was like really glorious, like making a world, that's one of the best parts. (,Q\&A“)

Ana Lily Amirpour rekurriert hier auf einen sehr traditionellen Kunstbegriff, den sie jedoch für ihr Schaffen dahingehend aktualisiert, als dass sie die Wahl eines erfundenen Raumes ${ }^{38}$ nicht als unfreiwillige oder zweitrangige Lösung in Ermangelung realer Alternativen sieht, sondern als Chance, durch Film neue Räu- 
me zu erschließen und zu kreieren. Sie hat dadurch eine eigene Welt, ein Niemandsland zwischen den Vereinigten Staaten und Iran erschaffen. Die Elemente aus iranischen, amerikanischen und weiteren (Film-)Kulturen rücken den Film somit in die Nähe von Laura U. Marks' Konzept des intercultural cinema, denn „intercultural cinema is fundamentally concerned with the production of new languages“ (xiv). Hierbei ist das Adjektiv ,interkulturell“ - in Abgrenzung zu verwandten Begriffen wie „multikulturell“ (Shohat und Stam) oder ,transkulturell“" (Welsch) - als dynamische Triebfeder für neue diasporafilmische Räume zu sehen. Laura U. Marks meint ferner:

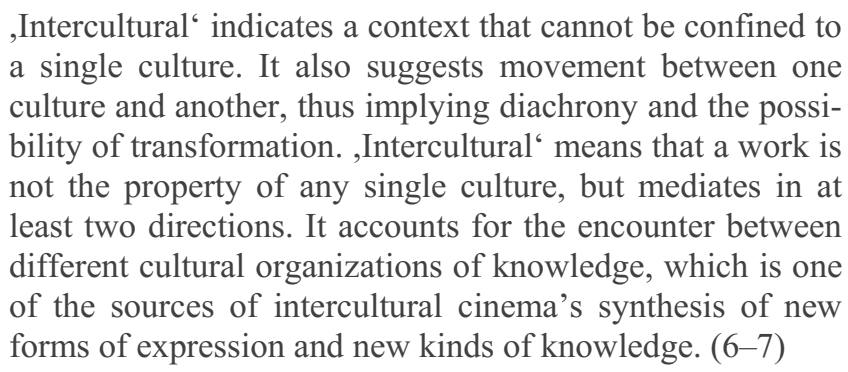

Ihr Konzept des intercultural cinema ist geprägt von und charakterisiert durch experimentelle Formen. Diese bedienen verschiedene filmische und kulturelle Einflüsse, um sich schließlich in einer zeitgenössischen Filmpraxis zu materialisieren: „Intercultural cinema draws from many cultural traditions, many ways of representing memory and experience, and synthesizes them with contemporary Western cinematic practices“(1-2).

Daran anschließend argumentiere ich, dass Shahr-i Bad nicht bloß ein Zwischenraum ist, weil der durch Tattoos und Piercings charakterisierte Drogendealer schwarzen Tee aus persischen kleinen Tassen trinkt und die Tschador tragende Protagonistin Lieder von den White Lies hört, sondern weil darin Leben und Tod, Tag und Nacht, Schwarz und Weiß, Bedrohlichkeit und Zärtlich- 
keit, Grausamkeit und Humor nah beieinanderliegen. Shahr-i Bad ist ein filmischer Raum der Bewegung, des Prozesshaften, des Fluiden und vor allem der kulturellen Aushandlung von Diaspora. Er ist kein trostloses „betwixt-andbetween“ (Turner 95), in dem die Figuren nicht wissen, wohin, vielmehr ist er ein produktiver Zwischenraum: „Ein durch eine ,raumkonstituierende Handlung“ entstehender ,Unort““ (Däumer, Gerok-Reiter und Kreuder 14). Der zu Michel Foucaults Heterotopie und Marc Augés Nicht-Ort eingeführte alternative Begriff des „Unortes“ der Germanist_innen Matthias Däumer, Annette Gerok-Reiter und des Theaterwissenschaftlers Friedemann Kreuder ist vornehmlich ein Raum, dem Transformation eingeschrieben ist:

Immer wird dieser Ort jedoch durch eine Transgressionsbewegung in Absenz versetzt, überhöht, umbesetzt oder durch $\mathrm{Ab}$ - und Ausgrenzung umdefiniert, so dass er sich nicht mehr als ,Ort' und nicht nur als ,Raum', sondern - im Spiel mit seinen Genesebedingungen - als ,Unort‘ präsentiert. (18)

Der „Unort“ ist, ähnlich wie der „Ab-Ort“, stärker durch Bewegung, Prozesshaftigkeit und Flexibilität definiert und daher für meine Konzeption des Zwischenraumes als interkultureller Raum brauchbarer. Denn Shahr-i Bad überschreitet kulturelle wie generische Zuschreibungen nicht nur, sondern zeigt, dass sich Diaspora durch Hybridität abseits kultureller Essentialismen auszeichnet. Das Hybride tritt in diesem Zwischenraum filmisch auf solche Art und Weise in Erscheinung, dass kulturelle Verortungen gar verunmöglicht werden. Die kulturellen und generischen Elemente stehen nicht nur Nebeneinander, sie verschmelzen mit erfundenen Elementen und legen dadurch ihre Konstruiertheit, gar Beliebigkeit offen. In diesem Sinne ist Shahr-i Bad ein interkultureller Raum der Überschreitung selbst; oder, um es mit Laura U. Marks’ Formulierung zu sagen: „Intercultural cinema is ceasing to be a movement and becoming a genre“ (2). Die 
Auflösung ethnischer Zuschreibungen fällt hierbei, wie ich nachstehend zeige, mit der Auflösung von Genre-Zuschreibungen zusammen.

\section{Shahr-i Bad als Genre-Raum}

Der Begriff des Genres wird gemeinhin im Lexikon der Filmbegriffe als „Sets kultureller Konventionen“, „zur Routine gewordene Erzählstrategien“, „Standardisierung arbeitsteiliger Produktionsprozesse“ oder „Ritualisierung kollektiver Ideale“ verstanden („Genre“). Trotz des Eindruckes hoher Schemahaftigkeit klassischer Hollywood-Genre-Filme weisen Genres, laut dem Film- und Literaturwissenschaftler Rick Altman, allerdings ein hohes Maß an Flexibilität auf, unterliegen ständiger Verschiebung und variieren vorgefundene Muster immer weiter:

Because a genre is not one thing serving one purpose, but multiple things serving multiple purposes for multiple groups, it remains a permanently contested site. [G]enres [are] ever in process, constantly subject to reconfiguration, recombination and reformulation. (195)

Basierend auf der genretheoretischen Grundannahme, dass Genrestrukturen in der Produktion und Zirkulation von kulturellen Artefakten ebenso wirksam sind wie in den diversen Zugängen zur Nutzung und Analyse von Medien, beschreiben auch die Medienwissenschaftler Ivo Ritzer und Peter W. Schulze Genre als nicht-hermetische Anordnungen: „Genres cannot be understood as closed systems, but only as processes of systematisation. They are always in flux and undergo changes“ (Genre Hybridisation 15). Dementsprechend zählen Genrekonfigurationen zu den diskursiven Größen, welche die Medienkultur maßgeblich prägen. Anhand von Genres lassen sich daher vielfältige Dimensionen der Medi- 
enkultur ausmachen und analysieren, unter anderem ästhetische, sozio-politische und ökonomische Aspekte, die sich in jeweils historisch wie kulturell spezifischen Konstellationen manifestieren. Zugleich fungieren Genrekonzepte in ihren unterschiedlichen Konturierungen auch als epistemologische und methodologische Kategorien, die ihren Gegenstand mit hervorbringen beziehungsweise beschreibbar machen. Ivo Ritzer und Peter W. Schulze betonen ferner: „Genres do not resemble each other because they have a common feature, but because they share multiple properties. Therefore, they cannot be designated essentialistically“ (Genre Hybridisation 10). Genre wird demnach in der neuesten Forschungsliteratur als ein offen-texturiertes Konzept verstanden ${ }^{39}$ und erweist sich gerade in dieser Unbestimmtheit und der Abwendung von Essentialismen für den Diasporafilm als nützlich. A Girl Walks Home Alone at Night wurde als ,the first Iranian Vampire Spaghetti Western“40 angepriesen und weist eine Fülle von Genre-Elementen auf, wobei sowohl der Vampirfilm als auch der (Italo-)Western für den diasporafilmischen Raum Shahr-i Bad die wes(ent)tlichen Referenzpunkte bilden.

Der Vampirfilm hat eine lange Traditionsgeschichte: Von den literarischen Vorlagen der deutschen Lyrik des achtzehnten und der englischen Prosa des neunzehnten Jahrhunderts über Friedrich Wilhelm Murnaus Nosferatu: Eine Symphonie des Grauens (Deutschland, 1922) und Carl Theodor Dreyers Vampyr: Der Traum des Allan Grey (Deutschland, 1932) bis hin zu Terence Fishers Dracula (Großbritannien, 1957), Francis Ford Coppolas Bram Stoker's Dracula (USA, 1992), weiter über E. Elias Merhiges Shadow of the Vampire (USA, 2000), bis hin zu The Twilight Saga (USA 2008-10) und Jim Jarmuschs Only Lovers Left Alive (USA, 2013), sowie weiteren Vampir-Fernsehserien (z.B. Buffy The Vampire Slayer, USA, 1997-2003;), um nur einige Beispiele zu 
nennen, sind sowohl das Motiv des Vampires (Dorn; Keppler; Klewer; Köppl; Pirie; Silver; Schott; Waltje) als auch der Vampirfilm als Genre (Lutschewitz) in der Forschungsliteratur breit diskutiert worden. ${ }^{41}$

Die filmische Inszenierung der Vampirin in A Girl Walks Home Alone at Night erfordert eine nähere Betrachtung: „The Girl“ wird zunächst in Alltagssituationen beim Spazierengehen, Schminken und Musikhören gezeigt. Erst als sie dem Drogendealer gegenübersteht, zeigt die Kamera ihr Gesicht in Großaufnahme und enthüllt damit ihre spitz zulaufenden Reißzähne. Sie stürzt sich auf ihn, saugt ihn aus und wird mit blutverschmiertem Gesicht erneut in der Großaufnahme gezeigt, ihre Augen high vom Blutrausch (Abb. 2.4 und 2.5).
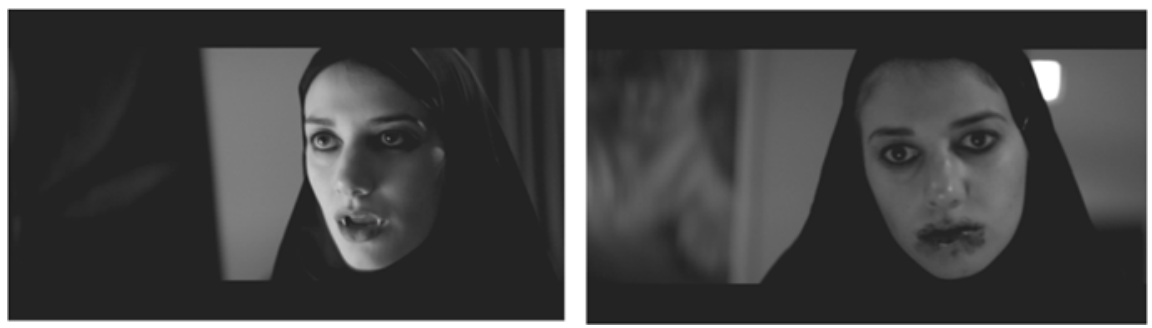

Abb. 2.4 und 2.5 A Girl Walks Home Alone at Night, „Vampirzähne“, USA 2014

Ähnlich inszeniert Jim Jarmusch seine Protagonistin 2013 in seinem Film Only Lovers Left Alive: Nachdem Eve (Tilda Swinton) zum ersten Mal beim Trinken von menschlichem Blut gezeigt wird, verharrt die Kamera in einer Großaufnahme auf ihrem Gesicht mit dem blutverschmierten Mund und den spitzen Reißzähnen, die Augen vor Genuss geschlossen. In beiden Fällen verschwimmt der umliegende Raum in der kompletten Ausfüllung des Bildes durch das Gesicht und tritt damit nicht nur in den Hintergrund, sondern verschwindet gänzlich aus dem Wahrnehmungsfeld. Sowohl die Wohnung des Drogendealers in Shahr-i Bad als auch Eves Wohnung in Tanger weichen einem neuen filmischen Raum, 
jenem der Transformation: Die menschlich geglaubte Frau wird zur Vampirin und der Film wechselt in das Vampirfilm-Genre. Die Großaufnahme wird hierbei bewusst als filmisches Mittel der (Un-)Sichtbarmachung verwendet: Beiden Figuren ist von außen, in totalen und halbnahen Aufnahmen, ihr Vampirdasein nicht anzusehen. Erst durch die Großaufnahme werden die vampireigenen Genre-Merkmale in einer Überausstellung von Blut und Reißzähnen sichtbar. Das Gesicht wird dabei zum filmischen Raum, der als Genre-Raum in Erscheinung tritt. Sich auf Bela Balázs Filmtheorie beziehend, schreibt der Philosoph Gilles Deleuze über die Großaufnahme als Affekt-Bild, dass sie das Gesicht nicht nur abbilde, sondern das Gesicht sei: „Es gibt keine Großaufnahme des Gesichts. Die Großaufnahme ist das Gesicht, allerdings genau in dem Maße, wie es seine dreifache Funktion aufgegeben hat. [...] Die Großaufnahme macht aus dem Gesicht ein Gespenst [...]. Das Gesicht ist der Vampir“ (139; Hervorhebung im Original). Affekt-Bild, Großaufnahme und Gesicht verwendet er synonym: „Ein Affektbild ist eine Großaufnahme, und eine Großaufnahme ist ein Gesicht“ (123). ${ }^{42}$ Statt den mimetischen Seelenzustand herauszustreichen, wird das Gesicht damit zur Projektionsfläche und die Großaufnahme zur Erscheinungsform, die auf die Bedeutung ihrer medialen Inszenierung verweist. Das Vampir-Gesicht der Frau ist in dieser Szene damit nicht nur als konstitutives Element des VampirfilmGenres zu sehen, sondern als jenes, welches den Genre-Raum durch die Überausstellung der Genreelemente (Reißzähne und Blut) erst etabliert.

Der Genre-Raum in A Girl Walks Home Alone at Night wird des Weiteren über Western-Elemente etabliert. Zum Western gibt es eine breite Forschungsliteratur (Hembus; Adams und Rainey; Cameron und Pye; Wright; French), die sich jüngst dem Genre auch als globales Phänomen annähert. In Form des mexikanischen Ranchera-Westerns, französischen Camargue-Western, 
Italo-Westerns, australischen Bushranger-Films, brasilianischen CangaceiroFilms, argentinischen Gaucho-Films und japanischen Samurai-Films hat sich der Western, laut Thomas Klein, schon früh und stetig weiter als weltumspannendes Phänomen verbreitet. Die Spezifika des Westerns als Genre sind demnach nicht nur transferierbar, sondern auch auf keinen wie auch immer gearteten Ursprung zurückzuführen. Grundsätzlich ist dem Western der Konflikt an der frontier jener imaginären Grenze, die mit der Landnahme bei der Besiedelung Amerikas immer weiter nach Westen getrieben wurde - eingeschrieben und macht sein grundlegendes Genreelement aus. Der Krieg gegen „die Indianer“ bezeichnet auch den Übergang von Natur zu Zivilisation: Die Durchsetzung der amerikanischen Rechtsordnung, die wirtschaftliche Erschließung des Landes (Industrie, Eisenbahn, et cetera) und die Etablierung von Kultur (Zeitung, Kirche, Schule et cetera). Die Hochphase des Westerns ist laut dem Lexikon der Filmbegriffe in den 1940er und 1950er Jahren anzusiedeln, im Spätwestern werden Helden- und Todesbild sowie Gewalt problematisiert („Genre“). In A Girl Walks Home Alone at Night besitzen die Protagonist_innen keine Pferde, mit denen sie gen Westen/Sonnenuntergang reiten, die frontier verschieben und damit das Land erobern können. Hingegen haben sie einen für den amerikanischen Lifestyle der 1950er Jahre stilbildenden Ford Mustang (der in seinem Namen das Motiv der frontier mit sich führt) und ein für die 1980er Jahre symbolträchtiges Skateboard. Die folgenden zwei Szenen illustrieren dies.

In einer totalen Einstellung wird eine mit Laternen gesäumte leere Straße gezeigt. In perfekter Symmetrie ist im Fluchtpunkt der mittigen Sichtachse die Vampirin zum ersten Mal auf dem Skateboard, welches sie einem kleinen Jungen weggenommen hat, zu sehen (Abb. 2.6). Sie fährt, ohne vermeintliches Ziel, die Straße hinunter und auf die unbewegliche Kamera zu, bis sie in einer Detailaufnahme mit wehendem Tschador gezeigt wird und kurz darauf aus dem 
Bild fahrend verschwindet (Abb. 2.7). Vom Bildrand zum Bildinneren ist sie somit nicht nur im Zentrum der Narration, sondern auch der Bildgestaltung.
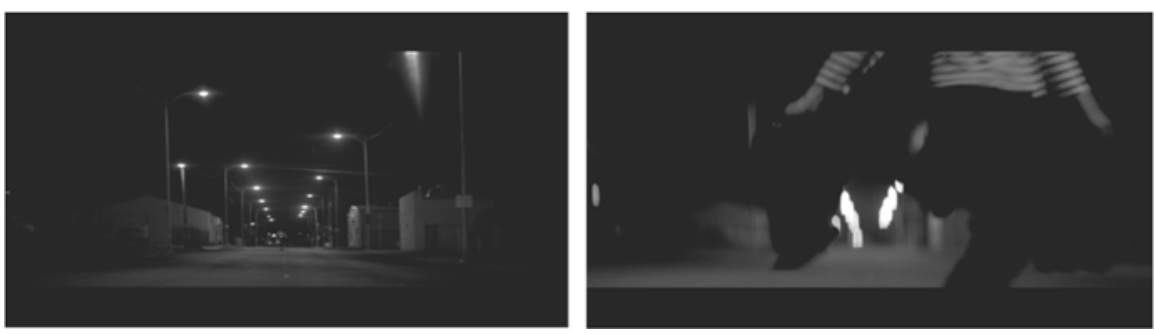

Abb. 2.6 und 2.7 A Girl Walks Home Alone at Night, „Skateboardfahren“, USA 2014

Das Ende des Filmes inszeniert den Ford Mustang in einer gegenteiligen Bewegung, von einer Detailaufnahme zu einer totalen Einstellung: Die Vampirin und Arash werden in der Sequenz zunächst frontal, die Katze aus dem Vorspann zwischen ihnen sitzend, in einer halbnahen Einstellung im Auto beim Musikhören gezeigt. Nach einem langen, verliebten Blick geht der Schnitt auf die Rückseite des Autos und offenbart mit dem Einschalten der Lichter, dass das Auto gestartet wurde und zur Abfahrt bereit ist. Die Lichter beleuchten das Nummernschild, auf dem in Farsi „Shahr-i Bad“ zu lesen ist, und setzen dadurch ein letztes Mal die Stadt auch bildlich in den Fokus (Abb. 2.8). Der Ford Mustang fährt über die staubige Wüstenstraße und damit nicht nur aus der Stadt, sondern auch aus dem Bild, einen Horizont aus Licht am oberen Bildrand hinterlassend, der in der Dunkelheit der Nacht schließlich verschwindet und durch eine Schwarzblende den Abspann einläutet (Abb. 2.9). 

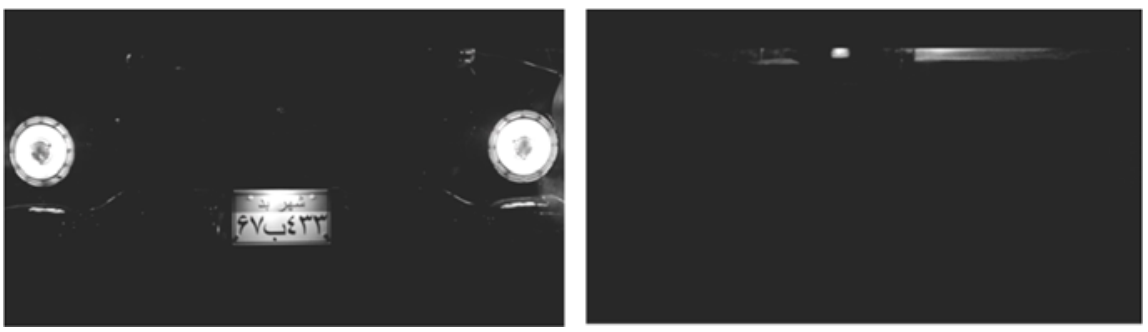

Abb. 2.8 und 2.9 A Girl Walks Home Alone at Night, „Autolichter“, USA 2014

Kathrin Rothemund schreibt über die frontier als Genreelement des filmischen Raumes:

Das Prinzip der Grenzverschiebung, das dem Konzept der frontier inhärent ist, lässt sich in vielen Filmen, insbesondere im Western, durch eine Differenz von außen und innen wiederfinden und zeigt sich in der filmischen Aneignung des Offs durch Kamerabewegung und Montage. Wird dieses Außen aber nun Teil des Bildinneren und lässt es sich durch filmische Mittel nicht mehr eliminieren oder annektieren, so verweist dies umso mehr auf die frontier als kulturelles Konzept, das in sich auch schon immer ein Außerhalb einschließt. („Übergänge“ 58; Hervorhebung im Original)

In beiden Szenen wird die Verschiebung vom On ins Off und vom Sichtbaren ins Unsichtbare durch das Zusammenwirken von Detailaufnahme und totaler Einstellung zum raumbildenden Filmmittel, welches die frontier als Genreelement aufgreift. In diesem Sinne schließt A Girl Walks Home Alone at Night als „Iranowestern“, wie ich ihn nennen möchte, Iran und Diaspora, Diaspora und Vereinigte Staaten ein und konzipiert damit den Gründungsmythos der Diaspora selbst, denn die frontier ist nicht nur verschoben, sondern im Sinne Edward Saids gänzlich aufgelöst: „All cultures are involved in one another; none is single and pure, all are hybrid, heterogeneous, extraordinarily differentiated and 
unmonolithic“ (Culture and Imperialism xxv). Der Western als „manifest destiny“ ist in seiner raumerschließenden Wirkung und Ästhetik als struktur- und identitätsbildendes Film-, Literatur- und Kunst-Genre für die Vereinigten Staaten maßgeblich. A Girl Walks Home Alone at Night stülpt jedoch in Produktion und Sprache des Filmes (in den Vereinigten Staaten hergestellt, Farsi in der Diegese), den Genre-Variationen Vampirfilm im Western und umgekehrt sowie den Geschlechterrollen kulturelle Zuschreibungen von Vereinigten Staaten und Iran ineinander und kreiert einen Genre-Raum, der als Beitrag zu einer filmischen Neuverhandlung von Diaspora gesehen werden kann.

Denn innerhalb dieses vornehmlich durch amerikanische filmische Bezüge bestechenden Genre-Raumes werden auch Elemente sichtbar, die zunächst irritierend anmuten. Die Vampirin in A Girl Walks Home Alone at Night trägt nämlich einen Tschador, ein großes, meist schwarzes Tuch in Form eines umsäumten Halbkreises, das vor allem von iranischen Frauen in Iran getragen wird. Der Tschador dient der Vampirin als Tarnung, aber auch als allabendliche Uniform. Auf die Frage nach dem Tschador als Kleidungsstück weiblicher Repression und dessen Umdeutung als rebellischer Vampirumhang sagt Regisseurin Ana Lily Amirpour:

The chador has this weight, this velvety, satiny [texture], it catches the air in a certain way, it felt like really nice. The thing about the chador or any of the things we do, it could be the bumper stickers on your car, how you organize your house, all the things that make the system of how we appear in the world. The truth is that whatever reason, once you start pealing back the layers there is very very strange things inside us people and often it contradicts the outside system. (,Q\&A“) 
Sie sieht in der Verwendung des Tschadors keine vordergründig politische Botschaft, sondern kehrt die taktile und haptische Ebene des Tschadors als Requisit hervor. Dem Kostüm kommt in der Kreation des filmischen Vampirmythos eine besondere Rolle zu, wie Vera Cuntz-Leng in einer fundierten Analyse von Tony Scotts The Hunger (USA, 1983) beschreibt. Darin kommt sie zu dem Schluss, dass die von den Protagonistinnen getragene Alltagskleidung ihnen ermöglicht, sich an Orten, an denen mensch sie nicht vermuten würde, wie beispielsweise der Disco, unauffällig zu verhalten und dadurch ihre Opfer leicht um den Finger zu wickeln. Dies führe zu einer „Grenzverwischung zwischen fantastischer und realistischer Zeichnung“ (48), die eine „Naturalisierung des Übernatürlichen“ (47) zur Folge hat. Der Tschador ist nicht nur für viele reale Frauen, sondern auch für die Protagonistin in A Girl Walks Home Alone at Night eine Alltagskleidung. Allabendlich wirft sie den schwarzen Umhang um die Schultern und geht damit zum Einkaufen, auf die Jagd oder zu ihrem Date mit Arash. Die Verwandtschaft mit dem Vampirumhang ist durch Farbe und Textur zwar gegeben, wird jedoch verfremdet und zunächst, im Gegensatz zu Reißzähnen und Blut, nicht vordergründig als konstitutives Genreelement des Vampirfilmes genutzt. Dies zeigt, ähnlich wie für die Protagonistinnen in The Hunger, auf, „dass Vampire nun in der gesellschaftlichen Mitte unerkannt angekommen sind“ (50). Keiner vermutet unter dem Tschador eine Vampirin, und doch ist im Film ihre unerkannte, beiläufige Integration in die Gesellschaft vordergründig. In Analogie zu Avtar Brahs Konzept des diaspora space kann daher folgerichtig festgehalten werden: Die Diaspora ist ebenfalls in der Mitte der Gesellschaft angekommen und kein vermeintliches Außen, Daneben oder Dazwischen mehr, sondern durch den diasporafilmischen Zwischenraum des Genre-Raumes nunmehr ein konstitutiver Bestandteil. Die Diaspora wird damit selbst zum Genre, die generischen 
Stereotype dienen in ihrer Summe der Erschaffung ihres Gründungsmythos und ihrer Festlegung in der Mitte der Gesellschaft.

\section{Shahr-i Bad als filmisch-hybrider Raum}

Shahr-i Bad besteht durch den Einsatz hybridisierter kultureller und generischer Elemente aus vielschichtigen interkulturellen Zwischenräumen und eröffnet dadurch ein Feld pluraler Potenzialitäten. Als filmisch-hybrider Raum tritt Shahr-i Bad derart in Erscheinung, dass die Genreelemente als filmische Mittel eingesetzt werden, um einen Genre-Raum zu erschaffen, der es erlaubt, komplexe kulturelle Austauschprozesse anhand raumübergreifender filmischer Elemente $\mathrm{zu}$ beobachten und zu analysieren. Shahr-i Bad ist ein Zwischenraum, in dem mehrere Räume, die sich eigentlich widersprechen und nicht miteinander verträglich sind, in einem filmisch-hybriden Raum nebeneinandergestellt werden. Die Medienwissenschaftlerin Yvonne Spielmann spricht in ihrer Monographie Hybridkultur dem Hybriden die Funktion einer medialen Nahtstelle zu:

Im Hybriden herrscht die verbindende vor der trennenden Kraft in ungleichartigen Konstellationen vor. Diese sedimentieren sich in Zwischenzonen und Zwischenräumen. Dabei kommt den Prozessen der Verschiebung und Wanderung, wie sie sich in medialen Zwischenzonen und kulturellen Zwischenräumen abspielen, besonderes Gewicht zu. (53)

Der Zwischenraum Shahr-i Bad ist demnach, so möchte ich argumentieren, nicht als ein in sich geschlossener Raum zu verstehen, ihm kommt im Sinne von Foucaults Konzept der Heterotopie gleichwohl

die merkwürdige Eigenschaft zu [...], in Beziehung mit allen anderen Räumen zu stehen, aber so, dass sie alle Bezie- 
hungen, die durch sie bezeichnet, in ihnen gespiegelt und über sie der Reflexion zugänglich gemacht werden, suspendieren, neutralisieren oder in ihr Gegenteil verkehren. (Heterotopien 320)

Ebenso wie Diaspora kein kulturell hermetischer Raum ist, ist es auch Film nicht, und so wird der filmisch-hybride Raum durch das In-Beziehung-Setzen verschiedener kultureller Elemente zu einem diasporafilmischen Raum, der sich durch eine atopische Struktur auszeichnet. Die flexible Bewegung von einem InBeziehung-Setzen und einem Sich-Entziehen von eindeutigen Zuschreibungen sind symptomatisch für die Ähnlichkeit von Genre und Diaspora. Diese ReKonfiguration des diasporafilmischen Zwischenraumes Shahr-i Bad liegt in der Emendation der Genreelemente aus Vampirfilm und Western begründet. Die frontier gibt es nicht mehr, der Raum wurde längst erobert, kulturelle und ethnische Zuschreibungen sind nicht mehr als hybride Formen erkenn- und identifizierbar, sondern als filmisch-hybride Räume, die den Zwischenraum weniger als Übergang oder Passage denn als Aufenthaltsort für künstlerisches und kreatives Schaffen begreifen. A Girl Walks Home Alone at Night reiht sich damit in jenes Filmschaffen ein, das ,survives (and at times thrives) at the symbolic and material intersection of ,Hollywood", the ,indie“ scene and the vestiges of what cinephiles used to call ,art" films" (Sconce 351). Der Filmwissenschaftler Jeffrey Sconce nennt in seinem Zeitschriftenaufsatz „Irony, Nihilism and the New American ,Smart" Film“ solch hybride Filme smart films und meint damit Filme, die sich jeglichen klassischen Kategorisierungsmustern (Narration, Ästhetik, Produktion, Rezeption et cetera) entziehen. Er spricht diesen Filmen damit eine gewisse produktive Gewitztheit zu:

,Smart' films nevertheless share an aura of ,intelligence that distinguishes them (and their audiences) from the perceived ,dross' (and ,rabble') of the mainstream multiplex. 
$[\ldots][\mathrm{T}]$ here is a ,sensibility ${ }^{6}$ in and around these films that does provide them with historical, thematic and even stylistic cohesion. (351)

A Girl Walks Home Alone at Night beschäftigt sich als filmisch-hybrider Raum mit filmischen Transformationsprozessen, die über seine eigenen ReKonfigurationen hinausgehen, und lässt damit Rückschlüsse auf allgemeine kulturelle Transformationen diasporafilmischer Räume zu. Mit Yvonne Spielmann gesagt:

Hybride Relationen drücken mobile und flexible Überlagerungen und Zusammenarbeit aus, was wiederum zu weiteren Verknüpfungen anregt. Diese Möglichkeit zur Veränderung beinhaltet, daß die Zusammensetzung der Merkmale in der Verknüpfung disponibel bleibt. Sie kann sich verändern und erneut konfiguriert werden. (53)

Als smart film verstanden ist die Aushandlung kultureller Verortung nicht mehr das Ergebnis, sondern die Prämisse des Werdens des Filmes. Insofern ist der filmisch-hybride Raum als einer der dialogischen Aushandlung zu verstehen.

Dem Diasporafilm ist, so haben die Analysen von Zanan bidun-i mardan und A Girl Walks Home Alone at Night gezeigt, der Zwischenraum nicht nur durch die eingangs erwähnte und offenkundige ,liminality of deterritorialization“ (Naficy, An Accented Cinema 155) eingeschrieben, sondern als Haltung eines diasporischen Selbstverständnisses, welches kreative Prozesse forciert und Diaspora als Medienraum ausweist. Es treten Zwischenräume in Erscheinung, die sich abseits von Umgrenzung, Parallelität und Übergang als Räume der kulturellen Verortung und Positionierung der iranischen Diaspora und deren filmischen Transformationen begreifen lassen. Eine weitere Kategorie bilden „kosmopolitische Räume“. Sie sind, im Gegensatz zu Zwischenräumen, stärker von 
Widersprüchlichkeiten und Kontrasten gekennzeichnet, wie ich anhand der nachstehenden Filmanalysen zu Shirin Etessams und Erica Jordans Walls of Sand und Marjane Satrapis Persepolis beleuchten möchte.

\subsection{Kosmopolitische Räume}

Kosmopolitismus ist, so James Clifford in seinem Zeitschriftenaufsatz „Diasporas“, eine von in einer Diaspora lebenden Menschen eingeübte Überlebensstrategie, um mit der Spannung zwischen Verlust (der Ursprungskultur) und Hoffnung (in der Ankunftskultur) zurechtzukommen: „Skills of survival: strength in adaptive distinction, discrepant cosmopolitanism, and stubborn visions of renewal. Diaspora consciousness lives loss and hope as a defining tension" (312). Ulf Hannerz, seines Zeichens Sozialanthropologe, schlägt seinerseits in seiner Monographie Transnational Connections: Culture, People, Places - in Anlehnung an Homi K. Bhabha und Stuart Hall - einen Begriff von Kultur als nie fertig oder abgeschlossen für das Verständnis von Kosmopolitismus im Zusammenhang mit Diaspora vor: „An orientation, a willingness to engage with the other $[\ldots]$, an intellectual and aesthetic openness toward divergent cultural experiences“ (103). Hybridität im Sinne Homi K. Bhabhas liefert einen brauchbaren Ansatz, um Diaspora als fluiden, flexiblen und sich immer wieder konfigurierenden Raum zu denken. Offenheit im Sinne Ulf Hannerz' konzeptualisiert Kosmopolitismus als unvoreingenommene Aufgeschlossenheit gegenüber der Welt. Steven Vertovec versteht Kosmopolitismus in seinem Sammelbandbeitrag „Cosmopolitanism“ auf ganz ähnliche Weise ,as comprising a combination of attitudes, practices and abilities gathered from experiences of travel or displacement, transnational contact and diasporic identification“(64). Dabei stützt er sich 
unter anderem auf den Soziologen Roger Ballard und seine in der Einleitung zu seiner Monographie Desh Pardesh: The South Asian Presence in Britain verfasste These: ,Just as individuals can be bilingual, so they can also be multicultural, with the competence to behave appropriately in a number of different arenas, and to switch as appropriate“ (31). Wenn Diaspora nun aus der ständigen Neuverhandlung von kulturellen Bezügen und hybriden Momenten erwächst und Kosmopolitismus vor allem durch eine offene Ausrichtung gegenüber verschiedenen kulturellen Erfahrungen gekennzeichnet ist, dann können die Begriffe Diaspora und Kosmopolitismus zusammen gedacht und als verwandt konzeptualisiert werden. Die Soziolog_innen Steffen Mau, Jan Mewes und Ann Zimmermann untersuchten den Zusammenhang zwischen transnationalen Bindungen und kosmopolitischen Haltungen mit folgendem Ergebnis:

People with cosmopolitan attitudes and values are characterized by their recognition of others because of their value and integrity as human beings, quite independently of their national affiliations. They share an open and tolerant world view that is not bound by national categories but is based on an awareness of our increasing economic, political and cultural interconnectedness, which they perceive as enriching rather than threatening. (5)

In einer Diaspora lebende Menschen können solch eine „kosmopolitische Kompetenz“ aufbringen, keineswegs kann hier jedoch der Rückschluss auf einen Automatismus gezogen werden. Nicht jeder Mensch, der in einer Diaspora lebt, ist automatisch weltoffen. Im Zusammenhang mit Diaspora ist Kosmopolitismus meines Erachtens als Prozess zu sehen, in dem die in der Diaspora Ankommenden Elemente der Ankunftsgesellschaft annehmen und zu einer neuen hybriden Kultur oder hybriden Identität umwandeln. Diese hybriden Identitäten erwachsen aus einer permanenten Dialektik zwischen dem Annehmen der und Abgrenzen gegen die Kultur des Ankunftslandes (Strohmaier, „Irangeles: Zwischenorte“) 
und sind somit jener „,cosmopolitan attitude“ nah, die von Steffen Mau, Jan Mewes und Ann Zimmermann beschrieben wurde (5). Diaspora als Aushandlungsraum, als diaspora space im Sinne Avtar Brahs, in welchem Begegnungen und Konfrontationen innerhalb einer Gesellschaft stattfinden und kulturelle Differenzen verhandelt werden können, bezeichnet einen Möglichkeitsraum, der Kultur ebenfalls nicht monolithisch, allerdings auch nicht hybrid, sondern polyvalent begreift, und demnach kosmopolitische Haltungen nicht automatisch impliziert, aber durchaus begünstigt. Unter „kosmopolitischen Räumen“ verstehe ich demnach in den nachstehenden Analysen filmische Räume, die eine solche kosmopolitische Haltung aufweisen.

\subsubsection{Deutschland, Manhattan, Absurdistan, Italien, Ramallah, Casablanca, Tokyo, Macondo, Georgien, Rudolfsgrund}

Inwiefern eine kosmopolitische Haltung, sprich: Zugehörigkeits- und Weltoffenheitsgefühl, im Zusammenhang mit Iran zu denken ist, geht der Philosoph Lucian Stone in seinem Sammelband Iranian Identity and Cosmopolitanism durch eine dreifache Perspektivierung nach: „To critically examine cosmopolitanism with specific reference to the Iranian nation-state, Iranian history and culture, and the lived experience of Iranians" (15). Dabei untersucht er das Zusammenwirken von Nationalstaatlichkeit, Geschichte, Kultur und Lebensrealität von in Iran lebenden Menschen. Farhang Erfanis Beitrag im Sammelband macht dabei aus einer philosophischen Perspektive deutlich, dass es weder innerhalb noch außerhalb Irans eine monolithische irāniyyat (,iranisch Sein“) gibt. Während „the younger generation is thrilled by anyone advocating for Iranian-Americans" (156) und ihre Bindestrichidentität als ,,a cultural passport to being an official minority“ (156) feiern, positioniert sich der Autor selber ,at the bottom edge of 
the previous disintegrated generation that is suspicious of the dash and considers it a cultural surrender. Not at home [in the US], this older generation has no hyphens, no center, and is suspicious of all messages“ („Cosmopolitanism“156). Unumstritten für ihn dabei ist die (Selbst-)Bezeichnung von außerhalb Irans lebenden Menschen als Kosmopolit_innen: „We cosmopolitans, the Iranian community abroad [...]“ (153).

Kosmopolitismus in Bezug auf iranische Filmschaffende außerhalb Irans behandelt der Filmwissenschaftler Shahab Esfandiary in seiner Monographie Iranian Cinema and Globalization. Er beschreibt sie folgendermaßen: „,cosmopolitan“ film-makers produce ,transnational cinemas' with universal themes that go beyond local/national prejudices, and address a much more diverse global audience“ (4). Demnach zeichnen sich kosmopolitische Filmschaffende durch transnationale Produktion, universelle Themen und größere Rezeptionsreichweite aus. Hamid Naficy seinerseits beschreibt zu Beginn seines Buches An Accented Cinema: Exilic and Diasporic Filmmaking diasporisches Filmschaffen auf ähnliche Weise:

A majority [of exilic and diasporic filmmakers] are from
Third World and postcolonial countries (or from the global
South) who since the 1960s have relocated to northern
cosmopolitan centers where they exist in a state of tension
and dissension with both their original and their current
homes. (10)

Dieses Filmschaffen ist, so führt Hamid Naficy im vierten Band seines Opus Magnum A Social History of Iranian Cinema weiter aus, geprägt von einer Suche nach einem Platz im sozialen Gefüge zwischen einer übermächtigen Ankunftskultur und einem vornehmlich verlorenen Heimatland. Diese Suche weicht einem Kosmopolitismus, der sich im Zugang der Filmschaffenden zur Welt und ihrer Abkehr von Ethnozentrismus und Ortsgebundenheit ausdrückt: 
Cosmopolitan filmmakers resisted any attachment to place, nation, and roots; instead, they emphasized routes, individualized identities, and auteurist authority. They rejected the politics of the ethnic hyphen, and they generally did not make films about Iran or Iranians. If they did, they did not tell their personal stories. (The Globalizing Era 397-98)

Er fasst darunter jene Filmschaffende, die außerhalb Irans Filme produzieren, jedoch weder einen direkten Bezug zu Iran noch zur iranischen Diaspora haben und dies auch in ihren Filmen nicht thematisieren. Im Gegensatz zum Diasporafilm, der vor allem autobiographische Geschichten und das binäre Verhältnis zwischen homeland und diaspora ins Zentrum seiner Aushandlung stellt, würden kosmopolitische Filmschaffende zwar einen universellen Anspruch verfolgen, dabei jedoch ihr Verloren-Sein in der Welt nicht verbergen können: „The cosmopolitans, on the other hand, claimed universality, and they make films about the human condition. Yet their assiduous denial of particularity and nationality reveals the undercurrent of anxiety about who they are and where they belong“ (The Globalizing Era 398). Den Unterschied zwischen diasporischen Identitäten und kosmopolitischen Identitäten macht er an den Modi „rooted modality“ und „routed modality“ fest: „In the rooted modality, identity is essentialist, nationalist, and binarist, characteristic of exilic and ethnic identities and films; in the routed modality, identity is multiple, fragmented, and global, characteristic of diasporic, émigré, and cosmopolitan identities and films“ (399). Seine Kategorie des cosmopolitan accented cinema umfasst Filmschaffende mit iranischem Migrationshintergrund wie Suhrab Shahid Sales, der ab den 1970er Jahren in der damaligen BRD Filme drehte, und Amir Nadiri, der seit den 1980er Jahren in den Vereinigten Staaten als Regisseur und Produzent tätig ist. Ihre Filme sind gekennzeichnet durch „discontinuity, heterogeneity, and specificity“ (398-99), beziehen sich nicht auf Iran, sondern auf universelle Themen wie 
Liebe, Fremdheit oder Cinephilie. Die Liste jener Filmschaffenden, die in erster oder zweiter Generation iranischen Migrationshintergrund haben und in ihren Filmen übergeordnete Fragen von Migration, Assimilation, Generation und Ethnizität behandeln, lässt sich in dieser Logik um folgende Filme erweitern: Hushang Allahyaris Geboren in Absurdistan (Österreich, 1999), Abbas Kiarostamis Copie conforme (Frankreich, 2010) und Like Someone in Love (Japan, 2012), Ali Samadi Ahadis Komödie 45 Minuten bis Rahmallah (Deutschland, 2013), Sudabeh Mortezais Dokufiktion Macondo (Österreich, 2013), Asghar Farhadis Guzashta (Frankreich, 2013), Mohsen Makhmalbafs The President (USA, 2014) und Arman T. Riahis Die Migrantigen (Österreich, 2016).

Ich möchte Naficys Kategorie des cosmopolitan accented cinema allerdings dahingehend kritisieren, dass sie den ethnischen Ursprung der Filmschaffenden zum Ausgangspunkt nimmt und sie damit gleichsam auf diesen wieder zurückführt. In diesem Sinne müsste beispielsweise ein in Frankreich produzierter Film des österreichischen Regisseurs Michael Haneke als kosmopolitischer Film der österreichischen Diaspora kategorisiert werden. Im Gegensatz dazu stehen in den folgenden Analysen Filme im Vordergrund, die den kosmopolitischen Raum filmisch ausweisen und, so meine These, zu kulturellen Transformationsprozessen abseits von Herkunft der Filmschaffenden und Produktionsland der Filme beitragen. Denn Kosmopolitismus ist, um mit dem Soziologen Asef Bayat zu argumentieren, gerade jenes Konzept, das kulturellem Essentialismus und Ethnozentrismus entgegengesetzt werden kann: „Cosmopolitanism has also ethical and normative dimensions; it is a project with humanistic objectives. In this sense, cosmopolitanism is deployed to challenge the language of separation and antagonism, to confront cultural superiority and ethnocentrism“ (Life As Politics 186). Im Zusammenhang mit soziopolitischen Graswurzelphänomenen in der MENA-Region plädiert er, entgegen Konzeptualisierungen eines Kosmopolitis- 
mus von oben als Eliten-Phänomen und -Formation, für einen „everyday cosmopolitanism“, einen Kosmopolitismus von unten. ${ }^{43}$ Darunter versteht er eine kulturelle Praxis, die auf der Ebene des Alltagslebens Begegnungen, Verbindungen und Austauschprozesse kreiert:

By everyday cosmopolitanism I mean the idea and practice of transcending self - at the various levels of individual, family, tribe, religion, ethnicity, community, and nation to associate with agonistic others in everyday life. It describes the ways in which the ordinary members of different ethno-religious and cultural groups mix, mingle, intensely interact, and share in values and practices - in the cultures of food, fashion, language, and symbols; in history and memory. (Bayat 187; Hervorhebung im Orginial)

Ich verstehe, dieser Argumentationslinie folgend, Kosmopolitismus im $\mathrm{Zu}-$ sammenhang mit Filmen der iranischen Diaspora daher als alltägliche kulturelle Praxis dieser iranischen Diaspora. So verstanden, inspiriert das Konzept nicht nur neue politische Visionen, sondern kann als Linse für Diskurse über das Andere und das Selbst für eine filmwissenschaftliche Neuverhandlung von kultureller Identität innerhalb des Diasporafilmes, der so einmal mehr Diaspora als Medienraum ausstellt, produktiv gemacht werden. Als Medium imaginierter Welten fällt, der Einschätzung der Soziologin Maria Rovisco folgend, hierbei vor allem dem Spielfilm eine kosmopolitische Dimension $\mathrm{zu}$ - „fiction film can be a springboard for the cosmopolitan imagination because it creates a discursive ethical space“ (153) -, wie ich nachstehend anhand der kosmopolitischen Räume „Wohnung“ und „Persepolis“ darlegen werde. 


\subsubsection{Wohnung}

Als erstes Beispiel wird dafür der Spielfilm Walls of Sand von Shirin Etessam und Erica Jordan (USA, 2001) und die darin vorkommende Wohnung näher betrachtet. Der Film erzählt die Geschichte zweier Frauen: der US-Amerikanerin Ellen Follette (Jan Carty Marsh), die unter Agoraphobie leidet, und der Iranerin Soraya Rahimi (Shirin Etessam), die ihren Platz zwischen Heimat und Ankunftsgesellschaft sucht. Zentrales Thema des Filmes ist die sich entwickelnde Freundschaft der beiden Frauen, die physisch und sozial abgekapselt sind. Der Film markiert, laut Christopher Gow, einen Umbruch innerhalb der Filmlandschaft der iranischen Diaspora: „[The film] signals a shift away from a focus or meditation solely on the harmful and traumatic effects of displacement, to an emphasis on the possibilities of positive change, and the need for self-adjustment and a cautious optimism about the future" (96). Migration und das daraus folgende Leben in der Diaspora werden nicht mehr als rein zerstörerisch und katastrophal dargestellt, wie dies noch in früheren Filmen der iranischen Diaspora der Fall war ${ }^{44}$, sondern über eine Vielzahl von Stilmitteln werden hybride und im Wandel begriffene Identitäten skizziert.

Wohnungen, wie jene von Ellen, sind in Filmen nahezu immer zu finden. Jedwede Erzählung kommt, laut dem Literaturwissenschaftler Thomas Düllo, nicht umhin, ihre Figuren auch räumlich zu verorten: „Jede Geschichte, jede Figur spielt in einem konkreten, gesellschaftlich konturierten Raum, sei er noch so abstrakt reduziert oder symbolisch verschoben und versteckt“ (358). Wohnungen sind mit Figuren verbunden, die diese bewohnen, und dienen zunächst einmal, ähnlich wie Kleidung und Sprache, der Verortung von Milieu, Herkunft und/oder Schicht, womit, Thomas Düllo zufolge, ,[d]ie vordringlichste Funktion, die das Wohnen im Film übernimmt, [...] eine soziokulturelle“ (369) ist. 
Wohnungen können, so der Autor weiter, sowohl explizit wie auch implizit in Filmen auftreten (358). Ein explizites Auftreten wäre, wenn die Wohnung als narrativer Dreh- und Angelpunkt innerhalb der Diegese fungiert und zum Hauptmotiv des Filmes wird. Ein Beispiel hierfür ist die US-amerikanische Produktion The House of Sand and Fog von Vadim Perelman aus dem Jahr 2003. Der Film handelt vom Streit um ein Haus zwischen einer jungen angloamerikanischen Frau und einer iranischen Familie. Das Haus tritt in diesem Fall - bereits durch den Titel, aber vor allem durch den Konflikt, den es auslöst - innerhalb der Diegese explizit als eigenständiger Akteur auf. Der Film lenkt, laut Christopher Gow, die Aufmerksamkeit auf die Lebenssituation iranischer Émigrés in den Vereinigten Staaten: „The importance of House of Sand and Fog undoubtedly lies in the way it brought its version of the Iranian émigré experience to mainstream audiences, its story being one that is frequently overlooked and marginalized by the mass media“ (121) und weist damit eine „pan-diasporic sensibility" (122) auf.

Die Wohnung als kosmopolitischen Raum zu bestimmen, mag zunächst in Anbetracht der ihr klassisch zugetragenen Funktion - „Dem Bleiben und Innen haftet der Verdacht des Konservativ-Restaurativen, des Privaten und Familiären an, dem Aufbruch und Außen dagegen ein Innovationsversprechen“ (Düllo 356) - paradox erscheinen. Ich möchte jedoch anhand der Filmanalyse zeigen, dass gerade der Wohnung durch den Zusammenhang zwischen Privatheit und Freiheit in Walls of Sand jener „everyday cosmopolitanism“ anhaftet, den Asef Bayat beschrieben hat. Dies möchte ich anhand von drei Sequenzen erläutern: Die erste zeigt Ellen alleine im Badezimmer und stellt die Wohnung als Raum des autonomen Selbst aus. Die zweite zeigt die Annäherung von Ellen und Soraya, die über alltägliche Haushaltsarbeiten einen kosmofeministischen Raum kreieren. 
Die dritte zeigt Sorayas Imagination ihres verstorbenen Onkels und den daraus entstehenden filmisch-verlebendigten Raum.

\section{Wohnung als Raum des autonomen Selbst}

Der Film beginnt mit einem Voice-Over Sorayas, in dem sie ihre Vorgeschichte skizziert: Sie kam als Jugendliche in die Vereinigten Staaten und wohnte zunächst bei ihrem Onkel (Ulysses) und dessen Familie. Sie machte ihren Schulabschluss, fing mit dem College an und lernte dort ihren Freund Chat (John Cragen) kennen. Ihre Familie war von einer Liaison mit einem Amerikaner wenig begeistert und verwehrte ihr fortan jegliche finanzielle Unterstützung. Soraya hoffte auf eine Heirat mit Chat, welche ihr auch die Greencard gesichert hätte. Doch dies geschieht nicht und so setzt der Film ein, als Soraya Chat verlässt. Nun, ohne familiäre Unterstützung, ohne Geld und mit der Bedrohung, ausgewiesen zu werden, nimmt sie ein Angebot als Au-pair-Mädchen an. Der Geschäftsmann Ted Follette (John Evans) kämpft mit seiner Exfrau Ellen Follette um das Sorgerecht für den gemeinsamen Sohn Alex (Benjamin Marsh). Soraya soll ihm in ihrer Tätigkeit als Au-pair-Mädchen Auffälligkeiten berichten, die er vor Gericht möglicherweise gegen seine Frau verwenden kann. Im Gegenzug verspricht er ihr eine Aufenthalts- und Arbeitsgenehmigung. Soraya zieht in die bürgerliche Wohnung von Ellen ein. Es ist eine Doppelhaushälfte der amerikanischen Mittelschicht, welche durch einen Kamin, Kerzen, Pflanzen, Kissen, Decken und Vorhänge mit Mustern und Ähnlichem eine wohnliche und heimelige Atmosphäre ausstrahlt. Innerhalb des Hauses übersetzen wiederum verschiedene ineinander verschachtelte Räume die verschiedenen Abstufungen des Privaten: Es gibt Gemeinschaftsräume wie die Küche und das Wohnzimmer, denen Ellen zunächst fernbleibt, in denen sie sich jedoch mit Fortschreiten des Filmes und durch die wachsende Nähe zwischen den beiden Frauen immer mehr einfindet, 
und Individualräume, also Alex', Sorayas und Ellens Zimmer, welches als einziges ein eigenes Bad hat.

Soraya bezieht ihr Zimmer in Ellens Wohnung und hängt dabei ein Filmplakat von William Wylers Wuthering Heights (USA 1939) über ihrem Bett auf. Als Alex ihr Zimmer betritt, rezitiert Soraya in dramatischer Geste längere Passagen aus dem Film ${ }^{45}$. Die Romanvorlage von Emily Brontë ist ein Beispiel für „unzuverlässiges Erzählen“, ein Klassiker des englischsprachigen Literaturkanons, gelesen in Schulen und Universitäten, und auch der Film, mit Laurence Olivier und Merle Oberon in den Hauptrollen, gehört zum kulturellen Erbe des angelsächsischen Raumes. Soraya kann dieses kulturelle Erbe problemlos teilen und wiedergeben. Die Szene macht damit deutlich, dass Sorayas Dilemma, im Gegensatz zu iranischen Migrant_innen erster Generation und deren Darstellung in früheren Filmen, nicht das Zurechtfinden in einer fremden Ankunftsgesellschaft, in diesem Fall den Vereinigten Staaten, ist. Sie spricht neben Farsi perfektes Englisch, trägt Jeans und Pullover und verfügt darüber hinaus, womöglich aus Schul- und Collegezeit, über Kenntnisse der englischsprachigen Literatur und des Filmes. Gleichzeitig weist der Topos der an den Konventionen einer Gesellschaft scheiternden Frauenfigur Emily Brontës mit der daran geknüpften Suche nach ,a room of one's own“ auf Sorayas eigene Lebenssituation hin.

Ellen hingegen verlässt das Haus nie, redet wenig und kapselt sich tagtäglich mit einer Packung Pralinen in ihrem Zimmer vor ihrer Schreibmaschine ab. Es findet keinerlei Interaktion mit dem Außen statt. Auch die Vorhänge im Wohnzimmer müssen immer geschlossen bleiben, und sogar als Soraya mit Alex auf dem hauseigenen Balkon tanzt, schaut Ellen aus dem Inneren des Hauses nur angsterfüllt durch das Wohnzimmerfenster zu. Soraya übernimmt alle Aufgaben des Haushaltes - vor allem jene wie Einkaufen, die draußen zu erledigen sind, und kümmert sich um Alex. Im Zuge des Filmes nähern sich die beiden Frauen 
an, Ellen beginnt Vertrauen aufzubauen, und schafft es am Ende des Filmes mithilfe von Soraya sogar, das Haus (kurz) zu verlassen.

Walls of Sand ist in Schwarz-Weiß gedreht und beinhaltet neben der Haupthandlung eine Metaebene: Die Haupthandlung wird immer wieder durch Bilder von verschleierten Frauen in der Wüste unterbrochen. Der Raum der Wüste rekurriert auf stereotypisierte orientalistische Zuschreibungen, die parallel verlaufende Traumlandschaft bildet so einen allegorischen Raum der Imagination und Erinnerung. Diese filmischen Räume bestechen durch ihre Widersprüchlichkeit (Innen/Außen, Westen/Iran) und Wechselwirkung (Situation der Frauen in beiden Fällen). Diese beiden kontrapunktischen Räume widersprechen und bedingen sich und tragen so wechselseitig zum Spannungsfeld bei, in welchem die beiden Frauenfiguren zwischen inneren und äußeren Räumen, Wohnung und Außenwelt, Diaspora und (imaginiertem) Herkunftsland oszillieren. Die Haupthandlung spielt bis auf wenige Ausnahmen komplett in Innenräumen.

Besonders eindrücklich ist dabei jene Szene, in der Ellen allein im Badezimmer steht und langsam ihr Haar löst, ihr Blick ist dabei fest auf das eigene Antlitz gerichtet. Die Kamera fängt eine Großaufnahme ihres Gesichtes im Spiegel ein und thematisiert damit das prekäre Verhältnis von Selbst und Anderem. Dem Spiegel kommt laut Thomas Elsaesser und Malte Hagener in ihrer Filmtheorie folgende Funktion zu: „Der Blick in den Spiegel konfrontiert einerseits mit dem Selbst, also dem eigenen Gesicht als Ausdruck der Innerlichkeit, andererseits ist dieser Blick ein Blick von außen, kehrt somit zum Selbst zurück als Blick des Anderen“ (76). Das Motiv des Spiegels dient in dieser Szene klar der Subjektwahrnehmung und -artikulation. Abgesehen von den Räumen, in denen das Vorkommen von Spiegeln erwartet wird, wie im Bade- oder Schlafzimmer, befinden sich in Ellens Wohnung auch ein Spiegel über der Spüle in der Küche und einer im Wohnzimmer über dem Sofa zwischen zwei großen Fenstern. In 
dem Moment, in dem Ellen ihre Augen schließt und sich vom Spiegel abwendet, nimmt auch die Kamera nicht mehr ihr Spiegelbild, sondern ihr Gesicht auf (Abb. 3.1). Teilten die Zusehenden die visuelle Perspektive mit der Figur bis dahin noch durch den Blick in den Spiegel, schließt diese sich nunmehr vollends in sich ein. Nachdem Ellen auch ihre Kleidung abgestreift und in die Badewanne gestiegen ist, nimmt die Kamera sie abermals in einer Großaufnahme mit geschlossenen Augen, diesmal, gleichsam einer optisch umgedrehten Spiegelung, unter Wasser auf (Abb. 3.2). Das Badezimmer als Raum des autonomen Selbst lässt sich, laut Thomas Düllo, ,ganz grundsätzlich [...] als derjenige Raumbereich bezeichnen, der im Film eine Grenze setzt zwischen Innen und Außen [...]. Wie im Leben ist der Wohninnenraum Refugium, Privatsphäre und Bereich der Abschottung“ (367).
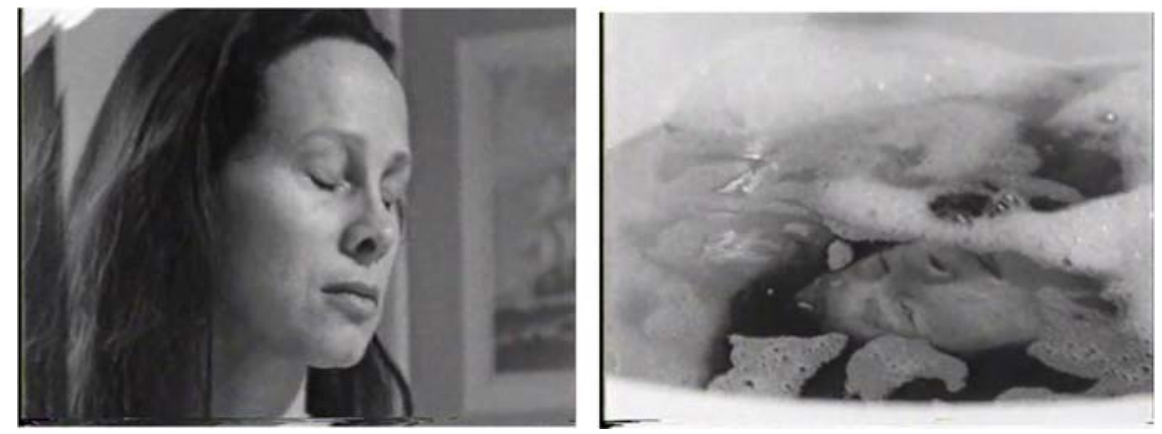

Abb. 3.1 und 3.2 Walls of Sand, „Ellen im Bad“, USA 2001

In dieser sowohl narrativ als auch zeitlich im Film zentralen Szene zieht Ellen sich auf mehreren Ebenen zurück: in die Wohnung, die sie ohnedies nie verlässt, in ihr Zimmer und weiter in das dadurch begehbare Badezimmer, in dessen Badewanne und durch die geschlossenen Augen schließlich in sich selber. Dem Badezimmer kommt hierbei eine besondere Funktion innerhalb der Wohnung zu. 
Um es mit den Worten von Thomas Düllo zu sagen: „Die Kontemplativität und Verletzlichkeit des Privaten lässt sich allein daran festmachen, wie häufig sich in Filmen die Figuren in die Badewanne zurückziehen und dabei - oft nur vorübergehend - zu sich finden oder aber dabei gestört werden“ (372). Dieser Rückzug bedeutet, so bekräftigt auch die Philosophin Beate Rössler in ihrer Monographie Der Wert des Privaten, nicht Scheitern, sondern Chance:

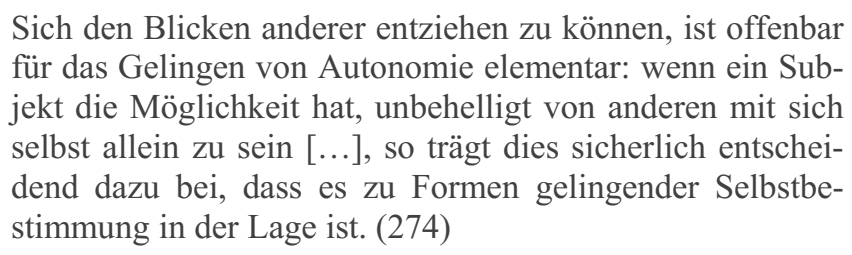

Im Gegensatz zu Hotels mit ihren Lobbys und Zimmern sind Wohnungen per se weitaus persönlicher und privater. Der Begriff „privat“ fungiert hierbei nicht nur als Gegensatz zu „öffentlich“, sondern kann auch in sozialwissenschaftlichen, juristischen und philosophischen Diskursen verortet werden: „,Privat' nennen wir einerseits Handlungs- und Verhaltensweisen, zum Zweiten ein bestimmtes Wissen und drittens Räume“ (19). Beate Rössler stellt fest, dass mit jedem individuellen Leben auch eine private Geschichte des Wohnens verknüpft ist. In der Wohnung konfigurieren die Bewohner_innen „mit der Inszenierung des Raums und der Art der Gegenstände in ihm zugleich ihre je individuelle Geschichte und [bringen] damit je ihre eigene Identität zum Ausdruck“ (260). Die Bestimmung des Wohnens führt also ins Zentrum der Frage nach der eigenen Identität. Das „Sich-einrichten-Können“ (261) ermöglicht „Weisen des Sichzu-sich-Verhaltens auszuprobieren, die verstanden werden können als Versuche der Selbst-Definition“ (261). Daraus ergibt sich eine Definition des Begriffes wie folgt: „In liberalen Gesellschaften hat das Private die Funktion, ein autonomes Leben zu ermöglichen und zu schützen“ (Rössler 10). Ellens Wohnung kommt 
daher meines Erachtens nicht nur die Funktion als „Spiegel der mentalen Situation de[r] Protagonisten“ (Düllo 362), sondern vielmehr der Inbegriff kultureller Autonomie und Ermächtigung zu. Das Baden, eine Alltagspraxis, wird für Ellen zu einem Moment größtmöglicher Aushandlung mit sich und der Welt: ein Mitsich-Sein, ein Rückzug, und eine der Kontemplation, der Erfüllung. Die Wohnung wird dadurch zum filmischen Raum des autonomen Selbst, das, wie Beate Rössler betont, „die Zuflucht des Privaten [...] um dieser Konfrontation mit sich selbst willen“ (Rössler 278) sucht. Die zunächst gegenüber Kosmopolitismus antonym anmutende Wohnung erlebt in diesem Zusammenhang einen erweiterten Bedeutungshorizont: Das autonome Selbst ist gleichermaßen bei sich und in der Welt. Diese Dialektik von Konflikt und Koexistenz weist den filmischen Raum als einen der kosmopolitischen Alltagspraxis aus.

\section{Wohnung als kosmofeministischer Raum}

Die Groß- und Nahaufnahmen in dieser Szene von Walls of Sand, wie auch im gesamten Film, verbildlichen Ellens Agoraphobie, jedoch nicht als Krankheit, sondern als selbstgewählten Rückzug des Protestes. Dieser Protest richtet sich gegen soziale Zwänge von Familie und Staat, in denen sich beide Frauen auf verschiedenen Ebenen befinden: Ellen in ihrer Rolle als Mutter, der sie droht, durch ihre Agoraphobie nach der Scheidung nicht gerecht werden zu können, und Soraya in ihrem Kampf um einen legalen Aufenthalt in den Vereinigten Staaten und eine Versöhnung mit ihrer iranischen Familie. Beide wehren sich in dem ihnen eigenen Handlungsradius gegen die ihnen auferlegten Erwartungen und Enttäuschungen und suchen Auswege. Ellens Wohnung wird hierbei im Laufe des Filmes immer mehr zum gemeinsamen Raum der Aushandlung ihrer Positionen als Frauen in der Welt sowie ihrer Ängste und Strategien, damit umzugehen. 
Verdeutlicht wird dies in einer Sequenz, die, nachdem Ellen und Soraya in der Wohnung aktiv gemeinsam jede Ecke aufgeräumt und geputzt haben, mit dem Bild der sich erschöpft im Gemeinschaftsraum des Wohnzimmers ausruhenden Frauen einsetzt. Es ist das erste Mal, dass sich beide gleichzeitig im Wohnzimmer aufhalten. Ellen liegt ausgestreckt auf dem Sofa, den Kopf in den Nacken gelegt. Soraya hat die Beine auf einem Sessel gegenüber hochgelagert. $\mathrm{Zu}$ sehen ist sie jedoch nur über die Projektion im Spiegel, die dem Raum dadurch Tiefe verleiht und die beiden Frauen in einer Doppelung, die zunächst nicht erkennen lässt, wer oder was nun das Gespiegelte ist, zeigt. Die vertikalen Streifen des Sofas korrespondieren mit den horizontalen Streifen des Sessels, die leichte Aufsicht etabliert eine Achse, die dabei nicht nur die Parallelität der Möbelstücke und Körperhaltungen der beiden Frauen verdeutlicht, sondern dadurch einen gemeinsamen Raum zwischen ihnen herstellt (Abb. 3.3). Dem Spiegel kommt in dieser Szene nicht die Funktion als Darstellung des Unbewussten, wie noch in der Badezimmer-Szene zu, sondern als Wiedergabe des Anderen, als reflexive Verdoppelung und somit der Frau als raumgreifendes Element.

Durch die verschiedenen Variationen weiblicher Aushandlung in den darauffolgenden Szenen wird dadurch der gemeinsame Raum als kosmofeministischer Raum verbildlicht. Unter dem Adjektiv „kosmofeministisch“ verstehe ich hierbei in einer Kopplung der Wortteile „cosmos“ (Welt) und „feministisch“ (die Rechte von Frauen betreffend) einen Raum der Selbstbestimmung der Frauen in der Welt. Dies ist eng an das von Nina Glick Schiller, Tsypylma Darieva und Sandra Gruner-Domic entworfene Konzept der „cosmopolitan sociability“ geknüpft: „We define cosmopolitan sociability as consisting of forms of competence and communication skills that are based on the human capacity to create social relations of inclusiveness and openness to the world“ (402; Hervorhebung im Orginal). 
Aufgelöst wird die Szene durch den hungrigen Alex, der nach dem Abendessen fragt, jedoch den Raum der beiden nicht betritt. Die nächste Szene zeigt Soraya, Alex und Ellen in einer halbnahen Einstellung zum ersten Mal gemeinsam am Esstisch sitzen und dabei chinesisches Fastfood-Essen teilen: das Bild der klassischen Kernfamilie beim Abendessen (Abb. 3.4). Dieses wird jedoch durch die Tatsache, dass es sich um zwei Frauen, die weder verwandt noch richtig befreundet sind, sondern in einem Arbeitsverhältnis stehen, gebrochen und unterwandert.

Nach der Szene des Abendessens sitzen Ellen und Soraya wieder wie zuvor im Wohnzimmer auf jeweils dem Sofa und dem Sessel. Die folgenden Einstellungen verdeutlichen eine umgekehrte Kameraposition, also nicht von Ellen auf die im Spiegel zu sehende Soraya, sondern von Soraya auf Ellen. Das Oszillieren zwischen der Scharfstellung von Sorayas Gesicht im Vordergrund und Ellens Oberkörper im Mittelgrund etabliert erneut den geteilten Raum der beiden Frauen und führt den kosmofeministischen Raum fort (Abb. 3.5). Soraya gesteht Ellen in dieser Szene, dass sie nicht - wie ursprünglich erzählt - griechischer, sondern iranischer Herkunft ist. Ellen erwidert nur, dass sie vor der islamischen Revolution Ehemann Ted auf einer Geschäftsreise nach Iran begleitet habe und das Land als sehr schön erlebt hätte, möchte aber wissen, warum Soraya gelogen hat. Diese erwidert, sie hätte es aus Angst getan. In diesem Dialog nähern sich die beiden Frauen der jeweils anderen Lebensrealität an: Soraya, indem sie über ihre eigene Angst redend Ellens Agoraphobie anerkennt, und Ellen, indem sie durch das Wissen um Sorayas Herkunftsland ihre kulturelle und diasporische Identität anerkennt. „Cosmopolitan sociability“ meint „,an ability to find aspects of the shared human experience [...]. They do not exist in the abstract but are enacted and embedded within social relations and practice-based identities“ (403). Im Gegensatz zur Szene mit dem Spiegel im Wohnzimmer, in der der 
Raum und die Distanz unterstrichen wurden, hebt die Mise en Scène hier die Enge und Nähe der beiden Frauen hervor. Beide füllen je eine Hälfte des Bildes aus: Soraya in einer Naheinstellung im Profil, Ellen in einer halbnahen Einstellung ebenfalls von der Seite. Der Wechsel der Vordergrund-HintergrundRelation schafft entgegen der Standardvariante des Schuss-GegenschussVerfahrens bei derartigen Raumverhältnissen einen filmischen Raum nicht des Nebeneinanders, sondern der Tiefe und des Miteinanders, womit der kosmofeministische Raum einmal mehr filmisch etabliert wird.

Nebeneinander zu sehen sind Ellen und Soraya hingegen in der darauffolgenden letzten Einstellung der Sequenz, in der Ellen Soraya Bilder von ihrer Iran-Reise zeigt. Frontal, in einer halbnahen Einstellung, betrachten sie die Fotos, die den Zusehenden jedoch verborgen bleiben (Abb. 3.6). Die Bildgestaltung evoziert so die endgültige Verbundenheit beider Frauen, auch gegenüber den Zusehenden, die in diesem Fall nicht Teil des kosmofeministischen Raumes sind. 

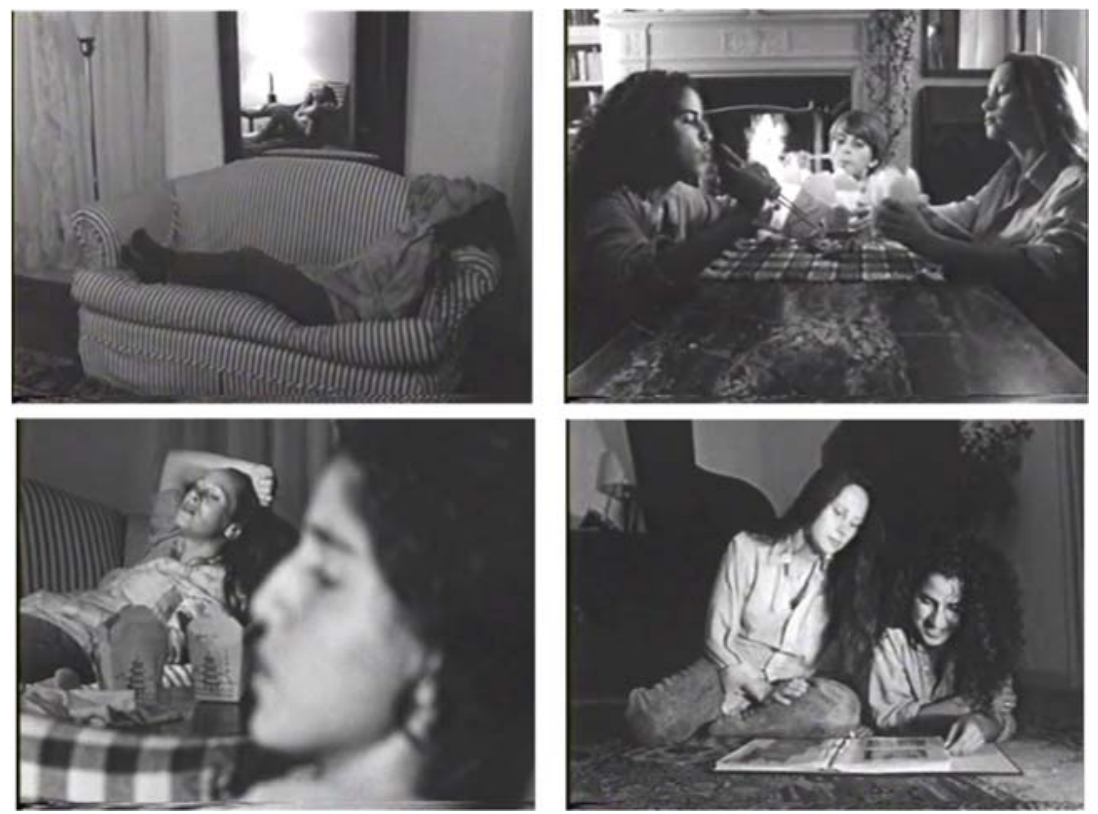

Abb. 3.3, 3.4, 3.5 und 3.6 Walls of Sand, „Ellen und Soraya im Wohnzimmer“, USA 2001

Der kosmopolitische Raum ist damit ein Raum der Frauen; zum einen, da sich in der Wohnung keine Außenstehenden einfinden - sogar Ex-Mann Ted bleibt beim Zurückbringen von Alex an der Türschwelle stehen. Zum anderen, und dies scheint gewichtiger, da weibliche diasporische Identitätsverhandlung und Subjektartikulation sich in dieser Abfolge von Szenen aus dem Privaten, der Autonomie, herausschält und so einen kosmofeministischen Raum kreiert, der wiederum in andere Räume zurückwirkt, denn kosmofeministisch ist, laut der Kulturwissenschaftlerin Susan Stanford Friedman, „, not based in a call for global sisterhood but rather situated in a feminist critique of the nation-state" (24).

Die Kritik am Nationalstaat ist im Diasporafilm kein überraschender Befund, markiert aber in Walls of Sand einmal mehr den dynamischen und prozesshaften Charakter von sowohl elitärer als auch subalterner Identität. Soraya 
steht im doppelten Konflikt, da sowohl Iran - in Form ihrer Familie, die sie, ob ihrer selbstbestimmten Haltung, verschmäht - als auch die Vereinigten Staaten aufgrund ihrer Herkunft aus Iran ist ihr Aufenthaltsstatus prekär - das Leben sowohl emotional als auch juristisch erschweren. In diesem Sinne verhandelt die Sequenz jene mäandernde Suchbewegung, die hier in Form eines kosmofeministischen Raumes in Erscheinung tritt, nicht durch eine Auslöschung des Nationalstaates und seiner physischen wie juristischen Grenzen, wie es der Philosoph Immanuel Kant in seinem Konzept des Kosmopolitismus vorschlägt, sondern durch eine ständige kulturelle Ver(un)ortung. Der Film adressiert diese Kritik laut Hamid Naficy nicht nur gegen Iran, sondern ebenso gegen die Vereinigten Staaten: „In its inscription of closed spaces, the film offers a feminist critique not only of women's confinement in Islamic societies but also of the freedom that American society promises but often fails to deliver to women" (An Accented Cinema 210). In diesem Sinne verstehe ich den kosmofeministischen Raum, als diaspora space im Sinne Avtar Brahs, nicht nur als einen, der in der iranischen Diaspora lebende Menschen iranischen Ursprunges, sondern alle marginalisierten sozialen Gruppen einschließt. Wohnen wird hierbei als existenzieller Teil der Lebensrealität begriffen und stellt demnach die Frage nach den Artikulationsmodi individueller wie kollektiver Identitätsmuster. Der diasporafilmische Raum ist damit nicht nur einer der iranischen Diaspora, sondern ein breiterer, über ethnische Zuschreibungen hinausgehender Raum.

\section{Wohnung als filmisch-verlebendigter Raum}

Sorayas individuelle Artikulation ihrer diasporischen Identität wird in jener Sequenz sehr deutlich, in der sie ihren verstorbenen Onkel im Spiegel imaginiert: Als sie an ihrem ersten Arbeitstag in Ellens Wohnung morgens in die Küche geht, um Frühstück zu machen, schaut sie sich in der noch unbekannten Küche 
erstmal um, wäscht sich die Hände und erblickt dann im Spiegel über der Spüle (in einer Vision) ihren vor kurzem verstorbenen Onkel (Abb. 3.7). In einer halbnahen Einstellung zeigt die Kamera Soraya und ihren Onkel umrahmt vom Spiegel. Er steht hinter ihr, isst ein Cookie und schaut sie ruhig an, während sie sich mit vor Schreck geweiteten Augen umdreht. Dadurch löst auch die Kamera sich vom Spiegel, der Blick ihres Onkels nun nicht mehr an sie, sondern die Zusehenden gerichtet (Abb. 3.8).
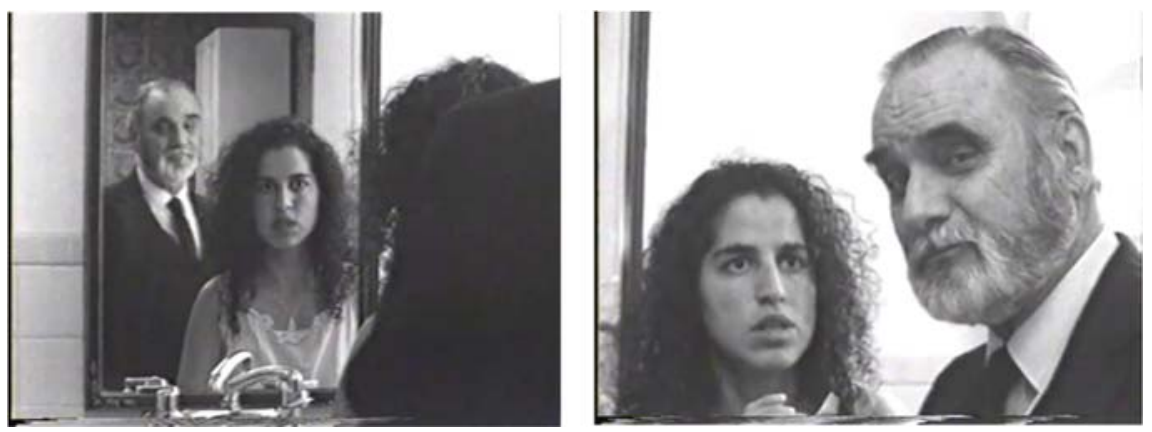

Abb. 3.7 und 3.8 Walls of Sand, „Verstorbener Onkel im Spiegel“, USA 2001

Die amerikanische Süßspeise, der Cookie, bekommt sein Pendant in der darauffolgenden Szene, als Soraya mit Alex im Supermarkt die iranische Süßigkeit „Gaz“ entdeckt und kauft ${ }^{46}$. Das amerikanische Cookie und das iranische Gaz existieren für Soraya widerspruchslos nebeneinander. Soraya kann zwischen den verschiedenen kulturellen Codes hin und her wechseln, ihre diasporische Identität ist, ganz im Sinne Stuart Halls, stärker von Hybridität als von Binarität geprägt:

Diaspora does not refer us to those scattered tribes whose identity can only be secured in relation to some sacred homeland to which they must at all costs return [...]. The diaspora experience as I intend it here is defined, not by es- 
sence or purity, but by the recognition of a necessary heterogeneity and diversity; by a conception of ,identity" which lives with and through, not despite, difference; by hybridity. Diaspora identities are those which are constantly producing and reproducing themselves anew, through transformation and difference. („Cultural Identity“ 120; Hervorhebung im Original)

Ermöglicht wird diese gelebte kosmopolitische Haltung in dieser Szene, exemplarisch für den gesamten Film, durch Sorayas verstorbenen Onkel im Spiegel. Soraya erinnert und imaginiert ihn immer wieder, beim Abwaschen im Spiegel über der Spüle oder auf der Straße vor dem Supermarkt. Sorayas Identität mäandert zwischen den Polen dieser Imagination und ihrem Alltag in den Vereinigten Staaten. Die Erscheinung des Onkels fungiert dabei als Schwellenfigur und eint die scheinbar gegensätzlichen Pole. Erinnerung tritt hier nicht in Form von Rückblenden oder Geschichten aus der Vergangenheit auf, sondern manifestiert sich in Sorayas Alltag und Gegenwart in Form einer Imagination, die ihr in der Küche bei der Hausarbeit oder auf der Straße beim Einkaufen begegnet. Über die Figur des Onkels wird ein kosmopolitischer Raum der Alltagspraxis eröffnet, in dem eine positive Wendung für die Figur möglich wird, welche durch ihre Mehrsprachigkeit, ihren Kleidungsstil, ihren sozialen Umgang mit Amerikaner_innen und ihre Affinität sowohl für iranische Traditionen (persisches Neujahrsfest) und Nahrungsmittel sowie für angelsächsische Literatur und Film jene „cosmopolitan attitude“ (Mau, Mewes und Zimmermann 5) beziehungsweise „cosmopolitian sociability“ (Darieva, Glick Schiller und GrunerDomic) an den Tag legt, die im Zusammenhang mit Kosmopolitismus oft beschworen wird.

Ausgangspunkt für Erinnerung ist dabei, mit dem Geschichtswissenschaftler Johannes Fried erklärt, die aktive Teilnahme an einem Geschehen. In seinem Sammelbandbeitrag „Geschichte und Gehirn: Irritationen der Geschichtswissen- 
schaft durch Gedächtniskritik“" weist er darauf hin, dass bereits vorgegebene Darstellungsmuster beeinflussen, woran sich erinnert wird, ebenso wie Wissensvorgaben, die die Erinnerung unbewusst konditionieren. Faktoren wie Wiederholungen oder die Anzahl und Dichte der zu verarbeitenden Geschehnisse führen zu einem Informationsbündel, aus welchem sich eine geschlossene Geschichte konstruiert. Diese entsteht durch verschiedene Prozesse, wie etwa die Kanonisierung wesentlicher Elemente, Kontaminationseffekte, Teleskopien und Überschreibungen, gleichartige Erlebnisse werden zu einem: Zeitlich Fernes wird durch zeitlich Nahes überformt und frühere Geschehnisse durch spätere verdrängt. Die eingehenden Signale sind mehrdeutig interpretierbar, wodurch auch Inversionen entstehen können. Der Akt der Wahrnehmung ist ein situativ bedingter Enkodierungsprozess, in den auch Emotionen hineinspielen. Die Wiedergabe all jener Eindrücke ist vom Moment des Abrufes abhängig und dadurch ebenfalls subjektiv. Deshalb heißt es: „Keine zwei Beteiligten desselben Geschehens erinnern sich an identische Wahrnehmungen“ (113). Im technischen Werkzeug der Kamera sieht die Filmwissenschaftlerin Getrud Koch in ihrem Sammelbandbeitrag „Nachstellungen - Film und historischer Moment“ ihrerseits die Möglichkeit eines „Aufzeichnungsinstruments“ (216), welches die Gegebenheiten der äußeren Welt zur Wiedergabe aufnimmt. Infolgedessen wird der Kamera „nicht nur die Rolle des ,neutralen“ Beobachters, [...], sondern auch die eines externen Gedächtnisses“ (217) zugeschrieben. Gertrud Koch weiter:

Es ist also nicht ganz von der Hand zu weisen, daß Film und die soziale Institution des Kinos erfolgreich immer wieder die Behauptung antreten konnten, unter der Metapher des ,Gedächtnisses ' des fotographischen Bildes und der ,Veranschaulichung' historischer Zeiten und Konstellationen durch Nachstellung in fiktionalen, aber wirkungsmächtigen Imagines auf zentrale Weise sich an dem zu be- 
teiligen, was man affirmativ die ,Verlebendigung' von Vergangenheit nennt. (217)

„Verlebendigung“, im Sinne von Erinnerung und Imagination, so mein Argument hier, ist eine dynamische Fähigkeit, welche nicht in den Untiefen des Gehirnes vergraben ist, kein fixes Objekt, sondern eine performativ-dynamische Kraft, welche jedes Mal aufs Neue konstruiert, kreiert und schafft.

Die etymologische Ableitung der Begriffe Erinnerung und Imagination verweisen auf diese performativ-dynamische Kraft. Erinnerung kommt vom lateinischen Wort aperīre und bedeutet „öffnen“ („Erinnerung“). Imagination wiederum kommt vom lateinischen Wort imāgo „Bild, Abbild, Vorstellung“ („Imagination“). Über die Fähigkeit des Gehirnes, sich zu öffnen, also zu erinnern, um Bilder, Abbilder oder Vorstellungen zu imaginieren, hinausgehend, schlägt Hamid Naficy vor, Imagination als soziale Praxis zu begreifen: „In such a mediated world, imagination itself must be regarded as a social practice“ ( $A n$ Accented Cinema). Er bezieht sich dabei auf Arjun Appadurai und sein Modell der global scapes, welches die immer dichter vernetzte, ineinandergreifende und verbundene Welt über den Begriff der Imagination zu fassen versucht: „The imagination is now central to all forms of agency, is itself a social fact, and is the key component of the new global order“ (Appadurai, Modernity at Large 31). Asef Bayat bekräftigt seinerseits:

Cosmopolitanism refers to both a social condition and an ethical project. In the first place, it signifies certain objective processes, such as globalization, migration, and traveling that compel people of diverse communal, national, or racial affiliations to associate, work, and live together. These processes lead to diminishing cultural homogeneity in favor of diversity, variety, and plurality of cultures, religions, and lifestyles. (186; Hervorhebung im Original) 
Als individuelle wie auch kollektive kosmopolitische Praxis gedacht, mit dem Vermögen, Öffnung gegenüber und Engagement mit der Welt, dem Kosmos, zu evozieren, verstehe ich Erinnerung und Imagination als dynamische und produktive Motoren von Kosmopolitismus. Als solche sind sie Schlüsselelemente für den filmisch-verlebendigten Raum.

Walls of Sand lässt sich meines Erachtens sowohl in Kosmopolitismus als soziale, ethische Haltung als auch in Kosmopolitismus als analytische Kategorie der Filmwissenschaft einbetten (Christen und Rothemund 98-99). Imagination und Erinnerung kommen dabei als gelebte Erfahrung der iranischen Diaspora besondere Aufmerksamkeit zu. Die „cosmopolitan coexistence“ (Bayat 186) zwischen Sich-vor-der-Welt-Verstecken und In-der-Welt-Sein drückt sich letztlich durch die Wohnung als jenen filmischen Raum der „Verlebendigung“ aus, der, wie auch Christopher Gow bekräftigt, deutlich zu einer Abkehr ethnozentristischer und kulturessentialistischer Positionen führt: „[The film] clearly acknowledge $[\mathrm{s}]$ the impossibility and undesirability of a utopian return to some original state of cultural stability or purity and point[s] toward the need for a malleable, open-ended concept of individual identity“ (106). Wohnungen können also sehr gut als Gegenwelten, Spiegelungen und Kommentare fungieren, die damit zwangsläufig kulturellen, politischen und/oder gesellschaftlichen, aber auch filmischen Transformationen unterworfen sind. Einen weiteren kosmopolitischen Raum bildet ein Film, der in der Filmlandschaft der iranischen Diaspora ein Novum darstellte, da er der erste - und bis auf den jüngst erschienenen Film Teheran Tabu von Ali Soozandeh (Deutschland, 2017) - auch einzige Animationsfilm in Spielfilmlänge war. 


\subsubsection{Persepolis}

Als zweites Beispiel für Kosmopolitismus als alltägliche kulturelle Praxis der iranischen Diaspora möchte ich im Folgenden auf Marjane Satrapis und Vincent Perronauds 2007 in Frankreich produzierten und auf der gleichnamigen Graphic Novel der Regisseurin basierenden Film Persepolis eingehen, der 2007 den Jury-Preis bei den Internationalen Filmfestspielen von Cannes gewann.

Buchstäblich eine Kombination aus Ethnie (perse) und Raum (polis) bedeutet das Wort „Persepolis“ - im Gegensatz zu Weltlichkeit (cosmos) und Raum (polis) in „Cosmopolis“ - die Stadt der/für Perser_innen und ist ein anderer Name für die altpersische Residenzstadt Takht-i Jamshid des antiken Großreiches unter der Herrschaft der Achämeniden. Der Film spielt jedoch nicht im altpersischen Persepolis, sondern im Teheran der 1980er Jahre und Wien der 1990er Jahre. Visuelle Inspirationsquellen für Persepolis' animierte Schwarz-WeißGestaltung finden sich, neben Art Spiegelmans mit dem Pulitzer-Preis ausgezeichneter Graphic Novel Maus: A Survivor's Tale von 1986, in der Tradition der Silhouetten-Theater und des Scherenschnittes, eine im mittel- und ostasiatischen Raum traditionsreiche Kunstform, welche von Lotte Reiniger im Deutschland der 1920er Jahre zu neuem Leben erweckt wurde. Bezeichnenderweise ist ihr berühmtester Film, Abenteuer des Prinzen Achmed (Deutschland, 1926), ein Märchen über einen orientalischen Prinzen mit verschiedenen Elementen aus Tausendundeiner Nacht. Marjane Satrapi spielt auf die mythischen Ursprünge und orientalistischen Faszinationen der Schattenspiele in den 1920er Jahren an, kehrt diese jedoch um, indem das Wien der 1990er Jahre zum Ort für „das Andere“ wird (Strohmaier, „Irangeles: Migration“).

Für die Analyse des kosmopolitischen Raumes Persepolis, der ähnlich wie die Wohnung in Walls of Sand zunächst voller Widersprüche erscheint, dienen 
mir die Anfangssequenz und die Gespräche der kleinen Marji mit Gott, um den kindlich-jugendlichen Raum zu beschreiben. Vier weitere kurze Szenen, in denen Jackie Chan, Punk, Godzilla und Terminator einen Auftritt haben, helfen den pop-kosmopolitischen Raum zu fassen. Zu guter Letzt möchte ich auf Persepolis als filmisch-animierten Raum eingehen.

\section{Persepolis als Raum des kindlich-jugendlichen Selbst}

Die Szenen zu Beginn und am Ende des Filmes, die Marjane am Pariser Flughafen Orly zeigen, sind als einzige in blassen Farbtönen gehalten. Diese bilden die Rahmenhandlung und die Gegenwart (im Jahr 2007), im Gegensatz zu den Schwarz-Weiß-Bildern, welche Rückblenden und Erinnerungen aus Marjanes Kindheit in Teheran und Jugend in Wien darstellen. Der Film besteht aus verschiedenen aufeinandergetürmten und ineinander verschachtelten Räumen. In der Nacherzählung der Erinnerungen, die den Großteil der Handlung ausmachen, zeichnet die Regisseurin Marjane (gesprochen im französischen Original von Chiara Mastroianni; in der deutschen Fassung von Jasmin Tabatabai) als Protagonistin die historischen Ereignisse in Iran vom Beginn der islamischen Revolution 1979 bis in die frühen 1990er Jahre nach. Eingeführt werden sie durch die Figur des kindlichen Alter Egos „Marji“, die fröhlich in ein Bild hüpft, in dem ihr erwachsenes Ich - über deren Lebensumstände sonst nichts preisgegeben wird - betrübten Gesichtes am Flughafen in Paris-Orly eine Zigarette raucht (Abb. 4.1). Dies ist die einzige direkte Begegnung der beiden im gleichen Bildkader, wodurch der Film durch das Nebeneinanderstellen der verschiedenen Altersphasen der Protagonistin vom transitorischen Raum des Flughafens in den kindlichen Raum des Selbst und somit von den Farbbildern zu den SchwarzWeiß-Bildern übergeht. 


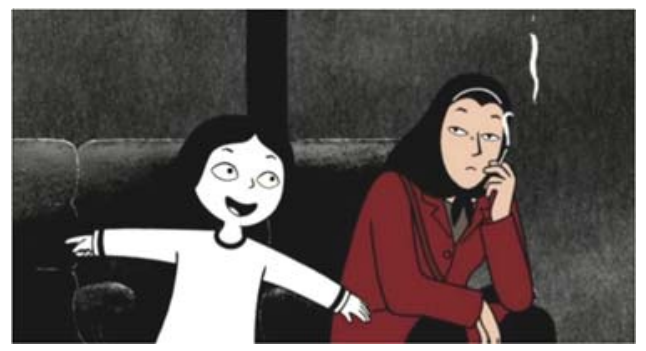

Abb. 4.1 Persepolis, „Kindliche und erwachsene Marjane“, Frankreich 2007

Die Literaturwissenschaftler_innen Nima Naghibi und Andrew O’Malley merken an, dass die Verschränkung des zweidimensionalen Animationsstiles und der kindlichen Protagonistin in einer ersten Instanz der Identifikation mit dem Anderen diene: „The ,cartooniness“ of her drawings encourages the reader to see herself in Marji, to see the self in the other, to erase all differences in a gesture of ,cultural understanding““ (228). Die Erfahrung, ein Kind zu sein, ist universell, alle Menschen waren mal eines. Mit der Betrachtung und Interpretation der historischen Ereignisse Revolution und Krieg durch die Augen eines Kindes etabliert der Film eine Perspektive, die der Erinnerung nicht nur Leichtigkeit und Humor verschafft, sondern auch Gleichheit menschlicher Emotionen und Entwicklungen in den Vordergrund stellt. Insofern hebt Persepolis das Element des Menschseins beziehungsweise des Kosmos-/In-der-Welt-Seins hervor. Erinnerung wird damit nicht nur kollektiv, sondern kosmopolitisch.

Innerhalb ihrer Kindheitserinnerungen sind Geschichten um die Machtergreifung des Schahs und die konstitutionelle Revolution 1905 sowie die dramatische Familiengeschichte ihres Onkels Anush als märchenhafte Erzählungen verschachtelt eingebaut, welche ihren Höhepunkt in Marjis Gesprächen mit Gott finden. Diese haben durchaus politischen Charakter, da sie brisante Ereignisse und Fragen in die Wattigkeit der Wolke, auf der Marjis imaginierter Gott 
schwebt (Abb. 4.2), einpacken. Diese fantastische Ebene spielt auch im Leben der jugendlichen Marji in Wien eine Rolle.

Ihre Jahre in Wien bilden den jugendlichen Raum und haben einen speziellen Stellenwert in ihren Erinnerungen. Durch die Verwendung stereotypisierter okzidentalistischer Fantasien, wie Sachertorte und lederhosentragende Jodler, stellen sie eine geschlossene Entität innerhalb ihrer Erinnerungswelt dar. Die Sequenz in Wien wird über Farbbilder der am Pariser Flughafen Orly sitzenden erwachsenen Marjane gerahmt: Vom Abschied am Teheraner Flughafen wird über die Farbbilder auf die schwarz-weiße Erinnerungswelt in Wien übergeleitet und am Ende der Sequenz aus der Erinnerungswelt wieder über die Farbbilder in die Wiedersehensfreude mit den Eltern in Teheran herausgeleitet. In Wien lebt Marjane zunächst in einem katholischen Mädchenpensionat und besucht das Lycée Français de Vienne - das französischsprachige Gymnasium in Wien. Sie lernt dort linksgesinnte Mitschüler_innen kennen, durchlebt die Pubertät, tanzt auf Punkkonzerten und lernt ihre erste große Liebe kennen. Im Mikrokosmos der Schule kann Marji jene „cosmopolitan attitude“ (Mau, Mewes und Zimmermann 5) an den Tag legen, welche bereits bei Soraya in Walls of Sand beobachtet werden konnte: Marji ist bilingual, spricht neben Farsi auch fließend Französisch und unterhält sich in einer Clique intellektueller Schüler_innen über marxistische Philosophie.

Bei einem Schulfest tauscht sich Marjane mit einem anderen Mitschüler über Bakunin und den Kapitalismus aus. Ihre intellektuelle Weltoffenheit überfordert den Jungen, und als er sie fragt, wo sie herkäme, antwortet sie, dass sie Französin sei. Diese identitäre Dissonanz überrascht bei der sonst so selbstsicheren Marjane zwar, ist jedoch in Diasporasituationen generell nicht unüblich. Der Wunsch der Zugehörigkeit wird oftmals über geänderte Staatsangehörigkeit oder Namensgebung dargestellt (Strohmaier, „Irangeles: Migration“). Auf dem 
Heimweg vom Schulfest, an der Sachertorte verkaufenden Konditorei Oberwalder mit gesenktem Kopf vorbeischlendernd, imaginiert Marjane anschließend ein Gespräch mit ihrer Großmutter (Abb. 4.3). Ihre Großmutter (im französischen Original gesprochen von Danielle Darrieux) nimmt sie auf den Arm und wundert sich, dass ihre Enkelin nun nicht mehr Iranerin, sondern Französin sei. Marjane entgegnet, dass es nicht einfach sei, in Wien Iranerin zu sein. Es sollte angenommen werden können, im internationalen Umfeld einer multikulturellen Schule wie dem Lycée Français de Vienne seien solch national-ethnische Zuschreibungen überflüssig. In dieser Szene jedoch, sowie in der ganzen Sequenz über ihre Zeit in Wien, scheint die „cultural diversity“ im Sinne einer klaren Zuschreibung und Trennung nach Nationalgrenzen und nicht Vereinbarkeit von „cultural difference“ in Marjanes Wahrnehmung im Vordergrund zu stehen. Marjanes Erinnerung an ihre Großmutter stellt über die Imagination eines Gespräches mit ihr eine Verknüpfung zu Herkunft, Familie und kultureller Identität dar. Als Kind noch Gespräche mit Gott führend, unterhält sich Marji fernab ihrer Familie in Wien nun in Gedanken mit ihrer Großmutter, die ähnlich wie Sorayas Onkel in Walls of Sand als Schwellenfigur und Bindeglied fungiert und dadurch erneut einen kindlich-jugendlichen Raum der Subjektwahrnehmung und Identitätsbildung eröffnet.

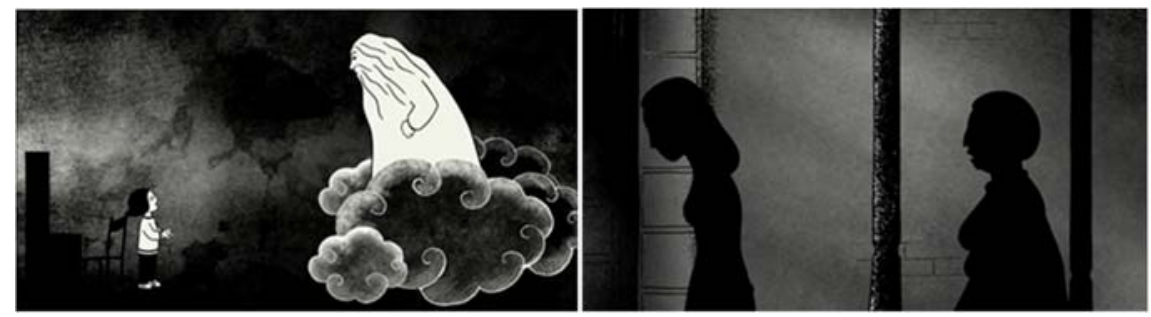

Abb. 4.2 und 4.3 Persepolis, „Marjanes imaginierte Gespräche“, Frankreich 2007 
Persepolis streicht die Bedeutung von Familie als Quelle persönlicher Stabilität heraus sowie als kosmopolitischen Raum für Versöhnung und Hoffnung, gleichzeitig aber betont er auch die Komplexität individueller Identität, welche auch in diesem Fall stärker von Hybridität als von Binarität geprägt ist. Diese Hybridität wird durch den zweidimensionalen Animationsstil in Kombination mit den kindlich-jugendlichen Alter Egos evoziert, übersteigt jedoch naive und universalistische Zuschreibungen zugunsten einer gemeinsamen (diasporischen) Erfahrung. Diese schlägt sich im kindlich-jugendlichen Raum nieder, welcher durch das Voice-Over der Regisseurin, die die Ereignisse ihrer Kindheit und Jugend immer wieder kommentiert und reflektiert, in diesem Sinne auch ein subversives Potenzial hat.

Persepolis als pop-kosmopolitischer Raum

Der Begriff der Subversion ${ }^{47}$ kann laut den Literatur- und Kulturwissenschaftler_innen Thomas Ernst, Patricia Gozalbez Cantó, Sebastian Richter, Nadja Sennewald und Julia Tieke in der Einleitung zu ihrem interdisziplinären Sammelband SUBversionen: Zum Verhältnis von Politik und Ästhetik in der Gegenwart in vier verschiedene Bedeutungsdimensionen eingeteilt werden: politischrevolutionäre Subversion, künstlerisch-avantgardistischer Begriff der Subversion, minoritärer beziehungsweise Untergrund-Begriff der Subversion und dekonstruktivistischer Begriff der Subversion (13-14). Den Subversionsbegriff aus einem popkulturell-ästhetischen Verständnis, wie ihn beispielsweise der Kulturwissenschaftler Diedrich Diederichsen 1993 in seinem Text „Subversion: Kalte Strategie und heiße Differenz" formulierte, zu denken, bedeutet im Zusammenhang mit der post-revolutionären Situation Irans, in der sich die kleine Marji wiederfindet, jene popkulturellen Elemente, die den Film durchziehen, in einer ersten Lesart als „,cultural force“ in resistance to the regime“ $\mathrm{zu}$ interpretieren, 
welche „part of Iranians' pushing back against the strict cultural confines created by the Iranian regime“ darstellen (Zeydabadi-Nejad, „Watching the Forbidden“ 100).

Dem Kind ist innerhalb der Diegese des Filmes dieser subversive Akt freilich als solcher nicht bewusst. In ihrem Kinderzimmer hängt, neben eigenen Zeichnungen, ganz selbstverständlich auch ein Plakat der Martial-ArtsFilmikone Bruce Lee, an dem die Kamera en passant vorbeischwenkt, ohne das offensichtliche Fantum der kleinen Marji bildlich in den Vordergrund zu schieben (Abb. 4.4). Die popkulturelle Referenz mit dem Schriftzug in Farsi wird als alltägliches Hintergrundphänomen ganz nebenbei vorgeführt. Dies markiert nicht nur, dass sich die Lebensrealität der kleinen Marji, abgesehen von der laufenden islamischen Revolution, von jener gleichaltriger Mittelschichtkinder rund um den Globus wenig unterscheidet, sondern spannt den Bogen zu dem, was Henry Jenkins pop cosmopolitanism nennt. Damit ist eine kulturelle Kompetenz gemeint, die ein neues Bewusstsein herbeiführt: „I will be using the term ,pop cosmopolitanism ' to refer to the ways that the transcultural flows of popular culture inspire new forms of global consciousness and cultural competency“ (156). Dieses Bewusstsein zeigt sich zu einem späteren Zeitpunkt im Film, als die junge Erwachsene Marjane im Badezimmer steht und vor dem Spiegel in Bruce-LeeManier jene Kampfgesten wieder aufgreift und nachmacht, die ihre Kindheit geprägt haben und nun zu Stärke im Umgang mit ihrer Depression verhelfen (Abb. 4.5). 


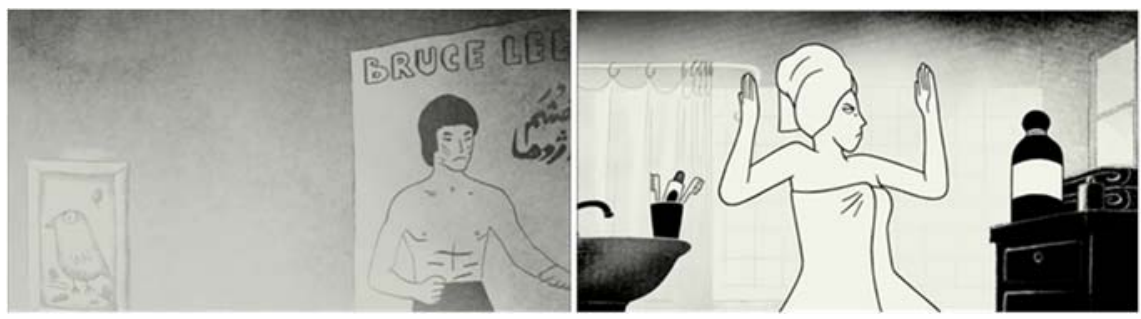

Abb. 4.4 und 4.5 Persepolis, „Bruce Lee und Marjane“, Frankreich 2007

Henry Jenkins meint ferner: „Cosmopolitans embrace cultural difference, seeking to escape the gravitational pull of their local communities in order to enter a broader sphere of cultural experience“ (155). Es ist der Zeitpunkt in ihrem Leben, als sie, zurück aus Wien, Schwierigkeiten hat, sich in Teheran wieder einzuleben. Die für Diaspora-Erfahrungen typische doppelte Entfremdung - in Wien als Iranerin und in Teheran als Zurückkehrende - kann in dem Moment überwunden werden, in dem sie sich von kulturell-ethnischen Zuschreibungen löst und sich, nach einem imaginären Gespräch mit Gott und Marx, auf ihr Selbst besinnt. Untermalt vom popkulturellen Chartbreaker „Eye of the Tiger“, dem Titelsong des Filmes Rocky, von der Band Survivor und im französischen Original interpretiert von Chiara Mastroianni, steht Marjane endlich aus dem Bett auf, duscht, schreibt sich auf der Universität ein, macht Aerobic und nimmt ihr Leben wieder in die Hand. Die Sequenz eröffnet dadurch filmisch einen popkosmopolitischen Raum der erweiterten kulturellen Erfahrung.

Im Zimmer der jugendlichen Marji muss das Bruce-Lee-Plakat dann einem Iron-Maiden-Plakat weichen. Das Debütalbum der gleichnamigen Band Iron Maiden (1980) sowie jenes der Punkrockband The Exploited (1981) - Punks Not Dead - ergattert sie auf dem Schwarzmarkt. Die von Ayatollah Khomeini proklamierte „Western cultural invasion“, die als „new weapon that worked silently, invisibly and imperceptibly“ (Naficy, The Islamicate Era 308) zu 
„moral corruption of the indigenous population“ („Islamizing Film Culture“ 32) führe, kümmern sie dabei nicht. Sie versieht ihre Jacke mit dem Spruch „Punk is not ded“" (in fehlerhaftem Englisch) und marschiert damit unbekümmert auf die Straße (Abb. 4.6). In diesem Moment wird ihre private Kleidung, nun im öffentlichen Raum sichtbar, Teil einer kulturellen Oppositionsbewegung. In der Seitenstraße mit den Kassetten- und Video-Dealern angekommen, hat Marji die große Auswahl und handelt selbstsicher die Preise herunter - sie ist offenkundig nicht zum ersten Mal da. Die informelle Distribution, wie sie auch Ramon Lobato 2012 in seiner Monographie Shadow Economies of Cinema für andere Weltregionen und Länder beschreibt, ist im Iran der 1980er Jahre eine alltägliche kosmopolitische Praxis. Zu Hause angekommen, legt Marji eine Kassette ein, nimmt ihren Tennisschläger als Gitarrenersatz und beginnt zur eigens für den Film von Olivier Bernet und Stéphane Garin komponierten Musik Master of the Monsters zu tanzen und zu headbangen (Abb. 4.7). Die Musik geht in Bilder von schießenden Kanonen und Panzern des laufenden Iran-Irak-Krieges über und stellt so die Unmittelbarkeit zweier gegensätzlicher, jedoch verbundener Lebensrealitäten dar.
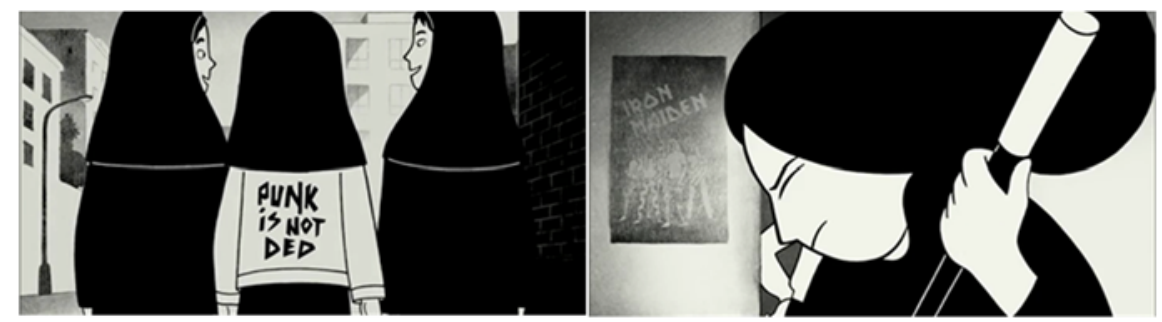

Abb. 4.6 und 4.7 Persepolis, „Musik und die jugendliche Marjane“, Frankreich 2007

Auf diese filmische Engführung greift der Film mehrmals zurück: In der Szene, in der die jugendliche Marji den feuerspeienden, destruktiven Godzilla 
im Kino sieht und tags darauf vor dem zerbombten Haus ihrer Eltern in Teheran steht (Abb. 4.8 und 4.9), sowie in jener Szene, in der Arnold Schwarzenegger in Terminator die Wut der jungen Erwachsenen auf die sie einengende Lebenswelt der repressiven Theokratie versinnbildlicht (Abb. 4.10 und 4.11) und damit popkosmopolitische Räume kreiert, die ihre eigenen Logiken, Intelligenzen und Kritiken generieren. Dadurch werden auch die Zusehenden mit der „history-as-ithappens“ (Anselmi und Wilson 257) konfrontiert und müssen sich mit dem Prozess der Geschichte (im doppelten Sinne der Narration und der Historie) durch mediale Praktiken auseinandersetzen.
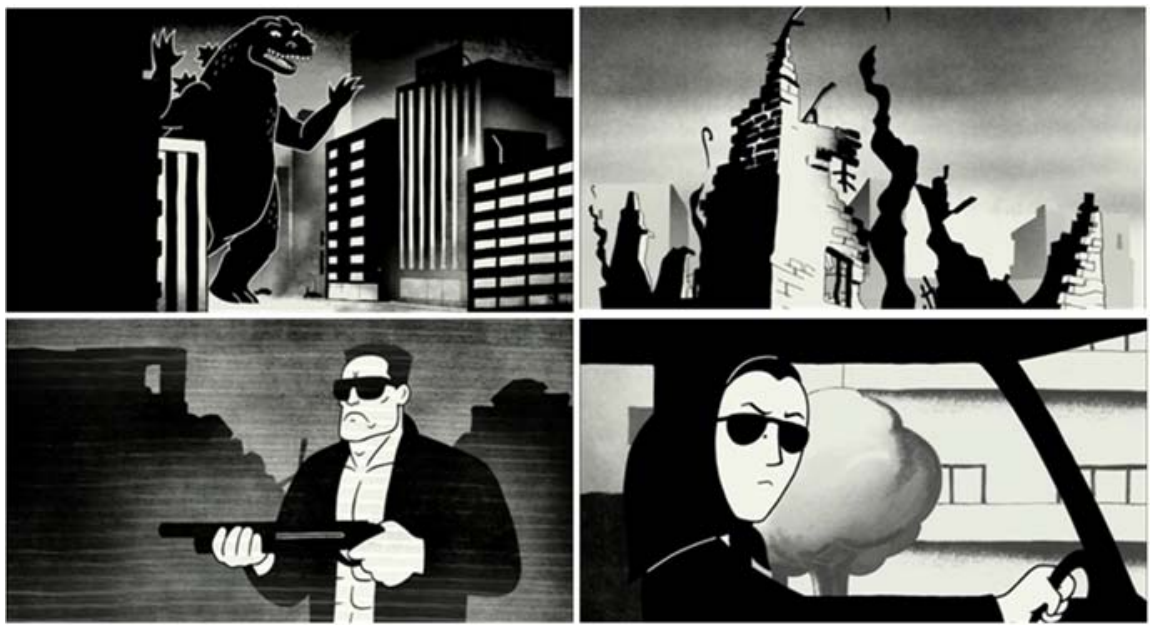

Abb. 4.8, 4.9, 4.10 und 4.11 Persepolis, „,Godzilla, Terminator und Teheran“, Frankreich 2007

Diaspora fungiert hierbei nicht als durch gemeinsame Abstammung oder Geschichte vorprogrammierte Entität, sondern als Raum, der immer wieder aktueller Bezugspunkte bedarf, um aufrechterhalten zu werden. In diesem Sinne ist Diaspora nicht statisch, sondern performativ und löst sich in eine Vielfalt von Positionen, kulturellen Techniken und medial-filmischen Formen und Räumen 
auf. Es handelt sich um einen Raum, der sich verändert und immer wieder neu begreift. Jede Form von Gemeinschaftsbildung setzt notwendigerweise Medien voraus, seien es Sprache, Musik, Kleidung, Fahnen et cetera, die Zusammengehörigkeit definieren und als konstitutive Merkmale erkannt werden. Diaspora ist von ihrer jeweiligen Mediensituation abhängig - definiert sich über ihre Medien beziehungsweise Kommunikationsformen - und wird dadurch erst erzeugt. PopKosmopolitismus steht jenseits der Diaspora. Insofern ist die diasporische Bindung über popkulturelle Elemente wie Musik und Film nur eine weitere Stufe einer längeren Entwicklung.

\section{Persepolis als filmisch-animierter Raum}

Wenn Animation im wörtlichen Sinne des lateinischen Ursprunges animare (animieren, beleben, beseelen), verwandt mit dem von Gertrud Koch geprägten Begriff der „Verlebendigung“, interpretiert wird, kann - wie ich im Folgenden darlegen möchte - Animation als Mittel gesehen werden, historische Ereignisse, welche in das kollektive Gedächtnis der iranischen Diaspora eingeschrieben sind, zum Leben zu erwecken. Dadurch kann sie eine Öffnung im kosmopolitischen Sinne herbeiführen. Film - und in diesem Fall der Animationsfilm - selbst bietet einen Möglichkeitsraum, in dem dieser Prozess sowie Wünsche, Hoffnungen und Visionen anderer möglicher Welten kreiert werden können, wie auch die Literaturwissenschaftler_innen William Anselmi und Sheena Wilson in ihrem Sammelbandbeitrag „Technologies of Memory, Identity, and Oblivion in Persepolis (2007) and Waltz with Bashir (2008)“ hervorheben:

Perhaps the penned image - the drawings and animation is somehow able to represent reality more accurately in the contemporary world than ,real' pictures, since everything around us reminds us of our presence in the image-based media environments and associated pathos, with neither a 
link to critical distancing nor the ability to process beyond sensorial gratification. (255)

Die narrative und ästhetische Anordnung, so haben die obenstehenden Analysen gezeigt, taucht die Protagonistin von Persepolis in ungeahnte kosmopolitische Räume, welche letzthin als ineinander verschachtelte und miteinander verwobene Palimpseste von Imagination und Erinnerung fungieren. Sie verdeutlichen, wie Narrative ineinander verschränkt sein können, und zeigen so den filmischtransformativen Aspekt von individuellen und kollektiven diasporischen Identitäten auf.

In diesem Sinne sind diese kosmopolitischen Visualisierungsstrategien für meinen Diasporabegriff als produktive Spannungen zu interpretieren. Die in Persepolis angelegte Kreativität ob der Möglichkeiten, Diaspora anders zu leben, verdeutlicht die Nähe der beiden Konzepte Kosmopolitismus und Diaspora. Kosmopolitismus speist sich als Haltung und Offenheit gegenüber der Welt doch, wie im eingangs erwähnten Zitat von Steven Vertovec, aus den Erfahrungen der Diaspora (64), welche sich mit den Worten Stuart Halls folgendermaßen formulieren lässt: „The diaspora experience is defined, not by essence or purity, but by the recognition of a necessary heterogeneity and diversity; by a conception of ,identity" which lives with and through, not despite, difference; by hybridity“ (Hall, „Cultural Identity and Diaspora“ 235; Hervorhebung im Original). Die produktive Spannung der iranischen Diaspora liegt, so mein Argument, darin, Visualisierungsstrategien anhand filmischer Räume auszubilden, in denen Identitäten widerhallen und gespiegelt werden können. Identität wird in diesem Kontext als immer wieder, synchron und diachron, austarierende Beziehung zur Welt, dem Kosmos, gesehen, bei dem im Falle von Persepolis den PopKosmopolit_innen eine besondere Funktion zukommt: „The pop cosmopolitan walks a thin line between dilettantism and connoisseurship, between orientalistic 
fantasies and a desire to honestly connect and understand an alien culture, between assertion of mastery and surrender to cultural difference“ (Jenkins 164). Erinnerung und Imagination sind dabei entscheidende Elemente dieser produktiven Triebkraft. Der Diasporafilm verändert konstant auf imaginative Art und Weise seine Ausformung und Gestalt und trägt in diesem Sinne dazu bei, Erinnerung nicht nur als etwas in die Vergangenheit Gerichtetes, sondern auch und vor allem als etwas in die Zukunft Blickendes, etwas Bildendes und Gestaltendes, zu konzeptualisieren. Kosmopolitische Räume sind demnach filmische Räume der Verschachtelung, der Verdichtung, der Gleichzeitigkeit und der Verlebendigung.

Kosmopolitismus als alltägliche kulturelle Praxis im Sinne Asef Bayats tritt sowohl in Walls of Sand als auch in Persepolis in verschiedenartigen filmischen Räumen in Erscheinung: Der Raum des autonomen Selbst, der kosmofeministische Positionen ermöglicht und damit als verlebendigter filmischer Raum fungiert, und der Raum des kindlich-jugendlichen Selbst, der infolge als popkosmopolitischer und animierter Raum auftritt, tragen dazu bei, Diaspora als Medienraum zu konzipieren, indem filmische Räume als Räume der kulturellen Verortung und Transformation sowie als Räume der Aushandlung der eigenen Position zum Tragen kommen. Einen weiteren solchen Raum bildet der rebellische Raum, den ich nachstehend anhand der beiden Filme The Green Wave von Ali Samadi Ahadi und Schwarzkopf von Arman T. Riahi näher untersuchen möchte. 


\subsection{Rebellische Räume}

In seinem umstrittenen Artikel „Wovon träumen die Iraner?“ verwehrte sich Michel Foucault bereits im Zusammenhang mit der islamischen Revolution der Bezeichnung „Revolution“ und bevorzugte stattdessen jene der „Revolte“, da mit ihr etwas Neues entstehe, das sich traditionellen Einordnungsversuchen und Klassifizierungen entziehe. Das Revolutionäre liege demnach nicht darin, dass die islamische Revolution soziopolitischen Umbruch bedeutete, sondern vor allem darin, dass sie traditionelle Definitionen von Revolution selbst in Frage stellte:

Wir erkennen eine Revolution, wenn wir zwei Dynamiken ausmachen können: die erste ist die der Widersprüche innerhalb der Gesellschaft, des Klassenkampfes oder der großen sozialen Auseinandersetzungen. Darüber hinaus eine politische Dynamik, das heißt die Anwesenheit einer Avantgarde, Klasse, Partei oder politischen Ideologie, kurzum: einer Speerspitze, welche die gesamte Nation mit sich zieht. Mir scheint, daß man bei den Ereignissen im Iran keine dieser beiden Dynamiken erkennen kann, die für uns die entscheidenden Merkmale und expliziten Zeichen eines revolutionären Phänomens sind. (Foucault, Dits et Ecrits III, 744)

Der Begriff Revolution würde die Ereignisse anhand vorprogrammierter Muster kategorisieren. Was Foucault am Begriff Revolution ablehnt, ist die geschichtsphilosophische Perspektive, die für das politische Denken seit dem 18. Jahrhundert kennzeichnend ist. Foucault rückt hingegen die Revolution als Ereignis, das heißt als Rebellion gegen existierende Denk- und Praxisformen, in den Vordergrund.

Der Begriff der Rebellion ist dem der Revolte verwandt und bezeichnet vom Römischen Reich bis ins neunzehnte Jahrhundert ein von Obrigkeiten mit 
Schrecken wahrgenommenes und mit Gewalt bekämpftes Phänomen soziopolitischer Unruhen (Koselleck 655). Diese pejorative Definition änderte sich auch innerhalb kolonialer Aufstände nicht, scheint jedoch jüngst, laut den Sozialanthropologen Felix Lang und Malcolm Théoleyre, in ihrer Einleitung zur Zeitschriftenausgabe „The Rebel“, eine Neudefinition erlebt zu haben: „Drawing on images of the bohemian and the outcast who purportedly resist the demands of conformity imposed by bourgeois society, the rebel-label becomes a mark of distinction for authenticity“ (8).

In frühen Spielfilmen der iranischen Diaspora hat, wie ich im Folgenden darlegen möchte, das „rebel-label“ eine vornehmlich negative Bedeutung. Im Gegensatz dazu stehen neuere Dokumentarfilme, die ich anhand der Analysen der darin vorkommenden rebellischen Räume in den Fokus rücken möchte. Unter rebellischen Räumen verstehe ich Räume, die durch Überlappung, Durchlässigkeit und Gegenwärtigkeit abseits geographischer und ethnischer Zuschreibungen bestechen und so einmal mehr die kulturelle Verortung und Positionierung der iranischen Diaspora aushandeln.

\subsubsection{Botschaft}

Die islamische Revolution 1979 in Iran dient den meisten Filmen der iranischen Diaspora als historischer Ausgangs-, Dreh- und Angelpunkt sowie als Referenzrahmen in der Beschäftigung mit Diaspora und ihren Folgen. Ein Spezifikum der iranischen Diaspora in den Vereinigten Staaten im Umgang mit dem Ereignis ist hierbei die in den Novembertagen des Jahres 1979 stattgefundene Geiselnahme von Teheran, bei der iranische Studierende die US-Botschaft in Teheran stürmten und zweiundfünfzig Geiseln nahmen. Die durch die breite Medienberichterstattung forcierte feindliche Haltung führte laut Nilou Mostofi zu alltäglichen 
Diskriminierungen von zu dem Zeitpunkt in den Vereinigten Staaten lebenden Iraner_innen: „The lranian hostage crisis of 1979 and the following decade consisted of either direct or indirect bigotry, prejudice, and hatred toward Iranian immigrants in the United States“ (691). Gut zwanzig Jahre später beschäftigen sich zwei knapp hintereinander erschienene Spielfilme mit der Thematik - America So Beautiful und Maryam -, indem sie ihre Narrationen jeweils in der Zeit der Geiselnahme in Teheran und der Unruhen, die die Fronten zwischen den Vereinigten Staaten und Iran Ende der 1970er Jahre verhärteten, ansiedeln.

America So Beautiful von Babak Shokrian, ein im Jahr 2001 in den Vereinigten Staaten durch Mittel privater Sponsoren der iranischen Gemeinschaft in Los Angeles entstandener Film, erzählt die Geschichte von Hushang (Mansur), der mit der Hoffnung, schnelles Geld zu machen und den sozialen Aufstieg über die Beteiligung an einem Disco-Unternehmen zu erreichen, nach Los Angeles kommt. Das Intro beginnt mit gerasterten Fernsehbildern von der Inthronisierung des Schahs bis zu seinem Sturz, der Revolution und der Rückkehr Khomeinis nach Iran. Diese Bilder sind mit iranischer Musik unterlegt und suggerieren damit eine Verbindung zu Iran. Die Einblendung „Los Angeles, California, November 4, 1979. Americans Held Hostage. Day 1“ bettet die Handlung vollends in ihre räumliche, zeitliche und politische Dimension ein ${ }^{48}$. Die Einblendungen „Day 2“, „Day 5“, „Day 6“ markieren in Folge einerseits Hushangs Ankunft und erste Schritte in den Vereinigten Staaten, parallel dazu aber auch die Ereignisse der Geiselnahme von Teheran, und verbildlichen damit die Gleichzeitigkeit zwischen den Ereignissen in Iran und jenen in der Diaspora, nicht zuletzt vor allem auch über die Einbettung der gerasterten Fernsehbilder von 1979, welche die Narration immer wieder unterbrechen. Zudem infiltrieren Fernsehreportagen und Radiosendungen der Ereignisse im Laufe des Filmes jeden diegetischen Ort, vom Auto über Restaurants und Cafés bis hin zur Wohnung von Lucy, einer Barkee- 
perin (Diane Gaidry), mit der Hushang eine kurze Liebesbeziehung eingeht. Auch die Zeitung berichtet über die iranische Revolution und die Geiselnahme von Teheran. Alle für die späten 1970er Jahre relevanten Medien tragen im Film ihren Teil zur Übertragung feindlicher Stimmung bei. In einer Szene, in der Hushang und seine Freunde bei einer Raststation haltmachen, um kurz die Toilette zu benutzen, wird die ablehnende Haltung der Kellnerin nicht nur durch ihre Aussage: „The whole world is laughing at us. They don't respect us anymore. America for the Americans! Toilets for customers only!“, sondern vor allem durch die Berichterstattung über die Geiselnahme im Fernsehen über der Theke, die prominent ins Bild gesetzt wird, deutlich. Die Männer versuchen, sich gegen diese Medien- und Bilderflut wiederholt abzugrenzen, wie bei der gemeinsamen Autofahrt im Taxi von Parviz (David Diaan), bei der sie lieber Pläne für ihre Zukunft in den Vereinigten Staaten schmieden, als den Nachrichten im Autoradio zuzuhören, und es daher ausmachen. Das nächste Bild zeigt jedoch erneut die gerasterten Fernsehbilder von Khomeini und der Revolution und erlaubt so nicht an dem Pläneschmieden der Männer teilzunehmen, sondern markiert durch Naheinstellungen die extreme Nähe und Bedrohung der Ereignisse in Iran für jene Iraner_innen, die in den Vereinigten Staaten leben ${ }^{49}$. Diese Szene hallt im Epilog des Filmes wider: Die Überleitung von auditivem Nachrichtenmaterial aus dem Radio zu visuellem Nachrichtenmaterial aus dem Fernseher wird durch die Einblendung „483 days later ...“ eingeleitet: Hushang fährt, wie Parviz und Dutzende andere, denen ein sozialer Aufstieg nicht gelungen ist, Taxi. Die Fernsehübertragungen von Präsident Ronald Reagans Angelobung und der Freilassung der amerikanischen Geiseln in Teheran werden in dieser Szene durch einen ironischen Schwenk auf die Mini-Freiheitsstatue am Armaturenbrett von Hushangs Taxi konterkariert ${ }^{50}$. 
Im Film Maryam von Ramin Serry, einem Spielfilm aus dem Jahr 2002, bildet die Geiselnahme von Teheran den dramaturgischen und narrativen Rahmen für die Umwälzungen im Leben der Jugendlichen Maryam (Maryam Parris), die lieber „Mary“ genannt wird (Strohmaier, „lrangeles: Migration“). Durch die Geiselnahme von Teheran beginnen Klassenkamerad_innen und Nachbar_innen sich ihr und ihren Eltern (Shohreh Aghdashloo und Shaun Toub) gegenüber seltsam zu verhalten. Als dann auch noch ihr religiöser Cousin Ali (David Ackert) aus Iran für sein Studium zu ihnen zieht, ist das Chaos in ihrem Leben komplett. Der Film beginnt mit generisch sehr ähnlichen, teilweise den gleichen Fernsehbildern der Inthronisierung des Schahs bis zu seinem Sturz und der Machtübernahme Khomeinis. Die Bilder werden in diesem Fall jedoch von einem amerikanischen Popsong begleitet und konterkarieren dadurch die Geschehnisse in Iran mit der Lebensrealität von Mary in den Vereinigten Staaten. Denn ab dem Zeitpunkt, als sie aus dem Off sagt: „As far as I was concerned, Iran had nothing to do with me“, verstummen auch die zaghaften orientalistischen Setar-Töne, die noch am Anfang zu hören waren, und Let the Good Times Roll von der Band The Cars setzt ein. „The good times“ - die guten Zeiten für den Schah sind zu Ende, die guten Zeiten für Khomeini und die Revolutionäre in Iran beginnen, jene für die in den Vereinigten Staaten lebenden Iraner_innen sind, wie im Laufe des Filmes gezeigt wird, ebenfalls vorbei. Über die Tonebene verortet sich Mary kulturell ganz klar in den Vereinigten Staaten. Das Objektiv einer Handkamera zur Aufzeichnung der Schulnachrichten wird sichtbar, und „New Jersey - 1979“ wird eingeblendet ${ }^{51}$. Die Handlung wird in Zeit und Raum genau festgelegt. Zusätzlich zu den Fernsehbildern, welche auch in diesem Fall im Laufe des Filmes immer wieder die Handlung unterbrechen, werden außerdem immer wieder Inserts mit genauen Orts- und Zeitangaben eingeblendet: „Tehran November 4th“, „Tehran November 6th“ et cetera, und zeigen die Paral- 
lelität beziehungsweise Simultaneität zwischen den Ereignissen in Iran und deren zeitgleichen Folgen für Marys Leben in den Vereinigten Staaten. Die geographischen (Iran/USA) wie medialen (Nachrichten/Filmdiegese) Entitäten bleiben jedoch nebeneinander stehen und erlauben keine gelebte „cultural difference“ im Sinne Homi K. Bhabhas, keine Durchlässigkeit, keine Vermischung oder Entstehung dritter, hybrider Räume. Unter Hybridität verstehe ich hierbei keine reine Vermischung, sondern denjenigen Raum, der kulturelle Artikulation insofern erst ermöglicht, als dass er als Auslagerungsraum dient, in dem die Möglichkeit zur Rekonfiguration und Neuverortung erst gegeben wird.

Dies ist allerdings weder in America So Beautiful noch Maryam möglich. Die Ausstattung beider Filme setzt auf einen Retrostil, der die Einbettung in die späten 1970er Jahre abrundet: Ray-Ban-Brillen, enge bunte Hemden, Schlaghosen, stilechte Autos und Musik, alles ist minutiös durchorchestriert, die USBotschaft in Teheran, der Ort der eigentlichen Rebellion, wird indes kein einziges Mal gezeigt. Diese Art von Film nennt der Literatur- und Kulturwissenschaftler Fredric Jameson „nostalgia film“, und er meint damit postmoderne Filme, die mit den Mitteln der Stereotypisierung arbeiten: „They show a collective unconscious in the process of trying to identify its own present the same time that they illuminate the failure of this attempt, seems to reduce itself to the recombination of various stereotypes of past“ (296).

Der Terminus nostalgia setzt sich aus den altgriechischen Wörtern nóstos (,Rückkehr, Heimkehr“) und álgos (,Schmerz“) zusammen und bezeichnet eine emotional geladene Sehnsucht nach Vergangenem oder der Vergangenheit. Um die Jahrhundertwende wurde er als spezielle Ausformung der Melancholie zur Bezeichnung eines Krankheitsbildes verwendet. Gemeinhin beschreibt der Begriff heutzutage in einem weitaus weniger klinischen Sinn Erinnerungen an früher oder „die guten alten Zeiten“. Diese Sehnsucht war bereits in der kulturge- 
schichtlichen Epoche der Romantik am Ende des achtzehnten Jahrhunderts ein zentrales Motiv. $\mathrm{Zu}$ diesem Motivkreis gehörten auch das Wander- und das Reisemotiv sowie das Fernweh. In diesem Zusammenhang kam auch eine verstärkte kulturelle und nationale Reminiszenz alter Werte und Vorstellungen auf.

In diesem Sinne meint auch der nostalgia film kein historisches Abbild, sondern die Sehnsucht und Erinnerung nach einer erinnerten Vergangenheit: „Nostalgia film evokes a sense of the narrative certainties of the past [...], however nostalgia films do not attempt to recapture or represent the ,real' past but are structured around certain cultural myths and stereotypes about the past" (Jameson 116). Was im Falle von America So Beautiful und Maryam zum Tragen kommt, ist keine reine Sehnsucht nach vergangenen Zeiten, Orten oder Menschen, sondern die Filme entstehen und bestehen aus dem, was Arjun Appadurai „imagined nostalgia“ nennt, ,nostalgia for things that never were“ (Modernity at Large 77). Fredric Jameson meint ferner:

An elaborated symptom of the waning of our historicity, of our lived possibility of experiencing history in some active way. It cannot therefore be said to produce this strange occultation of the present by its own formal power, but rather merely to demonstrate, through these inner contradictions, the enormity of a situation in which we seem increasingly incapable of fashioning representations of our own current experience. (21)

Es geht in der Darstellung sowie ihrer filmischen Vergegenwärtigung von Vergangenem also in diesen beiden Filmen nicht um eine getreue Abbildung, vielmehr spiegeln die Ereignisse aus der Vergangenheit gewisse Ereignisse der Gegenwart wider. In diesem Sinne interpretiere ich beide Filme auch als Kommentar zur muslimfeindlichen und diskriminierenden Stimmung nach den Anschlägen des 11. September 2001 in New York City und Virginia. Nostalgie schaltet sich in diesem Fall als Ersatz ein, ermöglicht dadurch eine Abhandlung gegen- 
wärtiger Phänomene unter dem Deckmantel von Vergangenem und dient so als Distanzierungs- beziehungsweise Falsifikationsmittel. Die Nostalgie tritt damit als kulturelle und darstellerische Praxis in den Vordergrund. Nostalgie als kulturelle Praxis verstanden ist damit nicht durch die ewige Sehnsucht nach einer Rückkehr ins Heimatland motiviert, sondern vielmehr durch das Verlangen, mit der Vergegenwärtigung der Vergangenheit eine Distanz zur diasporischen Lebensrealität herzustellen. Diese narrativen wie stilistischen Strukturen werden in America So Beautiful und Maryam auf zwei Ebenen dargestellt: erstens durch den Retrostil in Dekor, Kostüm und Musik der späten 1970er Jahre; und zweitens durch den Einsatz der die Handlungen immer wieder unterbrechenden Fernsehbilder, die durch die historischen Ereignisse die Figuren immer wieder an ihren Platz außerhalb (oder am Rande) der amerikanischen Gesellschaft erinnern.

Im Folgenden möchte ich anhand von Filmanalysen von Ali Samadi Ahadis The Green Wave und Arman T. Riahis Schwarzkopf darlegen, dass das narrative und ästhetische Nebeneinander, wie obenstehend beschrieben, in neueren Filmen der iranischen Diaspora filmischen Formen und Räumen gewichen ist, die stärker Überlappungen und Verflechtungen in den Blick nehmen und so rebellische Räume abseits und jenseits von Nostalgie kreieren.

\subsubsection{Straße}

Dreißig Jahre nach der islamischen Revolution ereigneten sich in Iran 2009 erneut populäre Aufstände. Nach der iranischen Präsidentschaftswahl am 12. Juni 2009 gab es in Teheran und anderen größeren Städten der Islamischen Republik Iran öffentliche Proteste und Demonstrationen gegen das amtlich bekannt gegebene Wahlergebnis, das dem bisherigen Amtsinhaber Mahmoud Ahmadinedschad mit über sechzig Prozent die absolute Stimmenmehrheit bescheinigte. Die 
Opposition unter den Präsidentschaftsanwärtern Mir Hossein Moussawi und Mehdi Karroubi warfen Ahmadinedschad massiven Wahlbetrug vor und forderten eine Annullierung der Wahl. Der Wächterrat schloss die Möglichkeit einer Neuwahl jedoch aus. Wegen der Farbe Grün, die zunächst an Handbändern, später auch an Schals und Kopftüchern der Demonstrant_innen sichtbar war, wurden die Unruhen schnell als „Grüne Revolution“ tituliert. Mit dem Slogan „Where is my vote?" demonstrierten die Menschen gegen das amtlich bekannt gegebene Wahlergebnis. Der Staat reagierte mit Gewalt und Repression. Eine Bilder- und Videoflut der Demonstrationen und Auseinandersetzungen überschwemmte die sozialen Medien, quasi in Echtzeit konnte der Rest der Welt den Ereignissen auf Teherans Straßen folgen. Die populäre Aufstandsbewegung in Iran 2009 war, Asef Bayat zufolge, eine ,incomplete revolution“ („A Wave for Life"), und so ging sie letztlich nicht als Grüne Revolution, sondern als Grüne Bewegung in die Geschichte ein. Der Begriff der Rebellion kann indes für die moderne Geschichte und Gegenwart Irans und der iranischen Diaspora, die im Angesicht der populären Aufstandsbewegung der Grünen Bewegung von 2009 einer kritischen Neubefragung bedürfen, nicht nur für eine gesellschaftliche, sondern vor allem auch für eine filmische Auseinandersetzung mit Transformationsprozessen produktiv gemacht werden. Der Straße kommt hierbei eine besondere Bedeutung zu.

Als erstes Beispiel für rebellische Räume möchte ich daher auf Ali Samadi Ahadis 2010 in Deutschland produzierten Dokumentarfilm The Green Wave und der darin in mannigfaltiger Art und Weise vorkommenden Straßen eingehen. Der Film verhandelt die Grüne Bewegung in Iran auf verschiedenen visuellen Ebenen. Erstens mit dem für den Dokumentarfilm klassischen Mittel von Interviews mit Expert_innen, Talking Heads von außerhalb Irans lebenden Aktivist_innen: die Journalistin Mitra Khalatbari, der Blogger Mehdi Mohseni, der 
ehemalige Milizionär Armin Farshad Ebrahimi, der Wahlkampfaktivist Babak (Pseudonym), die Rechtsanwältin Shadi Sadr, die Juristin und Friedensnobelpreisträgerin Shirin Ebadi, der schiitische Geistliche Mohsen Kadivar und der ehemalige UN-Ankläger Payam Akhavan. Eine weitere visuelle Ebene bildet das Internet-Material von YouTube-Videos, die Handyaufnahmen der Demonstrationen zeigen. Des Weiteren verwendet der Film Inserts mit ausgewählten Tweets von Menschen in Iran, die im Laufe des Filmes immer wieder die Handlung unterbrechen, kommentieren und ergänzen. Zu guter Letzt bilden die Animationen, in Form von Motion Comic, des in Deutschland lebenden Künstlers Ali Reza Darvish die visuelle Ebene für ausgewählte Texte von Blogger_innen aus $\operatorname{Iran}^{52}$, verkörpert durch eine weibliche Figur, Azadeh (Übersetzung: „Freidenkerin“), und eine männliche Figur - eingesprochen von den ebenfalls in Deutschland lebenden iranischstämmigen Schauspieler_innen Pegah Ferydoni und Navid Akhavan. Anhand der Analyse sieben kurzer Szenen möchte ich im Folgenden die Straße als kollektiven Raum, als gegenwärtigen Raum und als filmischtransvergenten Raum konzeptualisieren.

\section{Straße als kollektiver Raum}

Filme, die die Bilder der Grünen Bewegung - wie Green Days von Hana Makhmalbaf (USA, 2009) und The Green Wave von Ali Samadi Ahadi (Deutschland, 2010) - oder des zwei Jahre später stattgefundenen Arabischen Frühlings - wie Tahrir 2011: The Good, the Bad and the Politician von Tamer Ezzat (Ägypten, 2011) und The Square von Jehane Noujaim (Ägypten, 2013) direkt integrieren beziehungsweise kommentieren, bezeichnet Hamid Naficy als „internet cinema“. Er versteht darunter wechselseitige filmische Austauschprozesse, ,whereby one film breeds other films, interviews, and reactions, creat- 
ing a multilateral global echo chamber of voices and countervoices" (A Social History of Iranian Cinema 336). Die Islamwissenschaftlerin Ilka Eickhof definiert sie in einer ähnlichen Stoßrichtung als „rebel documentaries“ und meint damit Dokumentarfilme, die Straßenkünstler_innen und deren Kunst im öffentlichen Raum im Zusammenhang mit populären Aufstandsbewegungen in einem Akt der Solidarität beleuchten: „Part of the motivation behind directing these documentaries might have been a sense of solidarity and the wish to support the struggle for the one, truthful narrative of how things really were" (20; Hervorhebung im Original). Neben politischem Appell und Aktivismus sieht die Anthropologin Vanessa Marlog darin die Entstehung „neuer ethnologischer Filme“ begründet, die „nicht mehr nur Bilder zeigen, sondern von einer möglichen Kultur der Bilder erzählen“ (16), und auch Hamid Naficy bekräftigt das Potenzial für die Herausformung einer „new legitimate, artistic, and expressive form“ ( $A$ Social History of Iranian Cinema 448).

Menschen der iranischen Diaspora konnten über eine die sozialen Medien überschwemmende Flut unscharfer, verwackelter Bilder der Grünen Bewegung quasi in Echtzeit beiwohnen und darüber, so meine These, ihr ganz eigenes Verhältnis zu den Ereignissen in Iran sowie ihrer eigenen Position außerhalb Irans verhandeln. Einige dieser Videos fanden nicht nur virale Verbreitung, sondern wurden auch wieder verwendet, neu angeeignet und umgestaltet, wie beispielsweise jenes YouTube-Video, das auf knapp zweieinhalb Minuten den Tod der Demonstrantin Neda Agha Sultan zeigt ${ }^{53}$ : eine ohnmächtige Frau auf der Straße. Eine Person mit einer Handykamera läuft auf sie zu, um zu filmen, Männer beugen sich über sie und reden auf sie ein, Blut rinnt ihr aus der Nase und über ihr Gesicht, die Männer versuchen sie wiederzubeleben, doch sie stirbt noch vor Ort und vor laufender Kamera. „Where is our Neda?“, fragten daraufhin die Schilder der Grünen Bewegung. ${ }^{54}$ Ein anderes YouTube-Video fragte „Where is this 
place?"“: ein schwarzes Bild, ebenfalls offenbar mit einer Handykamera aufgenommen. In der Mitte des Bildes flackern zerstreute Lichter, die die Umrisse eines Mehrfamilienhauses erahnen lassen. In der Ferne sind Rufe zu hören, und in der Nähe spricht eine Frauenstimme auf Farsi: „Where is this place? Where is this place where the blood of its youth is spread on the street, and some stand and pray on those same streets?" Das schwarze Bild mit den zerstreuten Lichtern lässt den Ort buchstäblich im Dunkeln, die Straße in Nedas Video zeigt kein Straßenschild oder Gebäude - die Szenen könnten überall stattfinden ${ }^{55}$. „Where is my vote?“, „Where is our Neda?“, „Where is this place?“: Fragen nach der Verortung von historischen und kulturellen Prozessen, nicht das Wie, sondern vor allem das Wo steht in diesen Videos im Zentrum. Beide Videos kommen, prominent in die narrative wie zeitliche Mitte des Filmes gesetzt, auch in The Green Wave vor. Die Straße spielt in beiden Videos eine große Rolle, da sie zum Raum der Rebellion, der Gegen-Rebellion und Gewalt und letztlich auch der geteilten Erfahrung jener, die außerhalb Irans waren, wird.

Die zunächst euphorische Massenmobilisation und das Einnehmen jener Straßen wird in einer animierten Sequenz durch eine Szene aus grob kolorierten Bildern eröffnet: Ein junger Mann kommt auf der Straße auf Azadeh zu, die als freiwillige Helferin bei der Massenkundgebung von Moussawi Flyer verteilt. Er fragt, ob er auch helfen könne (Abb. 5.1). Ein weiterer junger Mann wird hinter ihm eingeblendet, gefolgt von einer jungen Frau sowie zwei weiteren Helferinnen (Abb. 5.2, 5.3, 5.4 und 5.5), bis eine Überblendung das Animationsbild über den Realfilm von Aufnahmen aus dem Stadion der Massenkundgebung legt (Abb. 5.6) und so das Ausmaß der Mobilisation vom animierten Raum in den Realfilm-Raum leitet, die animierten Figuren verschwinden dabei in der realen Masse, bis nur mehr diese zu sehen ist (Abb. 5.7). 

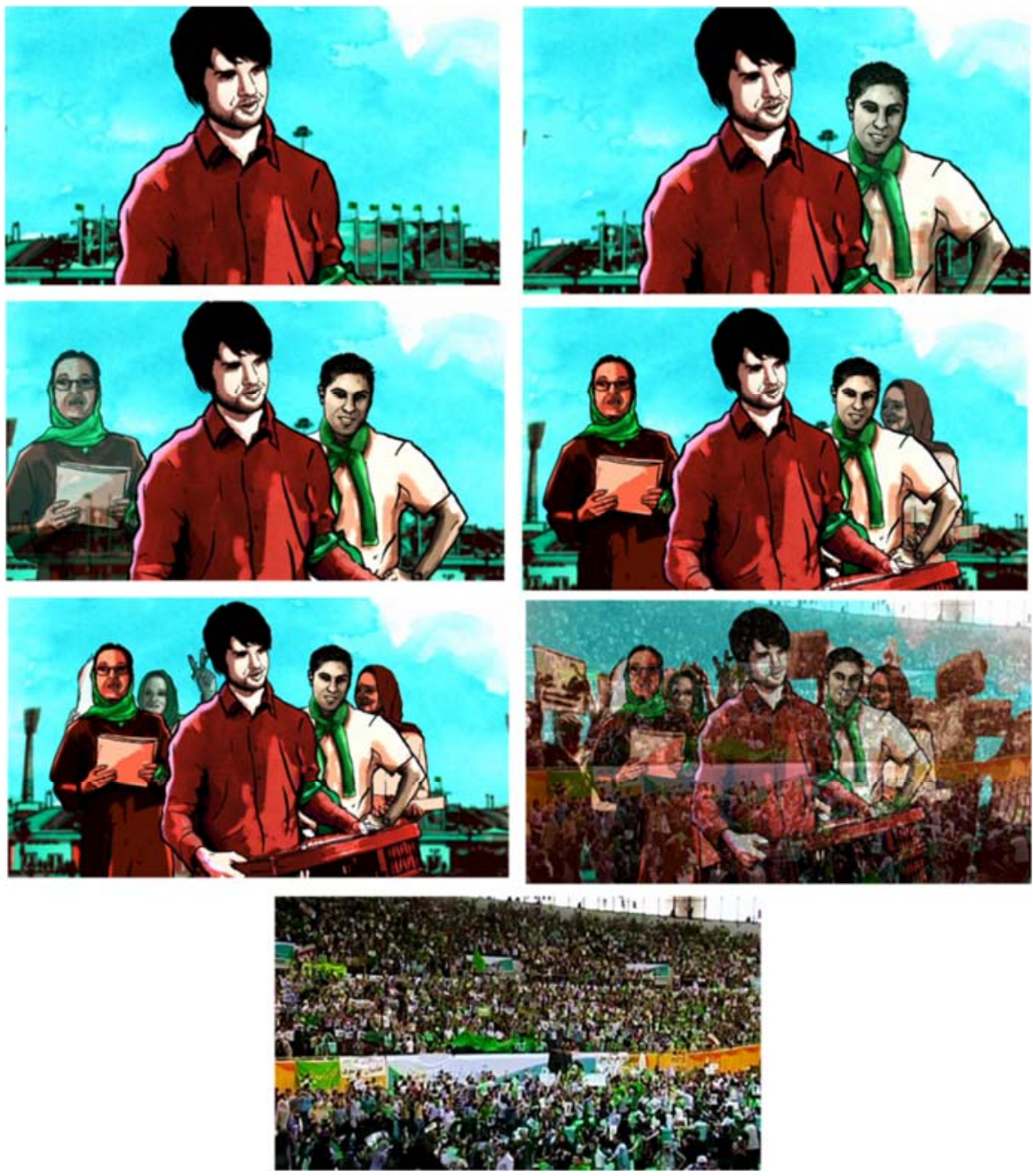

Abb. 5.1, 5.2, 5.3, 5.4, 5.5, 5.6 und 5.7 The Green Wave, „Vom Individuum zur Masse“, Deutschland 2010 
Dazwischen schneidet der Film immer wieder auf Talking Heads mit Expertenmeinungen und blendet Tweets ein. Mitra Khalatbari sagt: „Der Anlass war nicht so wichtig. Hauptsache, die Menschen konnten zwei, drei Wochen auch mal lachen, bis morgens auf der Straße sein und lautstark die Parolen rufen, die sie wollen. ${ }^{656}$ Damit hebt sie die Funktion der Straße als nicht nur politischen, sondern vornehmlich kollektiven Raum sozialer und menschlicher Interaktion hervor. Der Grundgedanke ist hierbei jener, der auch schon in Henri Lefebvres $L a$ Production de l'espace formuliert wurde, nämlich, dass Raum als Produkt sozialer Handlungen entsteht beziehungsweise durch Handeln erst erzeugt wird (167). Auch Armin Farshad Ebrahimi kehrt in der Sequenz hervor: „Ich kenne Leute, die zehn bis zwanzig Tage ununterbrochen auf der Straße waren. ${ }^{* 57}$ Der Film vereint durch die innersequenzielle Überblendung von Animation zu dokumentarischen Bildern alle visuellen Ebenen des Filmes. Die Rebellion bezieht sich in diesem Fall daher nicht nur auf die inhaltliche Ebene der politischen Opposition der Moussawi-Anhänger, mit denen dieser Diasporafilm eindeutig sympathisiert, sondern vor allem auf die filmische Ebene der Montage, denn der Montage kommt hierbei ein reflexives Moment zu. Der Filmwissenschaftler François Niney drückt dies folgendermaßen aus:

Die reflexive Magie der filmischen Montage besteht darin,
die offensichtlichen physischen Raum-Zeit-
Zusammenhänge entsprechend den (assoziativen) Modali-
täten der Welt der Ideen zu behandeln; und umgekehrt be-
deutet es, unseren Phantasmagorien und den Phantomen,
die unsere Geschichte heimsuchen, einen Körper (einen
augenscheinlich ,realen" Körper) verleihen zu können.
(118)

Damit trägt die Montage in dieser Sequenz zur Sinnstiftung im Zusammenspiel von Bild- und Tonebene bei. 
Der öffentliche Raum der Straße, der spontane Formen der Kollektivität ermöglicht, trägt wiederum zu dem bei, was der Politikwissenschaftler Benedict Anderson „an imagined political community“ (6) nannte. Sein Begriff bezieht sich auf eine Definition von Nation, die von Gemeinschaft charakterisiert und durch sie imaginiert wird:

It is imagined as a community because, regardless of the actual inequality and exploitation that may prevail in each, the nation is always conceived as a deep, horizontal comradeship. Ultimately it is this fraternity that makes it possible, over the past two centuries, for so many millions of people, not so much to kill, as willingly to die for such limited imaginings. (7; Hervorhebung im Original)

Die visuelle Ebene der YouTube-Videos zeigt im Laufe des Filmes diese Gemeinschaft in allen Formen und Varianten: scharf, unscharf, verwackelt, in Panoramaschwenks als Masse oder in Nahaufnahmen einzelner Körperteile, wie Köpfe, Arme und Beine oder gar Schatten. Zwei dieser Videos zeigen die von Anderson postulierte „horizontal comradeship“ besonders eindrücklich über ein langes grünes Tuch, unter welchem sich die Demonstrant_innen schützend versammeln. Die erste Szene wird nacheinander aus drei verschiedenen Kameraperspektiven gezeigt: aus der Vogelperspektive, wodurch die raum- und straßenfüllende Länge des Tuches und damit auch die Masse gezeigt wird (Abb. 5.8); aus der totalen Obersicht, die das grüne Tuch vertikal ins Zentrum der Bildmitte rückt (Abb. 5.9), und von vorne, wobei das Tuch von zwei Männern gehalten wird (Abb. 5.10). 

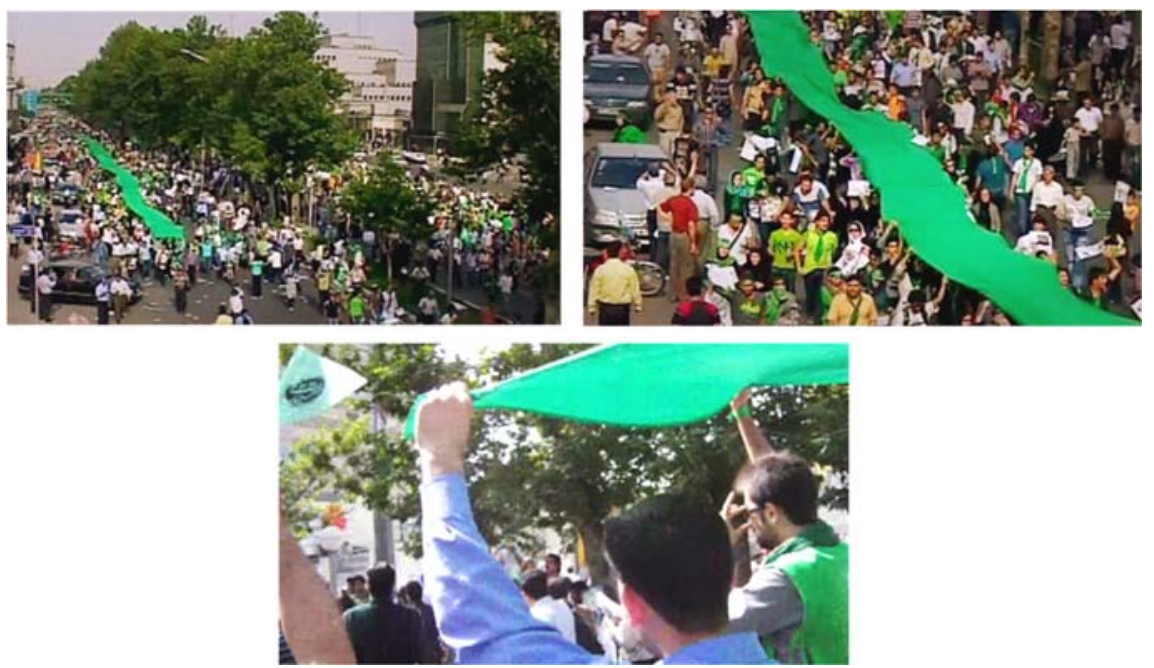

Abb. 5.8, 5.9 und 5.10 The Green Wave, „Grünes Tuch I“, Deutschland 2010

Wenig später wird das grüne Tuch erneut, diesmal in einem anderen Video, sukzessive in zwei verschiedenen Kameraperspektiven gezeigt: in einer Nahaufnahme, die wieder zwei das Tuch haltende Männer zeigt (Abb. 5.11), und von der Seite, entlang eines Spaliers, den die Vorbeiziehenden bilden und die das Tuch wieder, diesmal horizontal, in den Bildmittelpunkt stellen (Abb. 5.12).
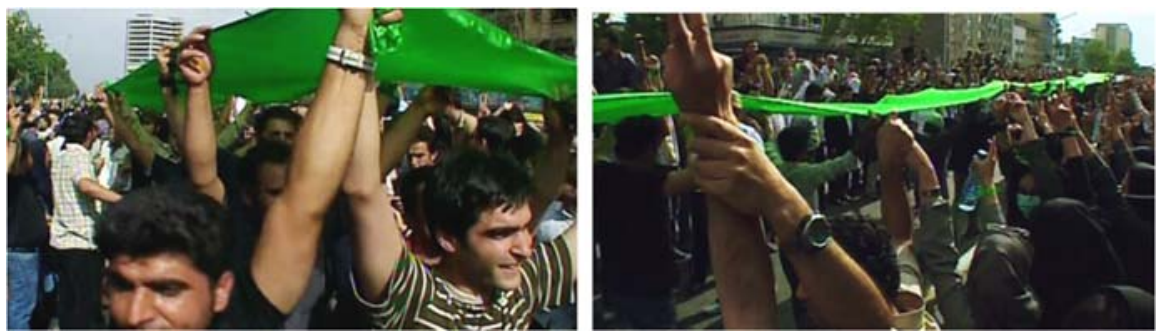

Abb. 5.11 und 5.12 The Green Wave, „Grünes Tuch II“, Deutschland 2010 
Die der populären Aufstandsbewegung ihren Namen verliehene Farbe Grün, welche neben Armbändern, Kopftüchern und Schals in diesen Szenen in Form des Tuches in Erscheinung tritt, war ein wichtiges Symbol, wie auch der Iranist Marzyar Lotfalian in seinem Zeitschriftenartikel „Aestheticized Politics, Visual Culture, and Emergent Forms of Digital Practice“ unterstreicht: „That helped create a social mood, a force that unified people and objects for a shared yet heterogeneous experience of diverse political forces“ (1387). Auch Azadeh sagt, einen Blogeintrag vom 08. Juni 2009 zitierend, in einer Szene darüber: „Ich liebe diese grünen Farben, all diese grünen Schals und Armbänder auf den Straßen. Sie bedeuten Gemeinschaft, Einheit; bedeuten, dass die Leute nicht gleichgültig sind [...]. Diese Farbe ist ein Zeichen von Anwesenheit. ${ }^{\text {"58 }}$ Die populäre Aufstandsbewegung in Iran hatte keinen zentralen öffentlichen Platz, wie dies in den meisten zwei Jahre später folgenden populären Aufstandsbewegungen der Fall war (Tahrir-Platz in Kairo, Sintagma-Platz in Athen, Gezi-Park in Istanbul, Maidan-Platz in Kiev, Zuccotti-Park in New York, Puerta del Sol in Madrid et cetera), sehr wohl jedoch eine Farbe, mit der die Straßen als kollektiver Raum der Rebellion markiert wurden. Das letzte Bild des Filmes schließt daher in einem Akt des Zelebrierens dieses kollektiven Raumes mit dem erneut gezeigten grünen Tuch und zwei aus einem fahrenden Auto herausgestreckten Armen.

Asef Bayat differenziert im Zusammenhang mit populären Aufstandsbewegungen im öffentlichen Raum zwischen „street politics“ und „political streets“ (Life As Politics 161-240). „Street politics“ meint demzufolge nicht die bloße Vereinnahmung der Straße als sozialen Raum der Rebellion durch die Formierung von Kollektiven, sondern:

,Street politics“ enjoys another dimension, that is, it is more than just about conflict between the authorities and the deinstitutionalized or, informal " people over the active use of public space and the control of public order. Streets as 
spaces of flow and movement are not only where people protest, but also where they extend their protest beyond their immediate circles to include also the unknown, the ,strangers' ${ }^{6}$ who might espouse similar, real or imagined, grievances. (211-12; Hervorhebung im Original)

Vielmehr würde die Straße dadurch eine Wirkmacht entfalten, die auch andere einschließe. Im Falle der Grünen Bewegung in Iran 2009 waren dies die außerhalb Irans lebenden Menschen, die durch den medialen Austausch ihre ganz eigene Beziehung zu den Ereignissen herstellen konnten. Ergo meint „political street“ die symbolische Äußerungsform der Straße als politisches Moment:

Political street signifies the collective sensibilities, shared
feelings, and public judgment of ordinary people in their
day-to-day utterances and practices, which are expressed
broadly in the public squares - in taxis, buses, shops, side-
walks, or more audibly in mass street demonstrations. (212;
Hervorhebung im Original)

Mit Asef Bayat argumentiere ich, dass die durch YouTube-Videos kreierte Straße im Film nicht bloßer Schauplatz der Grünen Bewegung in Iran ist, sondern ein medialer Raum, der auch Menschen außerhalb Irans inkludiert. In diesem Sinne entstand die ,imagined community“ nicht nur bei jenen, die auf den Straßen waren und in den Videos gezeigt werden beziehungsweise diese hergestellt haben, sondern auch bei jenen, die außerhalb Irans mit der Bewegung sympathisierten und die Videos durch die sozialen Medien rezipierten beziehungsweise, wie im Film The Green Wave, adaptierten und weiterverbreiteten.

\section{Straße als gegenwärtiger Raum}

Jene Kommentare - in Form von Erinnerungen oder Beobachtungen - von außen, die Kompilation von Handyaufnahmen, die in den sozialen Medien zum 
Zeitpunkt der Produktion des Filmes auffindbar waren, sowie die Animationen des vermeintlich Unzeigbaren bilden eine Collage aus Bildmaterial, welches zwar dokumentarischen Charakter aufweist, jedoch bezeichnenderweise nicht direkt in Iran gedreht wurde. Vor allem die Ebene der Animation rückt den Film damit in die Nähe von Ari Folmans 2008 produziertem Dokumentarfilm Waltz with Bashir, der die Erlebnisse israelischer Soldaten im Libanonkrieg 1982 in einem Akt individueller und kollektiver Trauma-Bewältigung erzählt. Hans Jürgen Wulff identifiziert darin fünf multimodale Erzählstrategien: Essentialisierung, Karikaturisierung, Groteskisierung und Absurdisierung, Verschiebung und Transformierung („Der Schock des Realen“). Im Gegensatz zu Waltz with Bashir, der erst am Ende Realfilm verwendet und somit, wie Hans Jürgen Wulff es ausdrückt, zum „Schock des Realen“ bei den Zusehenden führt, ist The Green Wave von einen ständigen Hin und Her zwischen Animation und Realfilm in Form von Internet-Material geprägt.

Bereits die erste Szene des Filmes nach dem Intro zeigt dies auf eindrückliche Weise: Die männliche Animationsfigur sitzt auf der Rückbank eines Taxis. Sein Blick aus dem Fenster wird durch Realfilmaufnahmen an vorbeiziehenden Geschäften und Fußgänger_innen dargestellt. Das Taxi sowie seine Insass_innen sind wie er selber animiert (Abb. 5.13). Sie reden über die bevorstehenden Präsidentschaftswahlen und führen damit auch die Zusehenden in die Vorgeschichte der Grünen Bewegung ein. Von einer frontalen halbnahen Aufnahme, die das Innere des Taxis zeigt, wird über die Windschutzscheibe des Taxis eine Überblendung auf die noch nicht mit Demonstrant_innen bevölkerte Straße gemacht. Die Perspektive geht durch die Windschutzscheibe, was aus der Reflexion der noch im Bild zu sehenden animierten Figuren erkennbar ist (Abb. 5.14). 

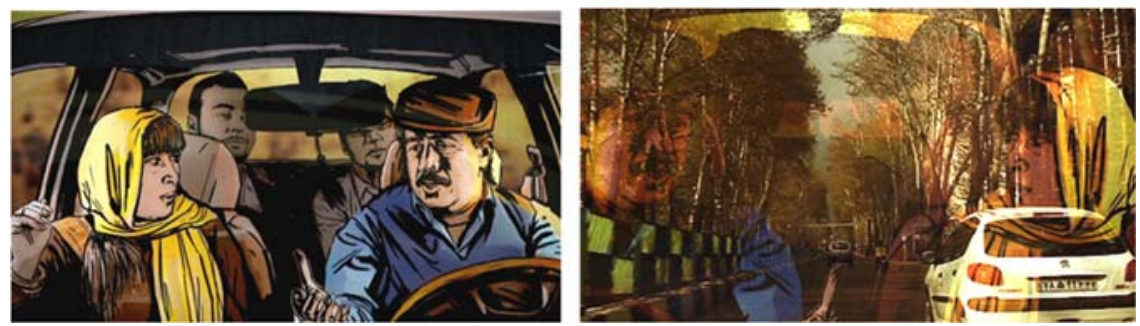

Abb. 5.13 und 5.14 The Green Wave, ,Taxi“, Deutschland 2010

In einer anderen Szene wird Azadeh ebenfalls über eine Überblendung, diesmal in umgekehrter Weise, nämlich des Realfilmes auf die Animation, eingeführt (Abb. 5.15). Die Vorstellung ihrer Person endet mit einem Blick von ihr - und damit der Zusehenden - aus dem Fenster ihrer Wohnung auf die von Menschen volle Straße und leitet so zurück auf den Realfilm und ein weiteres YouTubeVideo über (Abb. 5.16).
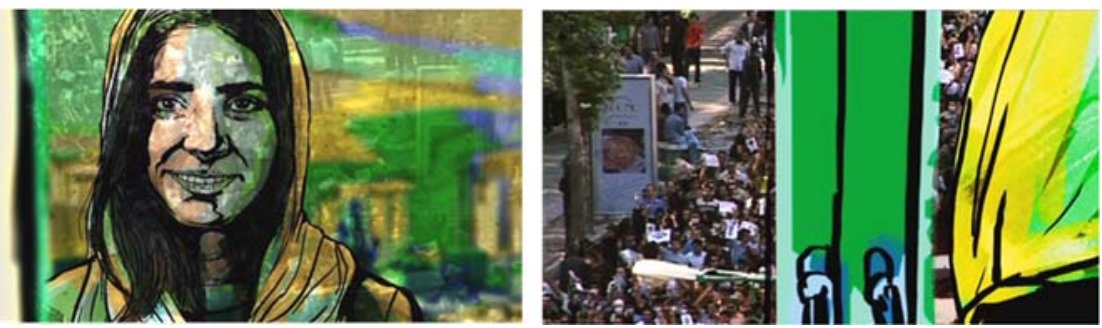

Abb. 5.15 und 5.16 The Green Wave, ,Vorstellung Azadeh“, Deutschland 2010

Innen und außen, Taxi/Wohnung und Straße, Individuum und Kollektiv sind in diesen beiden Szenen nicht klar bestimm- und ausdifferenzierbar. Genaue Zuschreibungen wie beispielsweise Traum/Hoffnung/die Guten sind animiert und Realität/Gewalt/die Bösen sind nicht animiert - oder umgekehrt - sind nicht möglich. The Green Wave nutzt durch die innersequenziellen Überblendungen Animation und Realfilm abwechselnd so, dass ein Raum im Raum entsteht, der 
sich genauen Zuschreibungsmechanismen entzieht. Hans Jürgen Wulff drückt das folgendermaßen aus: „Blendentechniken zeigen, was sie zeigen - aber sie zeigen auch, dass sie zeigen. [...] Blenden enthalten so ein reflexives Moment, sie verweisen auf die Tatsache der Darstellung durch den Film und auf die Filmwahrnehmung selbst“ (Wulff, „Visuelle Reflexivität“ 9). Zur Verwendung von Animation im Dokumentarfilm meint er:

Die Eindringlichkeit dessen, was man sieht, steigt. Nicht fällt. Man könnte ja annehmen, dass die offensichtliche Nicht-Realität dessen, was man sieht, das Reale aus dem Bewusstsein des Zuschauers verdrängen würde. Aber die Tatsache, dass es um Realität geht, bleibt immer bewusst. Das Reale hängt nicht am Photographischen. („Der Schock des Realen“ 2)

Die Kombination und das Zusammenspiel von Überblendung und Animation führen in diesen Szenen und im Film generell einen dokumentarischen Gestus mit.

Der Scheibe kommt dabei meines Erachtens eine besondere Funktion zu: Für den politischen Aktivismus, das subversive Handeln - sowohl derer, die in Iran Teil der Grünen Bewegung waren, als auch und vor allem für diejenigen, die in der Diaspora die Bewegung unterstützten - bleibt die Scheibe ein undurchdringliches Medium, durch welches nicht hindurchgegangen oder gegriffen werden kann. So trennt die Scheibe zwei Räume, Innen und Außen, Iran und Diaspora. Für die Wahrnehmung jedoch, zumindest für das Sehen, ist die Scheibe ein durchlässiges Medium, als Grenze praktisch unsichtbar. Die Scheibe selbst bleibt unwahrnehmbar, lässt aber sehen, was auf der anderen Seite ist. Hierbei nimmt sie die Funktion eines Portals ein und bietet als solches im Sinne Homi K. Bhabhas „cultural diversity“ die Möglichkeit eines hybriden Raumes. Der hybride Raum, der hier konzipiert wird, ist ein Raum transportabler Screens, 
dem ein Moment des Utopischen innewohnt, nämlich der geteilten Erfahrung. Diese Doppelfunktion der Scheibe - getrennt und verbunden zugleich - ist für die in der Diaspora lebenden Menschen das Portal zu den Ereignissen in Iran, denn als Portal ist sie in der Lage, mehrere geographische wie mediale Räume zu vereinen und miteinander in Beziehung zu setzen. Die Scheibe lädt die Gegenwart auf, und diese besondere Simultaneität kann sich auch in einer räumlichen Ausdehnung dessen artikulieren, was die Filmwissenschaftlerin Vivian Sobchack „Gegenwärtigkeit“ nannte: eine Vielzahl von Intentionen und Situationen doppelter Bildführung, Überblendung oder Montage:

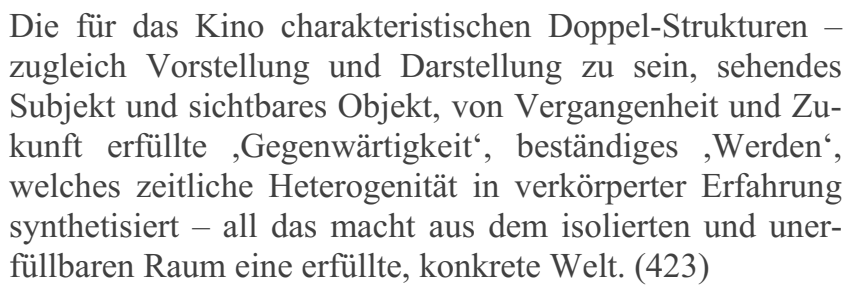

Weil sie durchlässig und trennend zugleich ist, konstituiert die Scheibe in beiden Szenen einen gegenwärtigen Raum der Bewegung und der Berührung, einen Raum, der Tiefe hat und eine Konstruktion aufweist, der nicht bloß das Sehen und Sichtbar-Werden ermöglicht, sondern auch spezifische Situationen wie die Grüne Bewegung nicht nur als Medienecho oder Erinnerung vermittelt, sondern für die Diaspora gegenwärtig macht:

In seinem Zusammenwirken mit der Film-Zeit ist der FilmRaum zugleich parzelliert und kompakt, wird er zugleich von innen und von außen erfahren. ,Gegenwärtigkeit' hat hier viele Orte - sie kann sich in das ,Da' vergangener und zukünftiger Situationen verlagern und diese Verlagerungen von einem ,Hier' aus steuern [...]. Die Parzellierung der Räume und die Diskontinuität der Zeiten artikuliert sich in der Verschiedenheit der Aufnahmen und Szenen. (423-24) 
Waren Taxi und Wohnung in Filmen des neuen iranischen Kinos von Abbas Kiarostami oder Jafar Panahi noch das notwendige Mittel, um öffentliche und private Sphäre voneinander zu trennen, so bildet die Scheibe hier, im Sinne Will Higbees cinema of transvergence, ein transvergierendes Interface, welches (trans)nationale Grenzen überschreibt. Von der Scheibe zum Bild, das wiederum zur Scheibe wird, stellt sich so die Frage nach der Zugänglichkeit von Bildern selbst.

Straße als filmisch-transvergenter Raum

The Green Wave endet mit einer Sequenz, in der die aus dem Gefängnis entlassene Azadeh, zunächst in einer totalen und gefolgt von einer nahen Einstellung, vor den Bergen an der iranisch-türkischen Grenze (Abb. 5.17 und 5.18) - ein Motiv, welches auch in anderen Filmen wie Mihman-ha-yi Hotel Astoria (USA, 1989) und Ein Augenblick Freiheit (Österreich/Frankreich, 2008) vorzufinden ist $-\mathrm{zu}$ sehen ist und sich fragt, ob sie nach der Niederschlagung der Grünen Bewegung außerhalb Irans mehr bewirken könne. Nach einem Schnitt wird Shadi Sadr in einer Nahaufnahme gezeigt, die sich ebenfalls die Frage stellt, welche Rolle sie künftig spielen und ob dies innerhalb oder außerhalb Irans sein kann (Abb. 5.19 und 5.20). Die Gegenüberstellung beider Frauen, der animierten und der realen, sowie des Grenzbereiches, den die Berge topographisch wie symbolisch darstellen, verbindet filmisch Iran und Diaspora. 

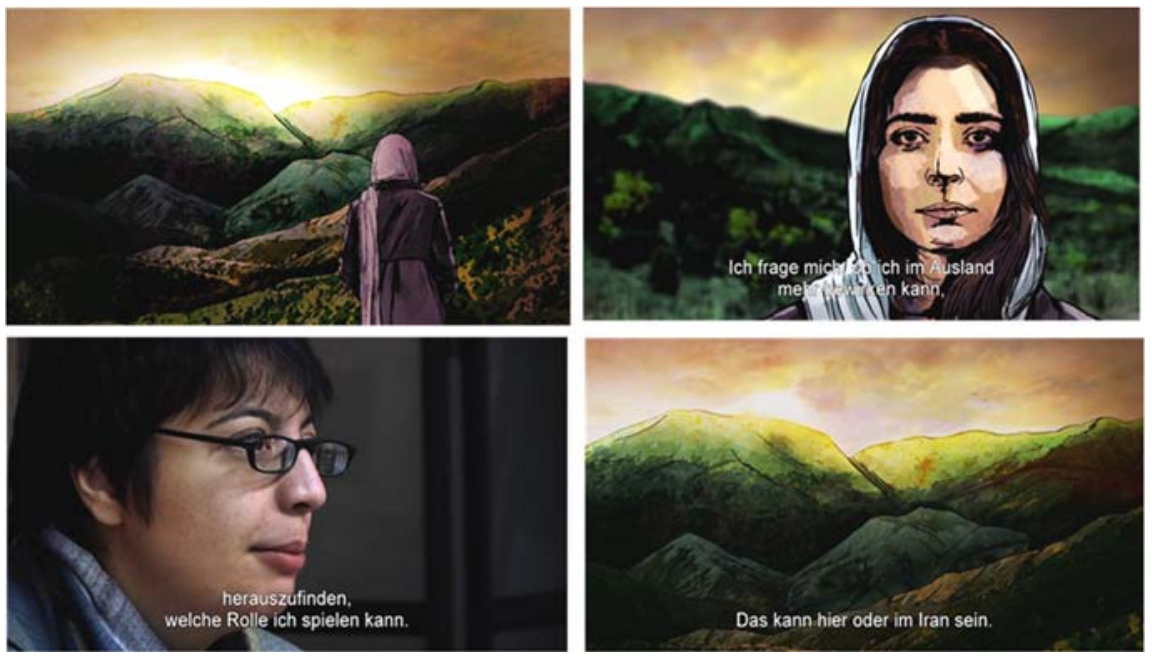

Abb. 5.17, 5.18, 5.19 und 5.20 The Green Wave, „Azadeh und Shadi Sadr“, Deutschland 2010

Benedict Anderson argumentiert, dass „every successful revolution has defined itself in national terms [...] and, in so doing, has grounded itself firmly in a territorial and social space inherited from the prerevolutionary, past" (2; Hervorhebung im Original). Dieser soziale Raum war in der Grünen Bewegung die reale und symbolische Straße. Benedict Anderson meint ferner:

The spontaneous distillation of a complex ,crossing ' of discrete historical forces; but that, once created, they became ,modular', capable of being transplanted, with varying degrees of self-consciousness, to a great variety of social terrains, to merge and be merged with a correspondingly wide variety of political and ideological constellations. (4)

Als kollektiver Raum ist die Straße, so haben die Analysen gezeigt, filmisch auf solch mannigfaltige Art und Weise in Erscheinung getreten, dass sie als komplexes Element in einem Gesamtsystem historischer wie sich verändernder filmischer Transformationsprozesse zu verstehen ist. Als gegenwärtiger Raum fand 
die Straße Eingang in die Diaspora, die, als prozessualer Raum begriffen, sich dadurch neu positioniert und konstituiert.

Durch eine erhöhte Mediensensibilität stellt der Film daher die Frage nach dem Verhältnis zwischen Nation und Diaspora neu. Mit Benedict Anderson argumentiere ich hier, dass der Begriff der Nation als kulturelles Artefakt zu verstehen ist: „Nationality, or, as one might prefer to put it in view of that word's multiple significations, nation-ness, as well as nationalism, are cultural artefacts of a particular kind“" (4). Der Montage kommt hierbei, um erneut François Niney zu bemühen, die Funktion zu, ,nicht in einer (unerreichbaren) Übereinstimmung mit dem ursprünglichen Ereignis, sondern in der Interpretation (ob nun stichhaltig oder nicht), die sie damit montiert“ (Niney 127), zu fungieren. Diaspora rekonfiguriert sich durch die Montage in The Green Wave in Referenz zu Iran immer wieder neu. Über die audiovisuelle Praxis in den sozialen Medien werden dadurch Verbindungen hergestellt, Nationales und Transnationales zugunsten von Transvergenz überwunden.

The Green Wave zeigt so, wie Film Räume verschiebt, öffnet und überschreibt. Durch diese Überschreibungen lässt sich beobachten, wie Medien kollektive Räume schaffen und Gemeinschaften bilden. Der Farbe Grün kam dabei eine gewichtige Rolle zu, da sie vom Film, prominent in den Titel gesetzt, nicht nur zum Zeichen politischer Solidarität aufgenommen und eingesetzt wird, sondern um einen eigenen (dritten) medialen Aushandlungsraum zu kreieren. Diaspora, über Medien gedacht, ermöglicht also, sie als eine Mediengemeinschaft in Weiterentwicklung von Homi K. Bhabhas Konzept des dritten Raumes sogar als einen vierten Raum kultureller (Neu-)Verortung zu konzipieren. Dieser vierte Raum schließt Zeit, Raum, Kultur und Medien ein. Das Ideal, sich zu solidarisieren, geht meines Erachtens in Anlehnung an Ilka Eickhofs „rebel 
documentaries“ einher mit einer Aufwertung der eigenen Lebensrealität, des eigenen Images als iranischstämmiger im Westen lebender Mensch:

The young educated male/female artist/revolutionary/rebel is an object of consumption because we ascribe a certain meaning to it: the signification works, telling a story that is widely accepted to manufacture commonality. The interest for ,the rebellious Other' was accompanied by a hope for a change from abject representations that were prevalent post $9 / 11$, and indeed these new images of the revolutionary rebel were far from the usual pictures of ,the Muslim'. (Eickhof 20)

The Green Wave ist kein Film über die Grüne Bewegung in Iran, sondern ein Film über den Umgang der iranischen Diaspora mit der Grünen Bewegung in Iran. Sie verhandelt darin ihre eigene Position und ihren eigenen Handlungsspielraum, ihr Verhältnis zu Iran und ihre eigene kulturelle Verortung, und dies nicht nur über Kommentare und Interviews von außen, sondern letztlich, so haben die Analysen gezeigt, über rebellische, diasporafilmische Räume.

\subsubsection{Tonstudio}

Als zweites Beispiel für rebellische Räume möchte ich auf den 2011 in Österreich produzierten Dokumentarfilm Schwarzkopf von Arman T. Riahi, der Leben und Schaffen des iranischstämmigen und in Wien lebenden Rappers Nazar (bürgerlicher Name: Ardalan Afshar) zum Inhalt hat, und das darin vorkommende Tonstudio näher eingehen. 
Tonstudio als Raum der Stimme

Die Lebensrealität einer Gruppe männlicher Jugendlicher und einer weiteren Gruppe männlicher Grundschulkinder in Wien, die allesamt migrantischen und sozial prekären Hintergrund haben, erweitert die Narration über die Biographie des Rappers hinaus. Die Auswahl der Darstellung dieser drei Generationen erklärt Regisseur Arman T. Riahi wie folgt: „Es war mir von Beginn an sehr wichtig, eine gesellschaftliche Entwicklung zu zeigen und ein Milieu zu studieren, statt einfach nur ein Einzelschicksal herauszuheben“ („Interview“). Der Film ist durch die Darstellung eines Musikers als Protagonist mit dem Musikfilm, genauer der Rockumentary ${ }^{59}$, zwar verwandt, rückt jedoch durch den Anspruch, ein Milieu zu zeigen, stärker in die Nähe von Bill Nichols Dokumentarfilm-Modus der performative documentary:

Performative documentaries try to give representation to a
social subjectivity that joins the general to the particular,
the individual to the collective, and the political to the per-
sonal. The expressive dimension may be anchored to par-
ticular individuals, but it extends to embrace a social, or
shared, form of subjective response. (133)

Das Performative ${ }^{60}$ bezieht sich in diesem Fall nicht nur auf den „Aufführungscharakter von Kultur“, sondern vielmehr auf die „Selbstbezüglichkeit von Handlungen und ihre wirklichkeitskonstituierende Kraft" (Fischer-Lichte 29). In diesem Sinne geht es auch in Schwarzkopf um das Herstellen von Bezügen zwischen dem individuellen Standpunkt von Nazar (Farsi für: „Meinung“) und dem kollektiven Standpunkt des sozialen Wiener Milieus. Ausgangspunkt dafür bleibt jedoch Nazar selbst, der sich im Laufe des Filmes immer wieder in Rückschau seines eigenen Lebens zu Wort meldet und über die Flucht mit seiner Familie aus Iran, seine Kindheit im zehnten Wiener Gemeindebezirk, seine Zeit im Gefäng- 
nis und den Stellenwert seines künstlerischen Schaffens und seiner Fans berichtet.

Seine Stimme begleitet aus dem Off die dokumentarischen Aufnahmen mit Jugendlichen und Grundschulkindern, überlagert dadurch zeitlich Nahes und zeitlich Fernes, Gegenwart und Vergangenheit, erwachsenes, jugendliches und kindliches Ich. François Niney meint zur Stimme im Dokumentarfilm allgemein: „Über die Bilder spricht die Stimme nicht nur als (repräsentierte) Welt, sondern als von einem bestimmten Standpunkt aus gemachte Aufnahmen, der auch von möglichen anderen ausgeht" (Niney 147-48). Die Funktion von Nazars Stimme hat auch in diesem Film keinen bloß informativen/bezeugenden Charakter, vielmehr verbindet sie verschiedene Bilder und damit auch Lebensrealitäten miteinander. Dadurch wird Nazars Stimme zu einem, so möchte ich mit François Niney argumentieren, überaus aktiven filmischen Element:

Die Stimme ist nicht mehr anonym, sondern persönlich; es ist die Stimme eines ,Ich', und selbst wenn es keinen Namen hat, handelt es sich doch um die Stimme der Bilder, von jenem oder jenen, die die Bilder gemacht haben, die sie an mich richten, nicht eine über die Bilder gelegte passive voice over. (147; Hervorhebung im Original)

Nazars Stimme tritt im Film überdies in einer zweiten Form in Erscheinung, und zwar durch die inner- wie außerdiegetische Darstellung seines RapGesanges. Die erste Tonstudio-Sequenz in Berlin wird mit einem Bildausschnitt eines kleinen neonbeleuchteten Fensters aus einer es dadurch zur Geltung bringenden leichten Untersicht eingeläutet (Abb. 6.1). Es ist das einzige Fenster in der kahlen grauen Wand, dahinter sind die Köpfe von Nazar und einem weiteren jungen Mann, der sich später als dessen Produzent entpuppt, erkennbar. Der Schnitt führt den Film in das Innere des Tonstudios, genauer in den Aufnahmeraum zum rappenden Nazar. Erneut in einer leichten Untersicht wird eine De- 
tailaufnahme seines sich durch das Rappen bewegenden Mundes gezeigt (Abb. 6.2 und 6.3). Die Kombination aus der das Dargestellte bereits vergrößernden Untersicht und der Detailaufnahme stellt die Bedeutung des Mundes und somit den Raum der Stimme maximal heraus: Rap ist Nazars Lebensinhalt, die Stimme jedoch ist hierbei auch das filmische Mittel, um in einen Austauschprozess zwischen Bild-, Ton- und Wahrnehmungsebene zu treten. Nachdem Nazar die letzten Zeilen - „Denn ich bin, NAZ-King. Punkt. Still.“ - seines Raps gesungen hat, bleibt nur mehr die Detailaufnahme des seine Stimme aufnehmenden Dispositives, das Mikrofon, sichtbar (Abb. 6.4).

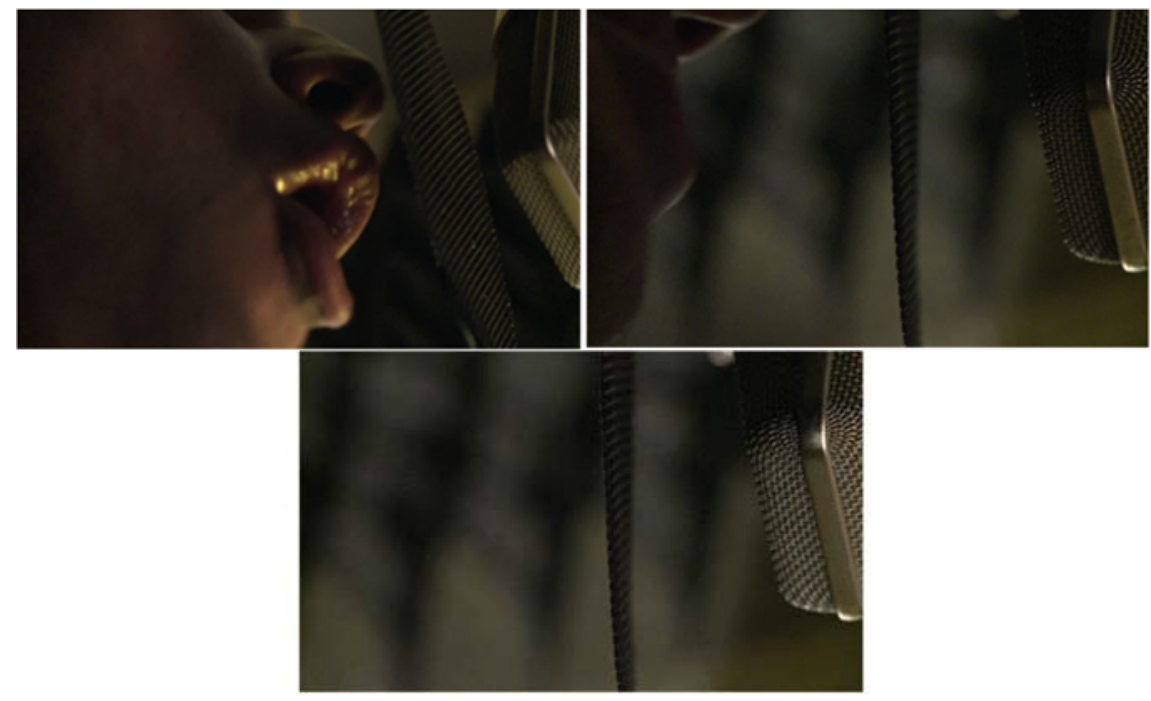

Abb. 6.1- 6.4 Schwarzkopf, ,Stimme und Mikrofon“, Österreich 2011

Die technische Reproduzierbarkeit der Stimme findet durch den nächsten Schnitt, der in einer halbtotalen Einstellung den Regieraum mit der zugleich trennenden und verbindenden Glasscheibe, in der sich ein PC-Bildschirm spiegelt, ihr Pendant: Die Stimme wird vom Produzenten am Mischpult mit Tonspu- 
ren unterlegt, „gemischt“ und bearbeitet, wodurch das Tonstudio nicht nur zum Raum der Stimm-Aufnahme, sondern auch zu einem Raum der Stimm-Bildung und -Wiedergabe wird. François Niney meint zur Dialektik der Stimme als zugleich hör- und sichtbares filmisches Element Folgendes:

Des Weiteren macht die Stimme des Ich eine überaus poetische Dialektik zwischen den tatsächlichen und anderen möglichen Bildfeldern erfahrbar, die auch hätten gefilmt werden können oder die die Sprache (aber auch die Musik) evoziert oder imaginativ entwirft. Andere mögliche Aspekte oder Assoziationen auf diese Weise verständlich zu machen, bedeutet eine Öffnung zum Virtuellen, zur Möglichkeitsform [...]; das führt - jenseits des gegenwärtigfaktischen Bildes - eine imaginäre und poetische Dimension ein, die das Wahrnehmungsfeld um die Reflexion des Zuschauers erweitert, anstatt es auf die begrenzte Realität des rein Sichtbaren zu reduzieren. (148)

Die Szene zeigt nicht bloß den dokumentierenden Akt der Entstehung von RapMusik oder den sprichwörtlichen Blick hinter die Kulissen durch die Betrachtung des Künstlers bei der Arbeit, vielmehr wird in der Bildgestaltung die Wandlung von Nazars Stimme vom kommentierend-erzählenden Ich zum performenden und zugleich performativen Ich gezeigt. Der Produzent kommentiert, sichtlich von Nazars Rap angetan, die Aufnahmesituation mit einer rhetorisch gemeinten Frage, auf die er sogleich auch selber eine Antwort gibt: „Wer ist dieser krasse Nazar? Das ist ein Super-Rapper!“ Nazar selbst setzt, einen persischen Akzent nachmachend, trotzdem zu einer ironischen Antwort an: „Voll die geile, persisch... voll die...", die er allerdings in einem Halbsatz stehen lässt, da er vom Produzenten mit den wiederholenden Worten: „Voll der geile SuperRapper!“" unterbrochen wird. Deutlich wird in diesem kurzen Dialog, dass für den Produzenten Nazars Stimme und sein Können als „Super-Rapper“ und nicht sein ethnischer Ursprung im Vordergrund stehen. Bildgestalterisch wird dies aus 
der Kameraperspektive, die den Produzenten und den Regieraum mit den Instrumenten in den Bildmittelpunkt und Nazar im Aufnahmeraum in den Bildhintergrund stellt, klar, die so einmal mehr das Tonstudio als einen nicht nur technischen, sondern auch filmischen Raum der Stimme konzipiert.

\section{Tonstudio als postmigrantischer Raum}

Regisseur Arman T. Riahi beschreibt den soziohistorischen Hintergrund seines Filmes und seiner Protagonisten in einem Interview wie folgt:

Es gibt einen Paradigmenwechsel in der Gesellschaft, der vor allem für Menschen der ersten Generation mit Migrationshintergrund, die aus anderen Kulturen kommen, schwierig zu verstehen ist: die Jugendlichen wachsen unter komplexen Umständen auf, die mit ihren Wertevorstellungen nicht vereinbar sind, nicht verständlich sind. Die Wertevorstellungen der ersten Generation greifen nicht mehr, vor allem nicht, wenn auch noch Migration ins Spiel kommt. (,Interview“)

Der von ihm geschilderte gesellschaftliche Paradigmenwechsel fand in der jüngsten kultur- und sozialwissenschaftlichen Forschung mit dem Begriff postmigrantisch $^{61}$ eine neue Beschreibungsebene. Der Begriff bezeichnet, ähnlich wie die verwandten Konzepte postethnic oder postracial $^{62}$, überwiegend im deutschsprachigen Raum eine neue soziologisch-handlungsbezogene Betrachtungsweise. Geprägt wurde der Begriff von der Theaterschaffenden Shermin Langhoff, die nach der Übernahme des 2008 wiedereröffneten Theaters Ballhaus Naunynstraße in Berlin-Kreuzberg die künstlerische Darstellung postmigrantischer Lebensrealitäten programmatisch ausrief: „Postmigrantisch“ [steht] in unserem globalisierten, vor allem urbanen Leben für den gesamten gemeinsamen Raum der Diversität jenseits von Herkunft“ („Die Herkunft spielt keine Rolle“). 
Dieser gemeinsame Raum steht, laut der Sozialwissenschaftlerin Naika Foroutan, „für einen gesellschaftlichen Wandel, der eine ganzheitliche Partizipation aller Mitglieder der Gesellschaft anstrebt" (232). Gemeint ist damit eine soziohistorische Betrachtungsweise, die Migration nicht als abgeschlossenen Prozess, sondern innerhalb ihrer gesamtgesellschaftlichen Folgen konzeptuell fasst:

\begin{abstract}
Das Präfix ,post ${ }^{\star}$ im Postmigrantischen macht deutlich, dass man eine gesellschaftlich etablierte und zunehmend defizitär konstruierte Unterscheidungskategorie - nämlich das Migrantische - zur Erklärung von gesellschaftlichen Ungleichheitsverhältnissen hinter sich lassen will. Gleichzeitig macht der Begriff deutlich, dass man sich dennoch erkennbar auf den dynamischen Faktor Migration bezieht. Ebenso wie das Postkoloniale sich auf ein Nachwirken von Kolonialisierungsprozessen in heutigen Gesellschaften von ehemals kolonisierten Ländern bezieht, rekurriert das Postmigrantische auf das Nachwirken von Migration über die Generationen hinweg - sei es als personales, familiäres oder gesellschaftliches Narrativ, als Ordnungskriterium sozialer und gesellschaftlicher Macht, als Zugangsbarriere zur Definition nationaler Identität oder als Konfliktlinie ideologischer Positionierung. (231)
\end{abstract}

In einer ähnlichen Stoßrichtung sieht die Theaterwissenschaftlerin Azadeh Sharifi die Entwicklung des Gegenwartstheaters, welches sich immer weniger mit klassischen Herkunftsnarrativen beschäftigt, da diese die Lebensrealitäten der Menschen nicht mehr adäquat abbilden:

Die meisten Künstler und Kulturschaffenden mit einer familiären Migrationsbiografie [sind] mindestens bikulturell, das heißt gleichzeitig durch die deutsche Kultur sowie die Kultur ihrer Familie geprägt und in ihrer künstlerischen Arbeit beeinflusst. Sie interessieren sich meist weniger für das Herkunftsland ihrer Familie, sondern mehr für ihre ei- 
gene Lebenssituation - einer Lebenssituation nach der Migration in Deutschland. (35)

Vielmehr würden neue künstlerische Ausdrucksformen gesucht und bedient, um den Aushandlungsprozessen mit Identität und Kultur gerecht zu werden:

Es geht um die Schaffung einer eigenen Identität in der deutschen Gesellschaft und dem theatralen Kosmos, in dem sich die postmigrantischen Künstler und Kulturschaffenden bewegen. Themen und Traditionen der deutschen Kultur und der Kultur der Familien müssen in einer neuen Art und Weise geschaffen und erzählt werden, weil die bisherigen Instrumente nicht ausreichen. (43)

Eines der wichtigsten Instrumente ist hierbei Sprache. Ähnlich wie im Postkolonialismus plädiert Shermin Langhoff, analog zu Gayatri Spivaks Frage „can the subaltern speak?", für die postmigrantische Ausdrucksform als Medium der Ermächtigung: „Ein Sprachbewusstsein, Assoziationen, es gibt aber auch ein Empowerment“ („Minus + Minus“). Ermächtigung bedeutet laut Naika Foroutan in diesem Fall auch Sichtbarmachung: „Die akteursbezogene Perspektive beinhaltet ein Empowerment, das darauf setzt, Migranten und ihre Nachkommen in der deutschen Hochkultur sichtbarer zu machen.“ (237) Regisseur Arman T. Riahi bekräftigt für die Populärkultur im Zusammenhang mit Schwarzkopf die Bedeutung des Raps für Nazar und die Jugendlichen in einer ähnlichen Ausrichtung: „Mit ihren Songs wollen sie sich Gehör verschaffen, und wenn ihnen dieses Gehör von der Gesellschaft zugestanden wird, dann wird sich ihre Situation auch verändern.“ („Interview“)

Nazar rappt auf Deutsch, seine Kunst ist von einer Auseinandersetzung mit der Sprache des Landes verknüpft, in dem er lebt. Für seinen in der Schweiz geborenen österreichisch-italienischen Kollegen RAF Camora (bürgerlicher Name: Raphael Ragucci) war dies zunächst die französische Sprache. Gemein- 
sam mit Nazar nimmt er dessen zweites deutschsprachiges Album auf. Eine Sequenz, die beide im Tonstudio beim Komponieren der Texte zeigt, verdeutlicht, wie „der Kreis der Subjekte [...] um Allianzen erweitert [wird], die nicht mehr herkunftsbezogen sind“ (Foroutan 235). Die Kameraperspektive zeigt in einer leichten Obersicht RAF Camora und Nazar nebeneinander im Prozess des Textens, Reimens und Lyrics-Entwerfens (Abb. 6.5). Die synchron zum Rhythmus bewegten Hände kehren die Gleichzeitigkeit ihrer Gesten und den dadurch entstehenden gemeinsamen musikalischen Raum heraus. Im letzten Viertel nimmt der Film die Szene wieder auf und führt sie fort, diesmal in einer Detailaufnahme der Worte selbst, die in Form von Schmierpapieren und Textentwürfen in den Vordergrund gestellt werden (Abb. 6.6). Damit wird bildgestalterisch zum einen der kreative künstlerische Prozess ausgestellt, die darauffolgende Szene der sich auf die Schultern klopfenden Männer (Abb. 6.7) öffnet jedoch zum anderen den Raum in einer halbtotalen Einstellung zu einem postmigrantischen Raum hin. In einem letzten Schritt dringt dieser durch die Projektion der beiden auf die Scheibe in die Außenwelt (Abb. 6.8) und dehnt damit „den Blick auf die Dynamik des Wandels und auf die Verantwortung der gesamten Gesellschaft für die stattfindenden [...] Transformationsprozesse“" aus (Foroutan 232). 

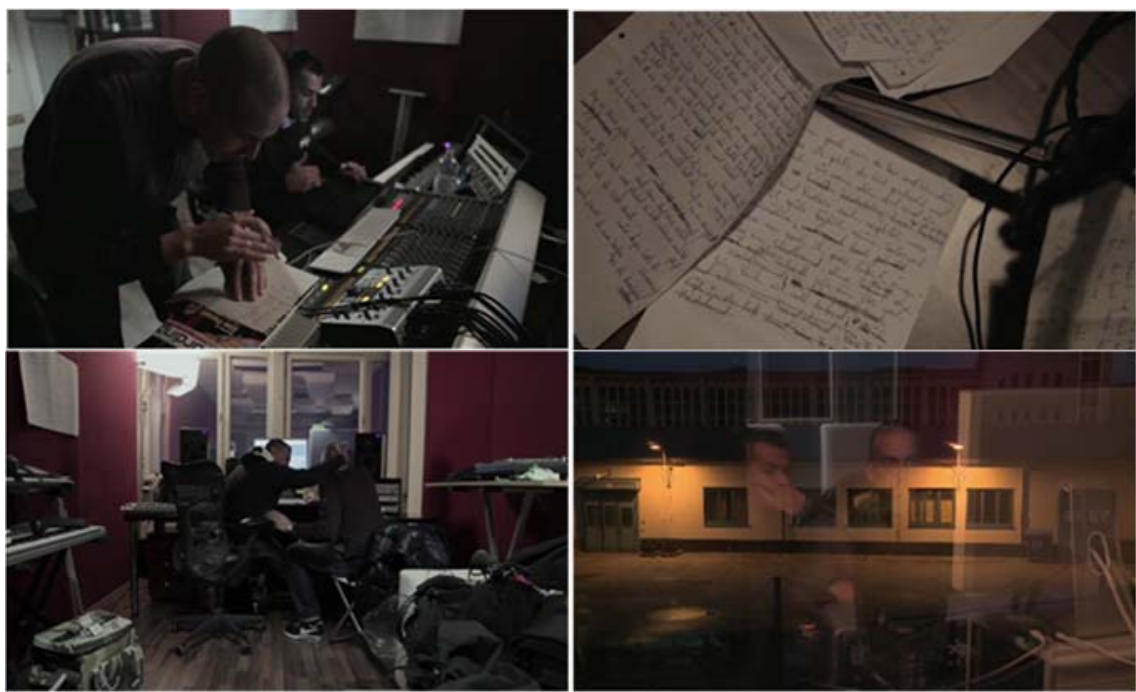

Abb. 6.5, 6.6, 6.7 und 6.8 Schwarzkopf, „Nazar und RAF Camora“, Österreich 2011

Der postmigrantische Raum schließt somit Innen- wie Außenraum, Tonstudio und Straße, Individuum und Gesellschaft ein und beinhaltet das Versprechen einer über migrations- und herkunftsbezogene Sichtweisen hinausgehenden Utopie der Gleichheit, die so künstlerisch (durch den Rap) und filmisch (durch Schwarzkopf) verhandelt wird. Das Tonstudio als postmigrantischer Raum wird in dieser Sequenz narrativ durch die befreundeten Künstler dargestellt, die in ihren Texten gesellschaftsrelevante Themen abseits ethnozentrierter Fragen komponieren - und filmisch durch die Vielschichtigkeit der Blickwinkel, die auch für eine Modulation gesellschaftlicher Perspektiven stehen, Fremdmarkierungsprozesse sowie Ausschlüsse zu hinterfragen und aufzuweichen. Der filmische Transformationsprozess geht hierbei mit dem gesellschaftlichen Transformationsprozess einher. 
Tonstudio als filmisch-rap-präsentativer Raum

Der Musikwissenschaftler Keith Negus beschreibt die soziokulturelle Funktion von Populärmusik wie folgt:

[M] usic has provided an affective form of communication that has not simply been subjective, intuitive and irrational, but which has been used to produce forms of ,counterrationality " which in turn have created affiliations, alliances and understanding amongst dispersed and diverse groups of people. (222)

Rap als Kommunikationsform streicht auch Regisseur Arman T. Riahi für den Film Schwarzkopf heraus: „Rap ist in der Recherchephase sowie im endgültigen Film immer ein Vehikel gewesen, eine Ausdrucksform, ein Ventil, um das ausdrücken zu können, was nicht kommunizierbar ist im Alltag, in der Schule oder mit den Eltern“ („Interview“). Rap steht hierbei, dem Arabisten Igor Johannsen folgend, für eine kulturelle Praxis ,to perform a viable representation of social, political, and/or religious/spiritual experiences or lifeworlds [...]. The practice of rapping is, understood in this way, a quest for meaning, for overstanding“ (87). Rap bedeutet in diesem Sinne aus seiner Entstehungsgeschichte heraus, wie die Soziologin Sujatha Fernandes hervorhebt, Sprache als Stimmerhebung: „,[H]ip hop was shaping a language that allowed young people to negotiate a political voice for themselves in their societies" (Close to the Edge 4), und im weiteren Sinne, wie Igor Johannsen hervorhebt, Sprache als Ermächtigung:

Putting the immediate social surrounding in the center and reflecting on its economic, political and religious/spiritual situation and discourse, rap was a way to artistically encounter the ,real world', and in doing so, empower oneself and one's community. This rebellious attitude, which is in- 
herent in the founding myth and history of hip hop, is a defining appeal for its adherents and was preserved when the culture spread globally. (88)

Die vom Anthropologen Samy H. Alim postulierte „global Hip Hop Nation“ (3) ist in der Forschung zu Hip-Hop breit diskutiert worden ${ }^{63}$. Der damit einhergehende Gedanke, dass Rap nicht nur die Sprache und Kommunikation einer einzelnen, sondern einer weltumspannenden Gemeinschaft bildet, ist für meinen Begriff der Diaspora als Raum der geteilten Erfahrung dahingehend produktiv zu machen, da er den performativen Charakter einer postmigrantischen Gesellschaft ausstellt.

Eine Sequenz, die den Protagonisten Nazar zu Beginn des Filmes in seinem Heimstudio zeigt, verdeutlicht dies eindrücklich: In einer halbtotalen Einstellung ist der Musiker beim Texten zu sehen (Abb. 6.9). Der Schnitt geht in eine ProfilNahaufnahme über, die ihn beim Rappen zeigt. Durch das verwendete LensbabyObjektiv, welches technisch ermöglicht, gezielt den Radius an Schärfe und Unschärfe zu bestimmen, verschwimmen die Umrisse des ihn umgebenden Raumes und betonen damit sein Gesicht und seinen sich durch das Rappen bewegenden Mund (Abb. 6.10). Den Moment, in dem er sich mit der Hand in einer Geste des Nachdenkens an den Kopf fasst, nimmt die Kamera in einer Detailaufnahme auf (Abb. 6.11). Nazar sagt dabei aus dem Off: „Wenn ich versuche, mich an meine Kindheit zu erinnern, dann weiß ich oft nicht, wie viel davon tatsächlich so passiert ist, und wie viel davon mir meine Mutter erzählt hat und dadurch erst in meinem Kopf entstanden ist.“ Als wolle die Kamera noch einmal sein Gesicht erhaschen, schneidet der Film zurück in die zuvor gezeigte Naheinstellung, doch seine Hand verdeckt diesmal sein Gesicht und die durch das Lensbaby-Objektiv verschwommene Umwelt nimmt immer mehr Raum ein (Abb. 6.12). Die letzte Einstellung zeigt eine extreme Detailaufnahme, bei der Raum, Kopf, Hand und 
Kugelschreiber nicht mehr auseinanderzuhalten sind und organisch ineinander übergehen (Abb. 6.13).
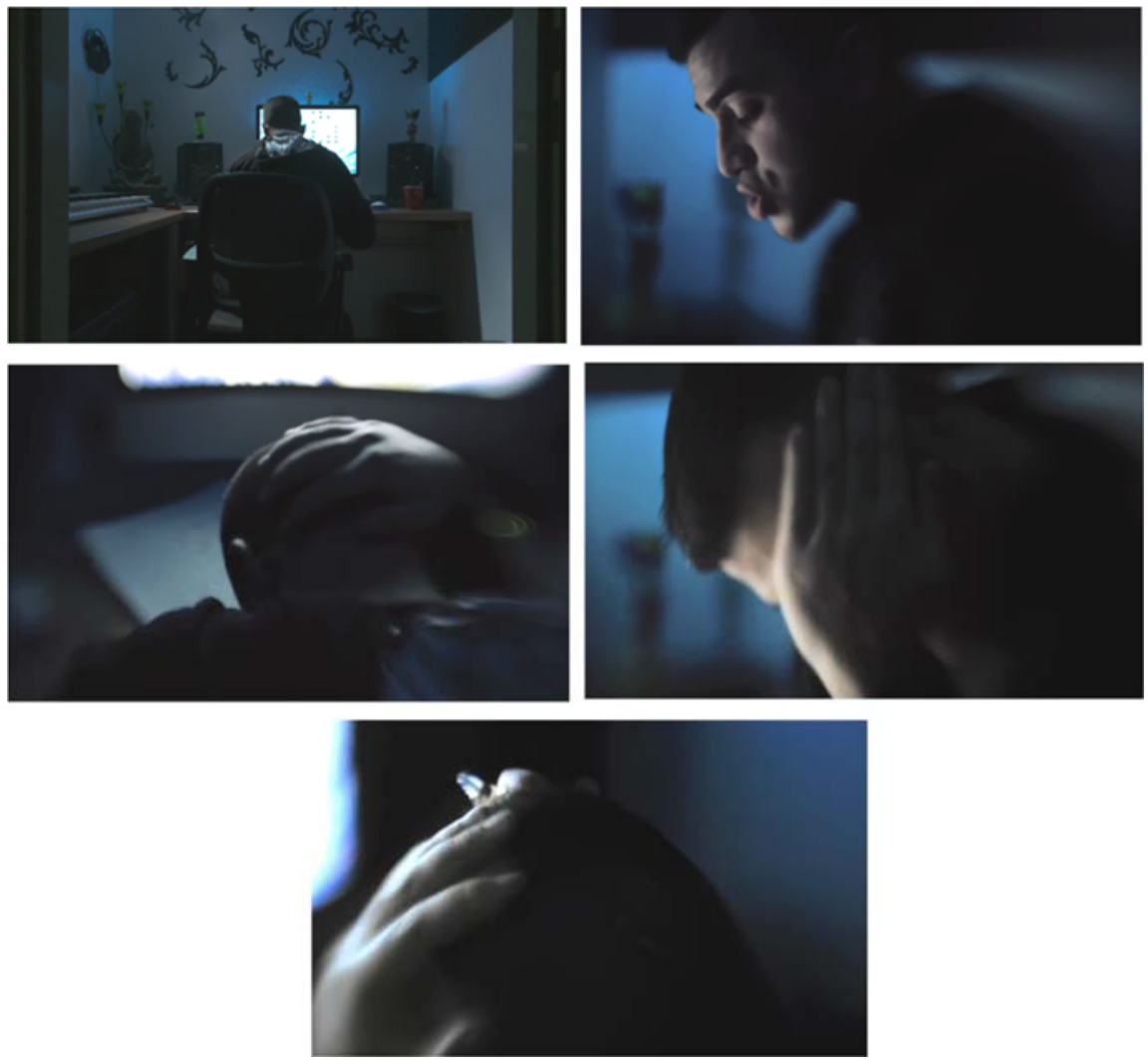

Abb. 6.9, 6.10, 6.11, 6.12 und 6.13 Schwarzkopf, „Heimstudio“, Österreich 2011

Die Szene visualisiert hierbei bildlich mit gesteigertem Nachdruck die subjektive Erfahrung von Erinnerung und Erzählung. Woran sich Nazar aktiv erinnert, was er mit Sicherheit weiß oder sich nur vorstellt, kann er nicht bezeugen, und so kann es auch der Film nicht. Das Bild selbst fragt: Was ist das Wissen über die Welt und wie erlangen wir es? Bill Nichols meint: 
Performative documentary shares a rebalancing and corrective tendency with auto-ethnography [...]. It does not, however, counter error with fact, misinformation with information, but adopts a distinct mode of representation that suggests knowledge and understanding require an entirely different form of engagement. (134)

Der in dieser Szene dargestellte Akt des Rappens ist im Gegensatz zur Szene mit RAF Camora ein einsamer Akt, dem ein (selbst-)therapeutisches Moment anhaftet. Die verschwommenen Nahaufnahmen heben das Bild als Bild hervor, welches, um es mit den Worten von Bill Nichols auszudrücken, „,constantly remind us that the world is more than the sum of the visible evidence we derive from it" (134). Der dadurch entstehende filmisch-rap-präsentative Raum impliziert die Position der Enunziation selbst: Von wo schreiben, sprechen, singen wir? Die Szene eröffnet so einen Raum, der individuelles Wissen mit soziokulturellen Prozessen verbindet und dadurch demonstriert, wie verkörpertes und körperliches Wissen Eingang in allgemeine kulturelle Prozesse findet. Nazar verhandelt in seiner Musik generell und in dieser Szene des Filmes speziell seine eigene Identität. Stuart Hall zufolge ist Identität prozesshaft und immer von einer doppelten Struktur geprägt: durch die Narration dessen, was erzählt wird, und durch Repräsentation dessen, was dargestellt wird: „Identity is always in part a narrative, always in part a kind of representation. It is always within representation. Identity is not something which is formed outside and then we tell stories about it“ („Old and New Identities“ 49). Repräsentation ist auch im Film Schwarzkopf kein historisch akkurates Abbild der Welt. Eher handelt es sich um eine ästhetische und filmisch ausdrucksstarke Aushandlung kultureller Verortungen und Positionierung iranischer Diaspora. 
Rebellische Räume treten in The Green Wave und Schwarzkopf in verschiedenartiger Weise auf: als kollektiver Raum, der gegenwärtig ist und eine horizontale, transvergente Spur hinterlässt, und als Raum der Stimme und der Stimmerhebung, die infolgedessen den Raum als post-migrantischen Raum ausweisen. Dieser richtet seinen Blick über das Migrantische und Diasporische hinaus, untersucht gesamtgesellschaftliche Aushandlungsprozesse und stellt somit die Frage nach der Repräsentation und der Wirkmacht von Bewegtbildern selbst.

\subsection{Gesamtschau}

In den Filmen der iranischen Diaspora treten filmische Räume in Form von Zwischenräumen, kosmopolitischen Räumen und rebellischen Räumen in Erscheinung. Die Analyse der sechs Filme - Zanan bidun-i Mardan, A Girl Walks Home Alone at Night, Walls of Sand, Persepolis, The Green Wave und Schwarzkopf - hat in der vorliegenden Arbeit, in Weiter- und Fortentwicklung bereits bestehender Raumkonzepte, mediale Transformationsprozesse veranschaulicht, die im Zusammenspiel ihrer Gemeinsamkeiten und Unterschiede insgesamt zu einem erweiterten Verständnis von Diasporafilm selbst geführt haben.

Im Debütfilm der feministisch orientierten Künstlerin Shirin Neshat, Zanan bidun-i Mardan, fand die Repräsentation von Weiblichkeit, durch eine Kopplung von Sozialkritik an Medienkritik im filmischen Raum des Gartens, an jener Schnittstelle zwischen den Kulturen statt, den Homi K. Bhabha als dritten Raum beschrieb. Die Diaspora wurde dabei als prozessualer Raum begriffen, der sich verändert und immer wieder neu definiert und konstituiert. Der Diasporafilm ist 
in diesem Zusammenhang nicht nur Teil des Raumdiskurses, sondern ein raumbildendes Element in sich.

Ana Lily Amirpours Debütfilm, A Girl Walks Home Alone at Night, konzipierte wiederum eine utopische Stadt, die kulturelle und generische $\mathrm{Zu}$ schreibungen herausforderte und damit darauf hinwies, dass sich Diaspora durch Hybridität abseits kultureller Essentialismen auszeichnet, dass dieses Hybride aber auch kulturelle Verortungen zunehmend verunmöglicht. Die kulturellen und generischen Elemente sind in Shahr-i Bad nicht nur nebeneinander-, sondern über- und ineinandergeschoben und markieren damit gleichsam ihre Konstruiertheit. Die kulturellen und ethnischen Zuschreibungen sind nicht mehr als hybride Formen erkenn- oder identifizierbar und filmische Hybridräume somit nicht das Ergebnis, sondern der Ausgangspunkt der Diaspora, ergo ist der Diasporafilm letzthin ein eigenständiges Filmgenre.

In beiden Filmen treten Zwischenräume in Erscheinung, die sich als Räume der kulturellen Verortung und der filmischen Transformation begreifen lassen. Dem Diasporafilm ist somit der Zwischenraum als Haltung eines diasporischen Selbstverständnisses, welches kreative Prozesse forciert, grundlegend eingeschrieben, und weist damit Diaspora wiederum als Medienraum aus.

Shirin Etessams und Erica Jordans Walls of Sand gestaltete die Wohnung als filmischen Raum kosmopolitischer Alltagspraktiken. Die zunächst gegenüber Kosmopolitismus antonym anmutende Wohnung erlebte in diesem Zusammenhang einen erweiterten Bedeutungshorizont, hin zu einem „everyday cosmopolitanism“ (Bayat, Life As Politics 208). Die Zuflucht im Privaten und die Entstehung eines kosmofeministischen Raumes infolge einer „cosmopolitan sociability“ (Darieva, Glick Schiller und Gruner-Domic) schlossen im Sinne von Avtar Brahs diaspora space nicht nur in der iranischen Diaspora lebende Menschen 
iranischen Ursprunges, sondern all jene durch Religion, Ethnie, Klasse und Gender marginalisierten und peripheren Gruppen ein.

In Marjane Satrapis Persepolis kam dem von Henry Jenkins entworfenen Konzept des Pop-Kosmopolitismus in diesem Zusammenhang eine besondere Funktion zu. Der Diasporafilm verändert konstant auf imaginative Art und Weise seine Ausformung und Gestalt und trägt in diesem Sinne dazu bei, Film als etwas Bildendes und Gestaltendes zu konzeptualisieren. Persepolis streicht hierbei Animation als filmisches Mittel heraus, historische Ereignisse, welche in das kollektive Gedächtnis der iranischen Diaspora eingeschrieben sind, zum Leben zu erwecken sowie eine Öffnung im kosmopolitischen Sinne herbeizuführen.

Kosmopolitismus als alltägliche kulturelle Praxis eröffnet in beiden Filmen kosmopolitische Räume der Verschachtelung, der Verdichtung, der Gleichzeitigkeit und der Verlebendigung. Kosmopolitismus als soziale, ethische Haltung, aber auch als analytische Kategorie der Filmwissenschaft (Christen und Rothemund) ermöglichte so, den Diasporafilm in deutlicher Abkehr ethnozentristischer und kulturessentialistischer Positionen zu erfassen. Die „cosmopolitan coexistence“ (Bayat, Life As Politics 186) ist hierbei die produktive Spannung der Filme der iranischen Diaspora und vielleicht jeglicher Form von Diaspora. Identität wird darin als immer wieder, synchron und diachron, austarierende Beziehung zur Welt, dem Kosmos, gesehen.

The Green Wave von Ali Samadi Ahadi kreierte durch das Motiv der Straße in Animation und Collage rebellische Räume, die im Angesicht der populären Aufstandsbewegung der Grünen Bewegung von 2009 nicht nur für eine gesellschaftliche, sondern vor allem auch für eine filmische Auseinandersetzung mit gesellschaftlichen und kulturellen Transformationsprozessen stehen. Abseits geographischer und ethnischer Zuschreibungen und Nostalgie fungieren diese filmischen Räume der Überlappung, der Durchlässigkeit und der Gegenwärtig- 
keit als Räume, die die eigene Position und den eigenen Handlungsspielraum der Diaspora, ihr Verhältnis zu Iran und ihre eigene kulturelle Verortung verhandeln. In diesem Sinne, ist die ,imagined community“ (Anderson) auch eine, die, abseits des Ideals sich zu solidarisieren, mit einer Aufwertung der eigenen Lebenserfahrung einhergeht.

Arman T. Riahis Schwarzkopf schließt an diese Aushandlungs- und Transformationsprozesse eigener diasporischer Lebenserfahrung an und etabliert das Tonstudio des Rappers Nazar als postmigrantischen Raum der Ermächtigung, das Innen und Außen, Individuum und Gesellschaft einschließt. Das Tonstudio als rebellischer Raum wird durch die Vielschichtigkeit der Blickwinkel, die auch für eine Modulation gesellschaftlicher Perspektiven stehen, zum filmischen Raum, in dem gesellschaftliche Transformationsprozesse mit filmischen Transformationsprozessen einhergehen.

Rebellische Räume treten in beiden Filmen in verschiedenartiger Art und Weise auf: in verschachtelten, sich überlappenden filmischen Räumen, die die Bilder so medial zueinander in Beziehung setzen und die Frage nach der Repräsentation und der Wirkmacht von Diasporafilm selbst stellen.

Zusammenfassend lässt sich sagen, dass die neuen diasporafilmischen Räume, wie ich sie in diesem Kapitel analysiert habe, einen Beitrag dazu leisten, den Diasporafilm abseits geographischer, ethnischer und kulturessentialistischer Engführungen als sich stetig transformierendes diskursives Feld zu betrachten. Die keineswegs statischen filmischen „Zwischenräume“, „kosmopolitischen Räume“ und „rebellischen Räume“ weisen eine Verspieltheit und Durchlässigkeit auf, die es ermöglichen, über Diaspora selbst neu nachzudenken. Hierbei kommt dem Diasporafilm als offenes System und nicht purer Repräsentation die Funktion zu, das diskursive Feld der iranischen Diaspora filmisch immer wieder aufs Neue auszuhandeln und zu überschreiten. 


\section{Neue diasporafilmische Räume}

Open Access Dieses Kapitel wird unter der Creative Commons Namensnennung 4.0 International Lizenz (http://creativecommons.org/licenses/by/4.0/deed.de) veröffentlicht, welche die Nutzung, Vervielfältigung, Bearbeitung, Verbreitung und Wiedergabe in jeglichem Medium und Format erlaubt, sofern Sie den/die ursprünglichen Autor(en) und die Quelle ordnungsgemäß nennen, einen Link zur Creative Commons Lizenz beifügen und angeben, ob Änderungen vorgenommen wurden.

Die in diesem Kapitel enthaltenen Bilder und sonstiges Drittmaterial unterliegen ebenfalls der genannten Creative Commons Lizenz, sofern sich aus der Abbildungslegende nichts anderes ergibt. Sofern das betreffende Material nicht unter der genannten Creative Commons Lizenz steht und die betreffende Handlung nicht nach gesetzlichen Vorschriften erlaubt ist, ist für die oben aufgeführten Weiterverwendungen des Materials die Einwilligung des jeweiligen Rechteinhabers einzuholen.

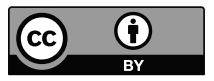

